\author{
UNIVERSIDADE DE SÃO PAULO \\ ESCOLA DE ENGENHARIA DE SÃO CARLOS \\ DEPARTAMENTO DE ENGENHARIA AERONÁUTICA \\ PROGRAMA DE PÓS-GRADUAÇÃO EM ENGENHARIA MECÂNICA
}

HERLANDSON CARDOSO DE MOURA

Supressão adaptativa de PIO em sistemas FBW

São Carlos

2018 

HERLANDSON CARDOSO DE MOURA

\section{Supressão adaptativa de PIO em sistemas FBW}

Dissertação apresentada ao Programa de PósGraduação em Engenharia Mecânica da Escola de Engenharia de São Carlos da Universidade de São Paulo, como requisito para a obtenção do Título de Mestre em Ciências.

Área de concentração: Aeronaves

Orientador: Prof. Dr. Jorge Henrique Bidinotto 


\section{ESTE EXEMPLAR TRATA-SE DA VERSÃO CORRIGIDA. \\ A VERSÃO ORIGINAL ENCONTRA- SE DISPONIVEL JUNTO AO DEPARTAMENTO DE ENGENHARIA MECANICA DA EESC-USP.}

\section{AUTORIZO A REPRODUC̄̃O TOTAL OU PARCIAL DESTE TRABALHO, POR QUALQUER MEIO CONVENCIONAL OU ELETRÔNICO, PARA FINS DE ESTUDO E PESQUISA, DESDE QUE CITADA A FONTE.}

Ficha catalográfica elaborada pela Biblioteca Prof. Dr. Sérgio Rodrigues Fontes da EESC/USP com os dados inseridos pelo(a) autor(a).

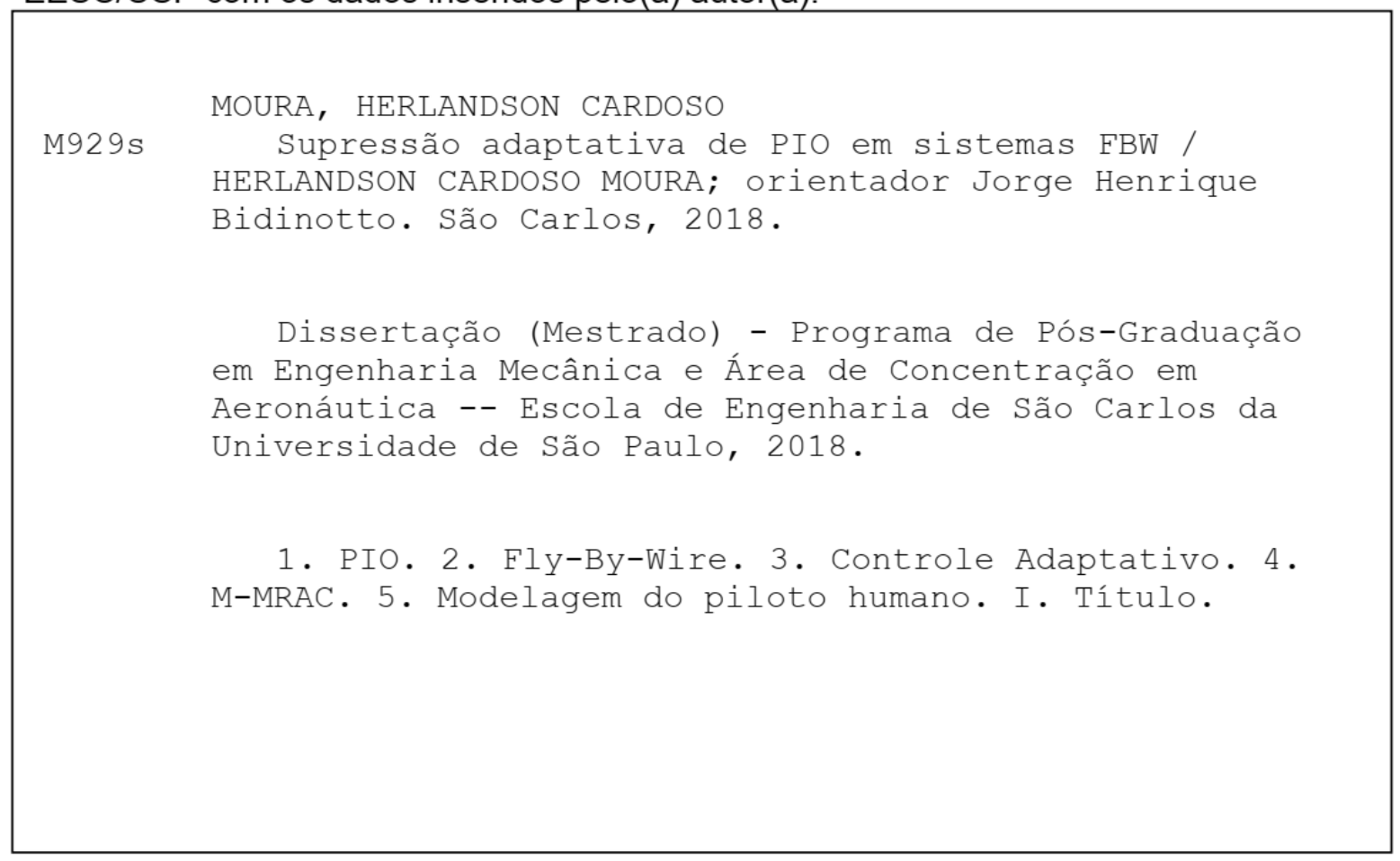

Eduardo Graziosi Silva - CRB - 8/8907 


\section{FOLHA DE JULGAMENTO}

Candidato: Engenheiro HERLANDSON CARDOSO DE MOURA.

Título da dissertação: "Supressão adaptativa de PIO em sistemas FBW".

Data da defesa: 04/02/2019.

Comissāo Julgadora:

Prof. Dr. Jorge Henrique Bidinotto

(Orientador)

(Escola de Engenharia de São Carlos/EESC)

Prof. Dr. Emilia Villani

(Instituto Tecnológico de Aeronáutica/ITA)

Prof. Dr. Rodrigo Cristian Lemes

(Instituto Federal São Paulo/IFSP-São Carlos)
Resultado:
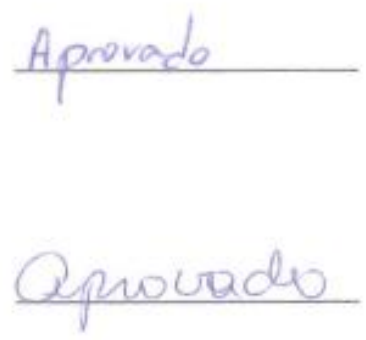

Aprovano

Coordenador do Programa de Pós-Graduação em Engenharia Mecânica: Prof. Associado Gherhardt Ribatski

Presidente da Comissão de Pós-Graduação:

Prof. Associado Luís Fernando Costa Alberto 



\section{AGRADECIMENTOS}

Primeiramente agradeço a Deus pela oportunidade de aperfeiçoar-me, profissionalmente e pessoalmente com a realização desse mestrado.

Aos professores Dr. Eduardo Morgado Belo e Dr. Jorge Henrique Bidinotto por minha aceitação na realização do mestrado, pela ajuda na definição da temática e pela orientação concedida durante a realização desse trabalho.

Agradecimentos aos colegas da pós-graduação, em especial Rodrigo Cristian Lemes e Mateus Moreira de Souza, pelo auxílio e conselhos dados durante o desenvolvimento do trabalho. Agradeço também aos professores dos departamentos de Engenharia Mecânica e Aeronáutica, os quais conseguiram repassar seus conhecimentos de forma dinâmica e agradável.

À minha família, que sempre me apoiou em minhas decisões e auxiliou-me sempre que necessário mesmo à distância.

Agradeço ao Conselho Nacional de Desenvolvimento Científico e Tecnológico (CNPq) pelo apoio financeiro concedido. 

"Jamais considere seus estudos como uma obrigação, mas como uma oportunidade invejável para aprender a conhecer a influência libertadora da beleza do reino do espírito, para seu próprio prazer pessoal e para proveito da comunidade à qual seu futuro trabalho pertencer".

(Albert Einstein) 



\section{RESUMO}

MOURA, H. C. Supressão adaptativa de PIO em sistemas FBW. 2018. 98 p. Dissertação (Mestrado em Engenharia Mecânica) - Escola de Engenharia de São Carlos, Universidade de São Paulo, São Carlos, 2018.

Com o advento dos sistemas de controle de voo Fly-By-Wire (FBW) foi aberta uma vasta gama de possibilidades para a arquitetura de controle em aeronaves. No entanto, esses sistemas herdaram ainda os problemas oriundos do controle manual, dentre eles o chamado acoplamento piloto-veículo ou mais conhecido pela sigla em inglês PIO (Pilot Induced Oscillations). Considerando-se esse contexto, o projeto busca o desenvolvimento de um algoritmo adaptativo de supressão do fenômeno. O algoritmo consiste em um sistema de controle adaptativo por modelo de referência modificado (M-MRAC) integrado com um sistema de ganho escalonado (gain scheduling). O algoritmo é, em uma primeira etapa, implementado e simulado no software MATLAB considerando-se, para tanto, a adoção de modelos do piloto humano e de aeronaves de forma a simular-se o comportamento do sistema em malha fechada. Os modelos de aeronave adotados descrevem apenas a dinâmica longitudinal de movimentação, enquanto os modelos do piloto têm os valores dos seus parâmetros estimados a partir de dados provenientes de ensaios realizados com pilotos. Através da ferramenta de identificação de sistemas do MATLAB (System Identification Toolbox) os valores dos principais parâmetros desses modelos são então estimados. O algoritmo de supressão e os modelos do piloto são então validados, em uma segunda etapa, através de ensaios realizados com voluntários utilizando-se um software de simulação de voo. Os resultados das simulações e dos ensaios obtidos mostram que o algoritmo desenvolvido possibilita a supressão do fenômeno em tempo real sem comprometer, no entanto, as características de qualidade de voo da aeronave simulada.

Palavras-chave: PIO. Fly-By-Wire. Controle Adaptativo. M-MRAC. Modelagem do piloto Humano. 



\section{ABSTRACT}

MOURA, H. C. PIO Adaptive suppression in FBW systems. 2018. 98 p. Master Thesis São Carlos School of Engineering, University of São Paulo, São Carlos, 2018.

With the advent of the flight control systems Fly-By-Wire (FBW) a wide range of possibilities for the control architecture in aircrafts was open. However, those systems inherited yet the problems arose from the manual flight control, among which the so called Pilot Induced Oscillations. Considering this context, the project aims the development of an adaptive suppression algorithm of the phenomenon. The algorithm consists in a modified model reference adaptive control system (M-MRAC) integrated with a gain scheduling system. The algorithm is, in a first step, implemented and simulated in the MATLAB software considering for that, the adoption of pilot human pilot models and of aircrafts to simulate the behavior of the closed loop system. The aircraft models applied describe only the longitudinal dynamics of movement, whereas the pilot models have their parameters values estimated using the data from piloted trials. By the use of the MATLAB System Identification Toolbox the values for the main parameters of the pilot models are the estimated. The suppression algorithm and the pilot models are then validated, in a second step, through trials performed with subjects using a flight simulator software. The results obtained from the simulations and trials performed show that the developed algorithm allows the suppression of the phenomenon in real time without compromise yet the characteristics of flight quality of the simulated aircraft.

Keywords: PIO. Fly-By-Wire. Adaptive control. M-MRAC. Human pilot modelling. 



\section{LISTA DE ILUSTRAÇÕES}

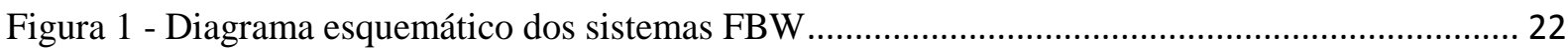

Figura 2 - Diagrama de blocos do sistema de controle de arfagem FBW …........................................ 23

Figura 3 - Controlador adaptativo por modelo de referência ............................................................. 31

Figura 4 - Diagrama do sistema de controle utilizado .................................................................... 39

Figura 5 - Notação do sistema de eixos de uma aeronave.................................................................. 40

Figura 6 - Modelo das superfícies de comando............................................................................. 44

Figura 7 - Representação do detector de picos do algoritmo ROVER: (a) Detecção dos picos de máximo; (b) Detecção dos picos de mínimo; (c) Retenção dos picos detectados ................................ 47

Figura 8 - Exemplificação do cálculo da frequência do sinal de velocidade angular no algoritmo ROVER

Figura 9 - Exemplificação do cálculo da diferença de fase entre o sinal de velocidade angular de

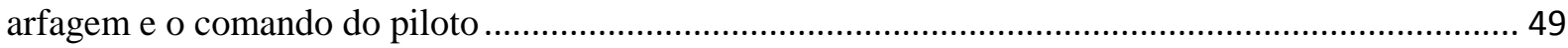

Figura 10 - Exemplificação da atuação do sistema M-MRAC ......................................................... 52

Figura 11 - (a) Horizonte artificial desenvolvido (b) Joystick utilizado nos ensaios .......................... 57

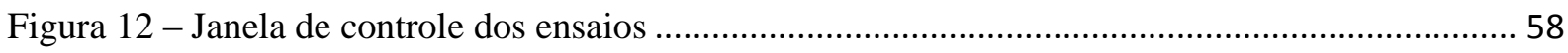

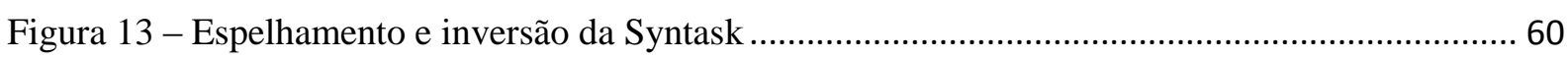

Figura 14 - Resposta modelo aeronave controlada na condição de pilotagem normal .......................... 64

Figura 15 - Resposta modelo aeronave controlado pelo piloto 1 na condição de pilotagem de alto

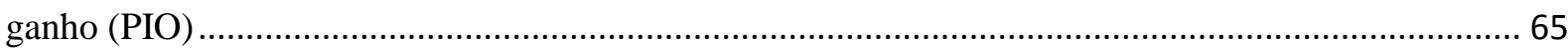

Figura 16 - Resposta das simulações do modelo A da aeronave comandado pelos modelos de piloto 70 Figura 17 - Resposta das simulações do modelo B da aeronave comandado pelos modelos de piloto 71 Figura 18 - Resposta das simulações do modelo $\mathrm{C}$ da aeronave comandado pelos modelos de piloto 72 Figura 19 - Resposta das simulações em espaço de estados do sistema M-MRAC para o modelo de referência B

Figura 20 - Resposta das simulações em espaço de estados do sistema M-MRAC para o modelo de

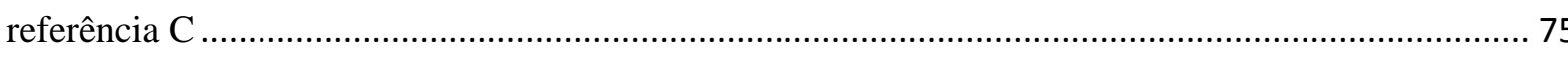

Figura 21 - Resposta das simulações em espaço de estados do sistema de supressão........................... 77

Figura 22 - Resposta das simulações do sistema M-MRAC integrado com o software FlightGear para

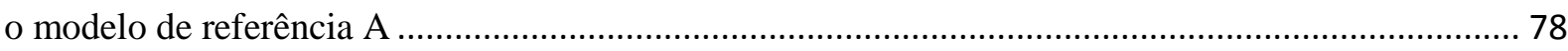

Figura 23 - Resposta das simulações do sistema M-MRAC integrado com o software FlightGear para o modelo de referência $B$

Figura 24 - Resposta das simulações do sistema M-MRAC integrado com o software FlightGear para o modelo de referência $\mathrm{C}$

Figura 25 - Resposta das simulações do sistema de supressão integrado com o software FlightGear. 82 Figura 26 - Resposta dos ensaios dos modelos de aeronave comandados pelo operador..................... 84 Figura 27 - Resposta dos ensaios em espaço de estados do sistema M-MRAC com o operador humano

Figura 28 - Resposta do ensaio em espaço de estados do sistema de supressão ................................. 87

Figura 29 - Resposta dos ensaios do sistema M-MRAC integrado com o software FlightGear .......... 89

Figura 30 - Resposta das simulações do sistema de supressão integrado com o software FlightGear. 90 



\section{LISTA DE TABELAS}

Tabela 1 - Sumário das funções de transferência características aproximadas do piloto ........................ 35

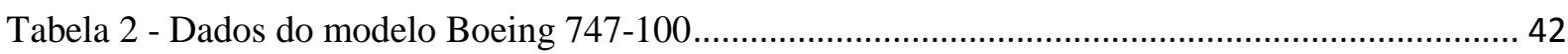

Tabela 3 - Derivadas dimensionais longitudinais da aeronave Boeing 747-100................................ 43

Tabela 4 - Características dos modos do modelo A ........................................................................ 43

Tabela 5 - Derivadas dimensionais longitudinais alteradas da aeronave Boeing 747-100 (Modelos B e

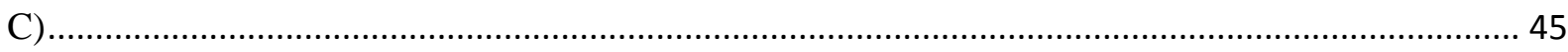

Tabela 6 - Características dos modos (Modelo B e Modelo C) …….......................................................... 45

Tabela 7 - Valores dos parâmetros do algoritmo ROVER ................................................................ 46

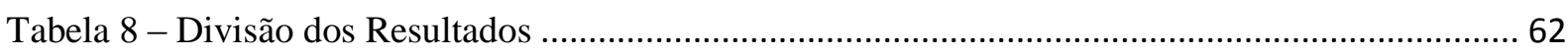

Tabela 9 - Parâmetros estimados dos modelos obtidos nos ensaios na condição normal...................... 66

Tabela 10 - Parâmetros estimados dos modelos obtidos nos ensaios na condição PIO ....................... 66

Tabela 11 - Parâmetros estimados do Modelo de Tustin obtidos dos ensaios com pilotos .................. 96

Tabela 12 - Parâmetros estimados do Modelo Crossover obtidos dos ensaios com piloto ................... 97

Tabela 13 - Parâmetros estimados do Modelo de Precisão obtidos dos ensaios com pilotos................. 98 



\section{LISTA DE ABREVIATURAS E SIGLAS}

\begin{tabular}{|c|c|c|}
\hline FBW & - & Fly-By-Wire \\
\hline LQR & - & Linear Quadratic Regulator (Regulador Linear Quadrático) \\
\hline $\begin{array}{l}\text { MRAC } \\
\text { referência) }\end{array}$ & - & Model Reference Adaptive Control (Controle Adaptativo por modelo de \\
\hline $\mathrm{PIO}$ & - & Pilot-Induced Oscillations (Oscilações Induzidas pelo piloto) \\
\hline ROVER & - & Realtime Oscillation Verifier (Verificador de Oscilações em tempo \\
\hline Real) & & \\
\hline SI & - & Sistema Internacional de Unidades \\
\hline
\end{tabular}





\section{SUMÁRIO}

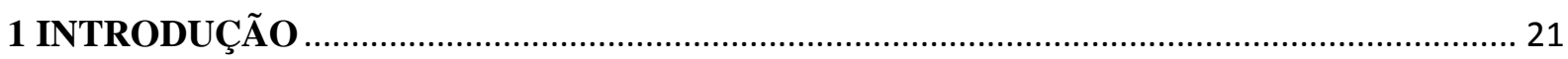

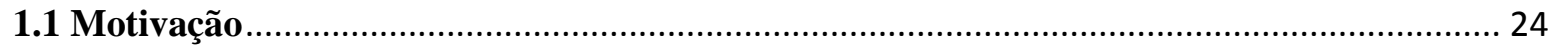

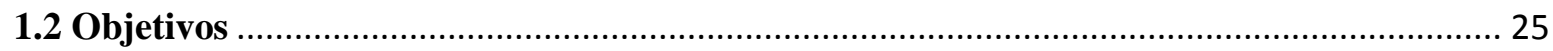

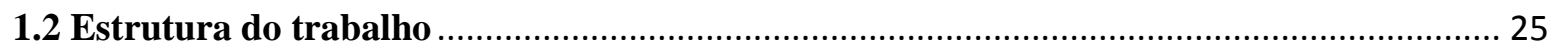

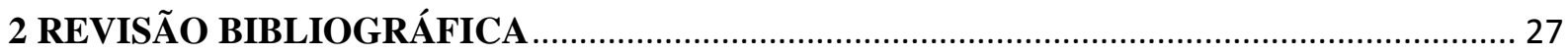

2.1 PIO

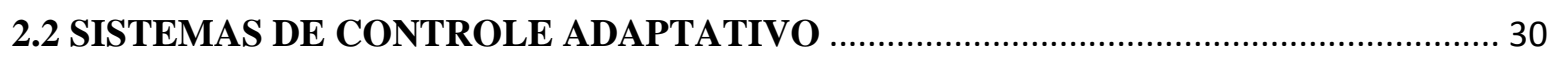

2.2.1 Controle Adaptativo por modelo de referência ......................................................... 31

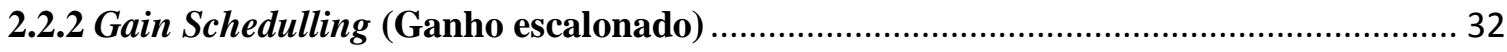

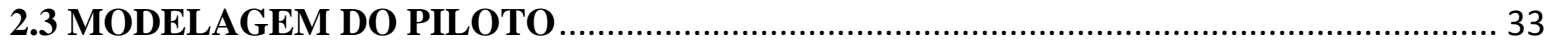

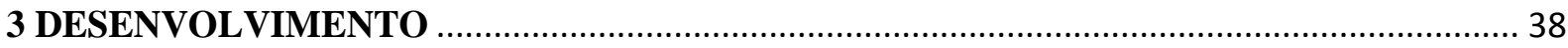

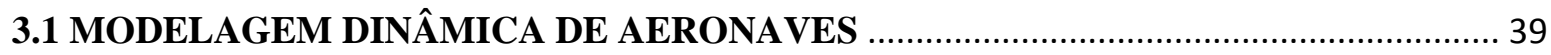

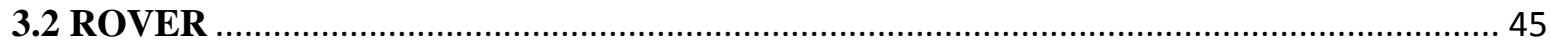

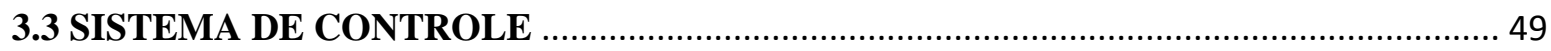

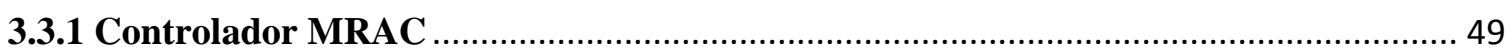

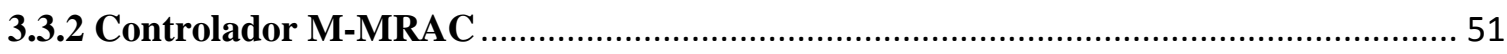

3.3.3 Controlador Regulador Linear Quadrático (LQR) ……............................................ 53

3.3.4 Supressão adaptativa do PIO: Ganho escalonado ........................................................... 54

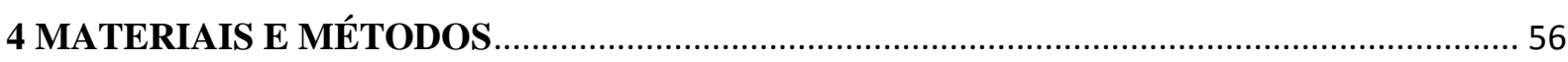

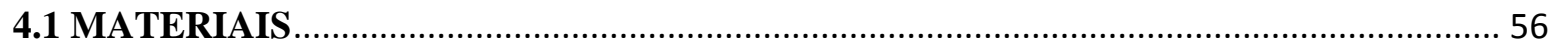

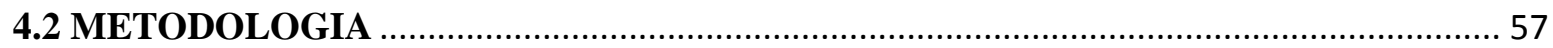

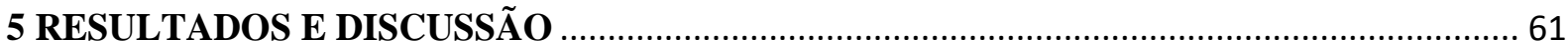

5.1 ENSAIOS PARA ESTIMAÇÃO DOS MODELOS DO PILOTO....................................... 63

5.2 SIMULAÇÃO DE MODELOS EM ESPAÇO DE ESTADOS …....................................... 68

5.3 SIMULAÇÃO DO SISTEMA M-MRAC: PLANTA EM ESPAÇO DE ESTADOS ........... 73

5.4 SIMULAÇÃO DO SISTEMA DE SUPRESSÃO: PLANTA EM ESPAÇO DE ESTADOS

5.5 SIMULAÇÃO DO SISTEMA M-MRAC: FLIGHTGEAR …............................................ 77

5.6 SIMULAÇÃO DO SISTEMA DE SUPRESSÃO: FLIGHTGEAR .................................... 81

5.7 ENSAIOS DOS MODELOS EM ESPAÇO DE ESTADOS …............................................. 82

5.8 ENSAIOS DO SISTEMA M-MRAC: PLANTA EM ESPAÇO DE ESTADOS .................. 85

5.9 ENSAIOS DO SISTEMA DE SUPRESSÃO: PLANTA EM ESPAÇO DE ESTADOS ..... 86 


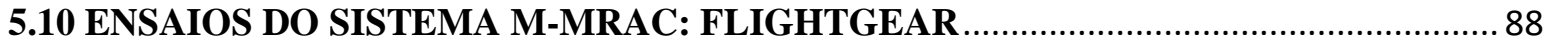

5.11 ENSAIOS DO SISTEMA DE SUPRESSÃO: FLIGHTGEAR ….................................... 90

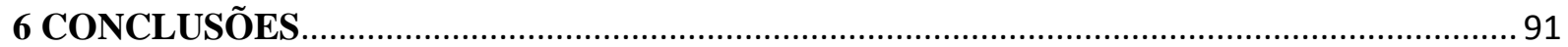

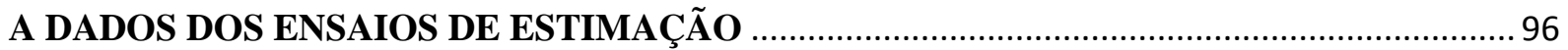




\section{CAPÍtulo 1}

\section{INTRODUÇÃO}

Nos sistemas Fly-By-Wire (FBW), como o esquematizado na Figura 1, os comandos realizados pelo piloto são convertidos em sinais eletroeletrônicos, os quais são enviados por cabos elétricos para um circuito eletrônico dedicado. Esse circuito eletrônico de controle nos aviões comerciais atuais possui em sua implementação um computador digital de comando de voo (fato que deu origem à outra nomeação do sistema a saber Digital Fly-By-Wire (DFBW)). Esse computador envia então sinais elétricos de comando aos atuadores elétrico-hidráulicos, os quais atuam nas superfícies móveis de comando de voo (como os ailerons, leme de direção e profundor), produzindo então a movimentação solicitada para a aeronave. Por fim, sensores de movimento captam os deslocamentos da aeronave e enviam esse feedback ao sistema de comando fechando a malha de controle. A arquitetura FBW foi criada em substituição aos sistemas de comando convencionais, puramente mecânicos ou hidráulico-mecânicos, nos quais a força exercida pelo piloto nos instrumentos de comando de voo é utilizada no sistema de acionamento sem passar por um processamento computacional. A utilização de um computador digital nas aeronaves FBW, por outro lado, possibilita ainda que diferentes algoritmos de controle sejam implementados, conferindo uma grande flexibilidade a esses sistemas. Através da utilização desses sistemas de controle, diferentes metodologias de modelagem dinâmica das aeronaves podem ser implementadas, utilizando-se por exemplo as chamadas derivadas de estabilidade (ou controle). Matematicamente esses parâmetros representam variações infinitesimais de forças e momentos resultantes de uma variação infinitesimal de uma variável do sistema, como por exemplo as componentes de velocidade da aeronave, medidas em relação a uma condição inicial de equilíbrio. 
Figura 1 - Diagrama esquemático dos sistemas FBW

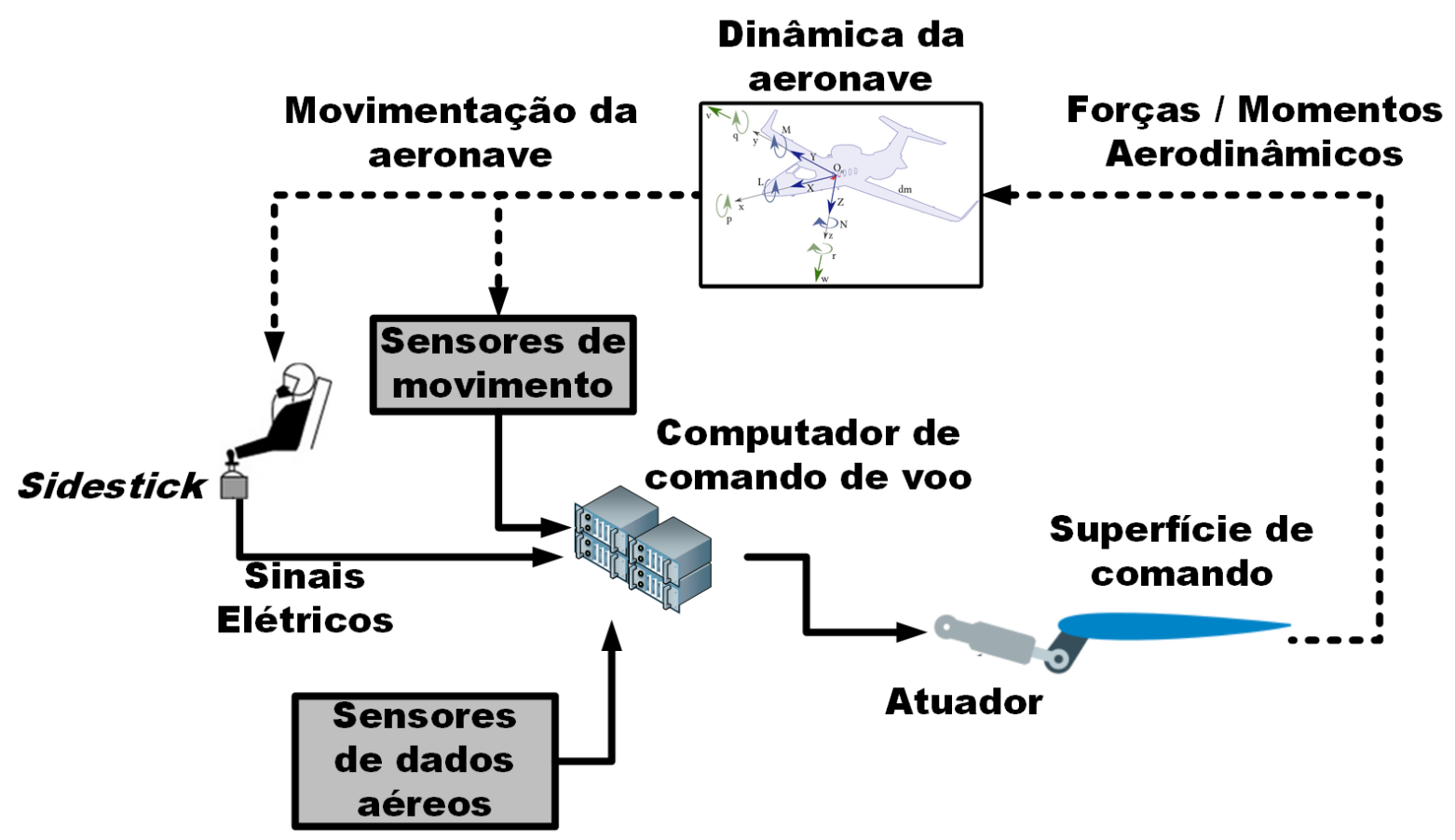

A Figura 2 representa, em diagrama de blocos, o sistema FBW utilizado para movimentação de uma aeronave no seu plano longitudinal, em uma manobra denominada arfagem (em inglês pitch), a qual será objeto de estudo desse trabalho. Da esquerda para direita temos: $\boldsymbol{\theta}_{\boldsymbol{r}}$ representando a referência do ângulo de arfagem requerida para uma determinada tarefa a ser executada pelo piloto. $\mathrm{O}$ erro, calculado como a diferença entre essa referência e o ângulo real de arfagem da aeronave, é então repassado para o piloto. Esse por sua vez capta esse sinal de erro através do seu sistema de sensoriamento, utilizando-se dos seus sistemas de visão (referenciando os instrumentos de medição fornecidos no cockpit) e vestibular (com a movimentação da aeronave). O piloto então aciona o manche, o qual tem seu deslocamento mensurado por um sensor de posicionamento, sendo um sensor LVDT (Linear Variable Differential Transformer ou Transformador Diferencial Variável Linear) comumente utilizado para essa finalidade. O sinal elétrico é então repassado para o bloco ACE (Actuator Control Electronics), que representa a eletrônica de comando. Essa eletrônica comanda então o bloco EHSV (ElectroHydraulic Servovalve) que representa uma Servo-Válvula Eletro-Hidráulica que então realiza o acionamento do atuador através do controle do fluxo / pressão do fluido hidráulico. Os atuadores, os quais consistem genericamente de cilindros hidráulicos, então movimentam o profundor, sofrendo esse um deslocamento angular $\boldsymbol{\delta}_{\boldsymbol{e}}$. Esse deslocamento 
angular da superfície de comando altera então as forças e momentos aerodinâmicos aos quais a aeronave é submetida, provocando assim uma movimentação da mesma no plano longitudinal. A resposta resultante a comandos em aeronaves dotadas de sistemas FBW pode ainda ser alterada através da implementação de modelos dinâmicos (através das chamadas derivadas de controle ou de estabilidade) a nível de software no sistema. A resposta resultante da aeronave, representada pelo ângulo de arfagem (pitch), é então mensurada por sensores (através de sensores inerciais, como o giroscópio) os quais apresentam essa informação ao piloto através de telas e painéis (como o horizonte artificial) fechando então a malha de controle. Cada um desses blocos possui uma reposta dinâmica que pode ser modelada matematicamente. Os sensores, os quais em muitos casos possuem parâmetros de resposta temporal pequenos se comparados com os outros subsistemas envolvidos, têm seus modelos dinâmicos desprezados.

Figura 2 - Diagrama de blocos do sistema de controle de arfagem FBW

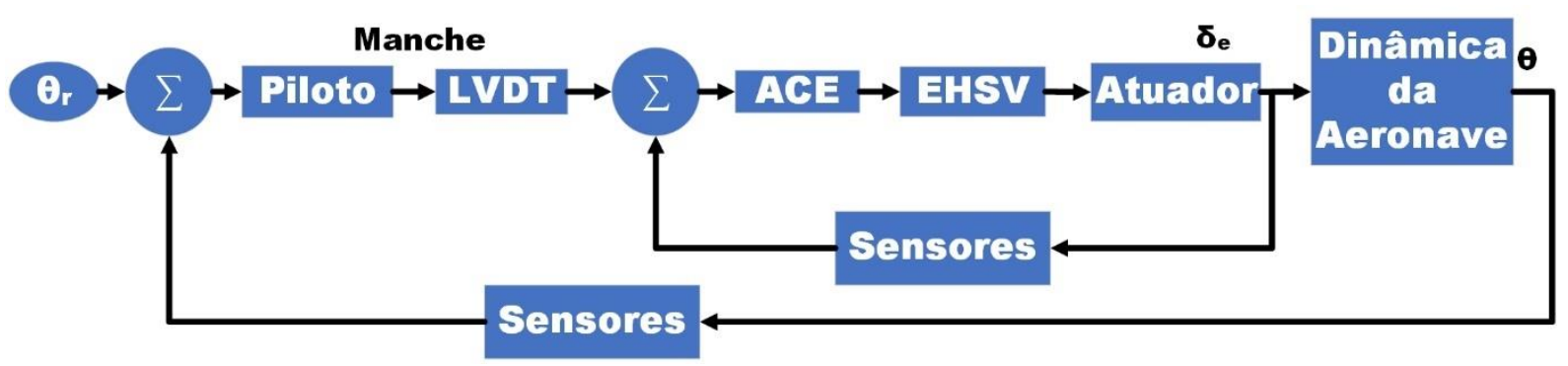

Fonte: Elaborada pelo autor.

Os sistemas de comando FBW não tornaram as aeronaves imunes aos problemas antes presentes nos sistemas de controle mecânico, como o estol, o fenômeno de parafuso e o PIO. Esses fenômenos representam uma grande preocupação no projeto de aeronaves, tendo em vista a maior susceptibilidade de ocorrência de acidentes em sistemas em que os mesmos se fazem presentes. O trabalho focará no fenômeno de PIO, definido comumente como "oscilações sustentadas ou não-controláveis decorrentes dos esforços do piloto em controlar a aeronave" (STANDARD, 1987) ou "oscilações sustentadas de aeronaves, mantidas inadvertidamente e que são consequência do acoplamento anormal mantido entre o piloto e a aeronave" (MCRUER, 1995). No projeto de novas aeronaves, não se tem garantido que a mesma esteja totalmente livre da ocorrência do fenômeno quando em operação. $\mathrm{O}$ máximo que pode ser realizado é um design que possua uma menor susceptibilidade ou tendência à ocorrência do mesmo. 


\subsection{Motivação}

O PIO foi indicado ainda como a causa de muitos acidentes e incidentes, tanto de aeronaves militares como civis, como os ocorridos com as aeronaves YF-22 (1992), JAS 39 (1993), MD-11 (1997), V-22 (2000) e C-17 (2001). Considerando-se esse histórico, o fenômeno tem sido objeto de estudo há décadas, tendo sido realizados diversos trabalhos para identificação das suas causas como em (ASHKENAS et al., 1964), (SMITH; BERRY, 1975) e (MITCHELL; KISH; SEO, 1998) além de sua detecção e supressão como em (SMITH; EDWARDS, 1980), (JOHNSON, 2002) e (LIU, 2012). A grande diferença das épocas de realização desses trabalhos revela que o ramo de estudo das causas, da detecção e em particular da supressão desse fenômeno ainda se mostra em aberto. Em particular, poucos foram os trabalhos realizados com a aplicação de métodos da teoria de controle adaptativo na supressão do fenômeno, podendo os recursos desse ramo da teoria de controle ainda serem explorados. Dessa forma, as metas desse trabalho, que incluem a detecção e supressão do fenômeno em tempo real aplicando-se o controle adaptativo, mostram-se válidas e factíveis.

No desenvolvimento do projeto serão realizados ainda ensaios utilizando-se um software de simulação de voo. De acordo com o relatório do National Research Council Committee (SAFETY, 1997), os simuladores de voo de base fixa embora não revelem sempre de forma fidedigna e satisfatória a tendência ao PIO nos modelos de aeronaves considerados, podem ser utilizados em pré-ensaios do sistema antes de implementá-lo em uma aeronave real. De acordo com esse relatório ainda, displays visuais de alta resolução e qualidade podem ser considerados mais efetivos que uma plataforma móvel de simulação de voo isolada. Isso pois a maioria das simulações em solo são realizadas com pilotos treinados que baseiam suas tomadas de decisão mais nos sinais visuais do que nos de aceleração de realimentação provenientes do seus sistema vestibular. Considerando-se esse contexto, o trabalho utilizará nos ensaios com voluntários apenas um software de simulação de voo para validação das simulações do algoritmo de supressão do PIO implementado, permitindo ainda aos participantes dos ensaios a avaliação das características dinâmicas do modelo resultante.

Objetivando-se a iniciação de trabalhos nesse campo foi iniciado em 2016 no laboratório de Dinâmica e Controle de Aeronaves do Departamento de Engenharia Aeronáutica da Escola de Engenharia de São Carlos / Universidade de São Paulo (SAA-EESC) um projeto de pesquisa (FAPESP N ${ }^{\circ}$ 2016/16808-5), o qual originou a temática do presente trabalho. Esse projeto propõe um estudo das derivadas de controle mais susceptíveis ao fenômeno de PIO, sendo os modelos validados futuramente com ensaios em uma plataforma móvel de voo. Dessa forma, o 
trabalho aqui descrito contribuirá para o desenvolvimento do projeto citado, fato que ressalta novamente a validade e importância do mesmo.

\subsection{Objetivos}

Este projeto tem como objetivo principal o desenvolvimento e implementação de um algoritmo adaptativo de supressão do fenômeno de PIO, aplicável em aeronaves dotadas de sistemas FBW. Como objetivo secundário, necessário para a simulação desse algoritmo, procura-se a estimação dos valores dos parâmetros de alguns dos modelos dinâmicos do piloto humano. Outro objetivo secundário do projeto será ainda a avaliação dos diferentes valores das chamadas derivadas de estabilidade das aeronaves simuladas, objetivando a obtenção de modelos com alta e com baixa propensão ao fenômeno de PIO, a serem utilizados nos ensaios e simulações do sistema de supressão. Para teste da eficácia do algoritmo de supressão e validação da modelagem do piloto serão então realizados ensaios com um software de simulação de voo bem como simulações computacionais. No processo de desenvolvimento do algoritmo de supressão do PIO considera-se que o mesmo seja causado pelos fenômenos de limitação de velocidade e posição dos atuadores, pelos altos ganhos empregados pelo piloto e pelos atrasos na reposta do sistema.

\subsection{Estrutura do trabalho}

A dissertação aqui apresentada está dividida em oito capítulos, sendo os mesmos descritos sucintamente a seguir. O capítulo 2 inicia com uma revisão bibliográfica dos principais tópicos abordados no trabalho, como o fenômeno PIO, os sistemas de controle adaptativo e a modelagem dinâmica dos pilotos. O capítulo 3 apresenta então a descrição dos sistemas desenvolvidos e implementados nos ensaios e nas simulações realizadas. Os materiais e recursos utilizados, bem como a metodologia empregada nos ensaios e simulações realizados são apresentados no Capítulo 4. O capitulo 5 apresenta então os resultados obtidos, seguidos de uma breve discussão dos mesmos. Esse capítulo inicia-se na seção 5.1 com a apresentação dos dados obtidos dos ensaios com pilotos humanos, os quais são então utilizados na estimação dos parâmetros dos modelos de piloto empregados. Esses modelos são então empregados em simulações realizadas, incluindo as que utilizam o sistema de supressão completo desenvolvido, 
sendo os resultados obtidos apresentados nas seções 5.2 a 5.6. Os modelos de piloto bem como o sistema de supressão são então validados com ensaios com o piloto, sendo os resultados obtidos apresentados nas seções 5.7 a 5.11. O capítulo 6, por fim, apresenta então as conclusões da dissertação bem como as principais propostas para os trabalhos possíveis de serem realizados. 


\section{CAPÍtULO 2}

\section{REVISÃO BIBLIOGRÁFICA}

O sistema de controle proposto envolve vários conceitos e metodologias as quais abarcam mais de uma área de estudo. O presente tópico apresenta uma rápida revisão bibliográfica dos conceitos presentes no sistema, iniciando-se com o aprofundamento do fenômeno PIO, passando por uma revisão dos sistemas de controle adaptativo implementados no trabalho e por fim a modelagem dos pilotos a serem utilizadas nas simulações.

\subsection{PIO}

De acordo com relatório do National Research Council Committee (SAFETY, 1997) os fenômenos de PIO registrados podem ser classificados em uma das seguintes categorias:

\section{$\underline{1^{a} \text { Categoria: Oscilações em sistemas lineares piloto-veículo }}$}

Nessa categoria estão presentes os sistemas que adotam um modelo de aeronave dotado de características essencialmente lineares, sendo ainda considerado o comportamento de resposta do piloto como "quase-linear" e constante no tempo. Os principais fatores contribuintes para a ocorrência de PIOs desse grupo são: o atraso excessivo em fase (ou temporal) entre o sinal de controle de entrada do piloto e a resposta da aeronave; e o ganho efetivo inadequado da aeronave, podendo esse ser muito alto (aeronave com alta sensibilidade ao controle) ou muito baixo (aeronave com resposta lenta ao controle). Antes do surgimento das aeronaves dotadas de sistemas FBW, praticamente todas as ocorrências de PIOs eram classificadas como pertencentes à essa classe. No entanto, a mesma mostra-se como a menos comum entre as ocorrências registradas de PIOs nas aeronaves em operação atualmente. 


\section{$\underline{2^{a} \text { Categoria: Sistemas quase-lineares com limitações de velocidade ou posiç̧ão }}$}

Nessa categoria estão os PIOs caracterizados por oscilações graves com amplitudes na faixa onde os fenômenos não-lineares de limitação da velocidade e/ou posição dos atuadores tornam-se dominantes. A limitação de velocidade dos atuadores hidráulicos das aeronaves adiciona ao sistema um atraso dependente da amplitude das oscilações, sendo essa amplitude determinada por esse fenômeno não-linear. Outras não-linearidades mais simples como a alteração do sinal de comando do piloto e aquelas relacionadas às características aerodinâmicas das aeronaves também podem estar presentes. No cenário atual, com aeronaves dotadas de sistemas FBW, grande parte dos acidentes e incidentes de PIO são classificados como pertencentes a essa classe.

\section{$\underline{3^{a} \text { Categoria: Oscilações não-lineares em sistemas piloto-veículo com transições }}$}

Classificados nessa categoria estão os PIOs dependentes fundamentalmente de transições não-lineares, presentes na aeronave controlada ou no comportamento dinâmico do piloto. A ocorrência dessas modificações no comportamento da aeronave controlada é comumente associada com a magnitude dos comandos do piloto. A transição do comportamento do piloto, por sua vez, é relacionada, possivelmente, a mudanças dos sinais de realimentação utilizados pelo piloto bem como a ajustes comportamentais desse. Esses ajustes do piloto objetivam adaptar sua estratégia de controle frente às modificações das tarefas executadas. Os PIOs desse grupo podem ainda ser resultantes de mudanças do modo de operação da aeronave, de alterações internas no sistema de controle de voo ou ainda de transições na configuração aerodinâmica/propulsiva da aeronave. Por envolver transições rápidas, essa classe mostra-se de difícil identificação e análise. Os PIOs nessa categoria são raros, embora resultem na maioria dos casos em oscilações graves, com perda de controle da aeronave.

Considerando-se esse esquema de categorização podemos apontar os principais fatores contribuintes para o aparecimento do fenômeno de PIO: as limitações de velocidade e de posicionamento dos atuadores das superfícies de comando; os altos ganhos empregados pelo piloto nos comandos; e os atrasos na reposta do sistema, incluído nesse o tempo de resposta do próprio piloto. Esses fatores contribuem para o aparecimento das oscilações sustentadas do PIO, caracterizadas por uma frequência na faixa de 1 a $8 \mathrm{rad} / \mathrm{s}$ e por um atraso de fase entre o comando do piloto e a resposta da aeronave da ordem de $180^{\circ}$. Nesse contexto, a expressão "alto ganho empregado pelo piloto" refere-se ao modo de pilotagem agressivo (ou abrupto) 
desencadeado por alguma situação de emergência, no qual o piloto executa manobras com um nível de comutação (ou chaveamento) da estrutura de comando relativamente alto.

Ao longo dos anos de estudo do PIO vários algoritmos de supressão do fenômeno foram desenvolvidos. Muitos desses algoritmos são baseados em técnicas de compensação lineares, implementados comumente através da utilização de filtros que atenuam o ganho dos comandos do piloto. Como exemplos de trabalhos seguindo essa metodologia temos os desenvolvidos por (SMITH; EDWARDS, 1980), (SHAFER et al., 1984) e (BAILEY; SMITH; SHAFER, 1982). Essa abordagem possui como desvantagem a introdução de um filtro que está sempre ativo, acarretando a introdução de um atraso de fase adicional entre os comandos do piloto e a resposta do sistema controlado, deteriorando assim a qualidade de pilotagem da aeronave. Esse atraso de fase pode ser da ordem de $50^{\circ}$ para filtros Notch Filter, os quais são comumente empregados.

Uma outra abordagem possível baseia-se na utilização de algoritmos de detecção, os quais na ocorrência do fenômeno ativam um método de supressão. Dessa forma o algoritmo atua apenas durante um determinado intervalo de tempo. Embora esses algoritmos possibilitem uma detecção do fenômeno em tempo real, o mesmo não pode ser identificado antes de sua ocorrência, pois não existem condições pré-PIO. Dentre os algoritmos de detecção mais utilizados temos o ROVER (Real Time Oscillation Verifier), desenvolvido em (MITCHELL; ARENCIBIA; MUNOZ, 2004), o qual é baseado na análise dos sinais de comando do piloto para deflexão do profundor e na velocidade de arfagem da aeronave. Com base nesses sinais, quatro parâmetros são monitorados e utilizados na atribuição do valor 0 ou 1 de quatro flags: magnitude e frequência da velocidade de arfagem, magnitude do comando do piloto e atraso de fase entre o comando do piloto e a velocidade de arfagem da aeronave. Quando os valores desses parâmetros recaem na faixa de valores característica do PIO (altas magnitudes, diferença de fase da ordem de $180^{\circ}$ e frequência da velocidade angular de arfagem no intervalo de 1 a 20 $\mathrm{rad} / \mathrm{s}$ ) as quatro flags têm seus valores alterados individualmente. Quando a soma dessas flags totalizam um valor igual a quatro há uma indicação de ocorrência do fenômeno. Devido a sua praticidade e eficácia o algoritmo ROVER já foi implementado em alguns trabalhos como os realizados em (LIU, 2012) e (JOHNSON, 2002). Além do ROVER outros algoritmos para detecção do PIO incluem: detectores baseados em lógica Fuzzy; o algoritmo Open Loop Onset Point (OLOP); e algoritmos baseados na Transformada de Fourier discreta recursiva.

Segundo Liu (2012), após a detecção do fenômeno são utilizados algoritmos para supressão ou mitigação do mesmo, podendo esses métodos serem classificados basicamente em três categorias: através da utilização de filtros, os quais compensam ou suprimem o PIO quando detectado; com a utilização de controladores adaptativos que possibilitam uma redução do 
ganho dos dispositivos de comando manual (como o manche e o side-stick) ou uma mudança na dinâmica do sistema operado em malha fechada; com a implementação de sistemas que fornecem um alerta visual ou tátil para o piloto indicando a ocorrência do fenômeno de forma que o mesmo possa tomar uma ação para controle do sistema. Os algoritmos de categorias distintas podem ser utilizados de forma combinada ou isolada. Dentre os métodos baseados em filtros, o chamado Notch Filter mostra-se como um dos mais utilizados, sendo esse filtro incluído na própria arquitetura do algoritmo ROVER original, possibilitando a esse a detecção e a supressão do fenômeno de PIO. O método baseado nos controladores adaptativos, por mostrar-se ainda pouco aplicado na área de estudo de supressão do PIO, será o utilizado no desenvolvimento do trabalho. Especificamente um método que possibilite a definição de um modelo de referência a ser seguido pela aeronave controlada é aplicado. A seguir é apresentada uma breve explanação da teoria envolvida nessa categoria de controladores.

\subsection{SISTEMAS DE CONTROLE ADAPTATIVO}

Os algoritmos de controle implementados em aeronaves dotadas de sistemas FBW lidam com variações, perturbações e incertezas inerentes ao tipo de sistema, visto esse estar sujeito a forças e condições difíceis de se modelar e prever. Nesse contexto, seria de extrema valia se esses algoritmos possibilitassem a alteração das características do controlador implementado durante o funcionamento da aeronave, levando-se em conta a dinâmica atual do sistema. Assim fenômenos como o PIO poderiam ser identificados e tratados com a aeronave em operação. A chamada teoria de controle adaptativo mostra-se com uma solução para essa problemática, visto possibilitar o desenvolvimento de controladores com as características citadas. Segundo (ASTROM; WITTENMARK, 1934), um sistema adaptativo possibilita a modificação do seu comportamento em resposta a mudanças na dinâmica do processo e nas características dos distúrbios. No contexto do PIO, na ocorrência desse fenômeno o piloto insere distúrbios não previstos no projeto da aeronave. Assim a implementação de um algoritmo adaptativo para supressão do PIO em sistemas FBW mostra-se como uma promissora alternativa, justificando a escolha desses sistemas na pesquisa aqui desenvolvida. De fato, ao longo dos anos de desenvolvimento de sistemas FBW, foram realizados trabalhos com a implementação de controladores adaptativos em aeronaves dessa classe como em (STEIN; HARTMANN, 1977), além de trabalhos que abordaram especificamente a supressão do fenômeno de PIO com esses controladores como em (WANG; SANTONE; CAO, 2012), os quais servirão como base para 
o desenvolvimento do trabalho. Dentre os algoritmos adaptativos de interesse utilizados nesses trabalhos podemos citar os controladores por modelo de referência e por ganho escalonado. Esses sistemas são descritos nas seções a seguir.

\subsubsection{Controle Adaptativo por modelo de referência}

Nessa classe, conhecida comumente por sua sigla em inglês MRAC (Model Reference Adaptive Control), os controladores implementados têm seus parâmetros ajustados de forma a forçar uma resposta da planta controlada de acordo com um modelo de referência definido, estando esse dotado de características de interesse. Dessa forma busca-se que o sistema tenha um comportamento igual ao do modelo, sendo os parâmetros do controlador ajustados de acordo com o erro entre a saída em malha fechada da planta real e a saída do modelo de referência. O sistema resultante pode nessa categoria ser dividido em dois loops, como mostrado na Figura 3: um loop interno composto pela planta controlada e pelo controlador; e um loop externo responsável pela alteração dos parâmetros do controlador. Os sistemas MRAC desenvolvidos podem ser classificados em duas categorias: direta e indireta. Quando os parâmetros do controlador são ajustados diretamente, a partir do sinal de erro como no sistema descrito na Figura 3, o sistema é classificado como MRAC de arquitetura direta. Já na categoria indireta um estimador de estados é utilizado para se estimar os parâmetros da planta, sendo os mesmos então utilizados na lei de controle de realimentação (KHARISOV; HOVAKIMYAN; ASTROM, 2010).

Figura 3 - Controlador adaptativo por modelo de referência

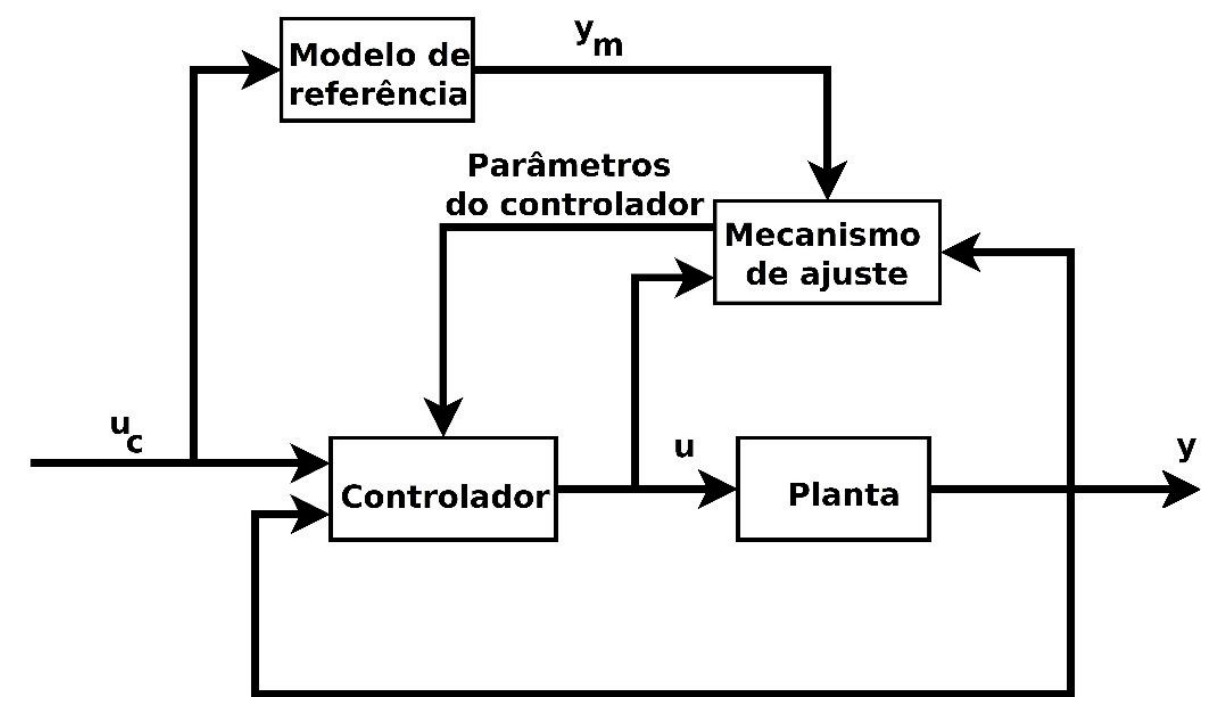

Fonte: Adaptado de (ASTROM; WITTENMARK, 1934). 
O mecanismo de ajuste dos parâmetros pode ser implementado utilizando-se o Método do Gradiente ou aplicando-se a Teoria da Estabilidade (Teoria da Estabilidade de Lyapunov ou Teoria da Establidade entrada-saída). Nos sistemas de comando de voo os sistemas MRAC são geralmente utilizados como o estágio final de outro algoritmo de controle implementado. No entanto, embora os sistemas MRAC possuam uma convergência assintótica a priori garantida, os mesmos podem apresentar uma resposta transiente oscilatória de alta frequência, especialmente para altos valores das taxas de adaptação. Trabalhos como de (STEPANYAN; KRISHNAKUMAR, 2010) propõem modificações do esquema MRAC tradicional de forma a evitar a geração dessas oscilações e aprimorar a resposta transitória. A abordagem proposta por esse trabalho, nomeada de MRAC modificado (M-MRAC), baseia-se na inclusão do erro de rastreamento de realimentação na dinâmica do modelo de referência, sem alterar dessa forma a estrutura do controlador e os ganhos adaptativos projetados. Os resultados obtidos por esses trabalhos mostram de fato uma melhora dos parâmetros citados, sem comprometer a estabilidade e o desempenho original do sistema. Outros controladores adaptativos como o L1, VS- MRAC, B- MRAC e $\alpha$-MRAC são fundamentados no princípio de controle dos sistemas MRAC, sendo apenas variações ou combinações da forma tradicional desse.

\subsubsection{Gain Schedulling (Ganho escalonado)}

Segundo Astrom e Wittenmark (1934), os sistemas de controle por ganho escalonado possibilitam que os parâmetros do controlador sejam modificados com o sistema em operação através do monitoramento das condições de operação do processo, obtidas na forma de variáveis auxiliares. Esse esquema pode, dessa forma, ser visto como um sistema de controle por realimentação, no qual há um ajuste dos ganhos de realimentação através de uma compensação por antecipação ou alimentação direta (feedforward).

A primeira etapa para sua implementação envolve uma escolha adequada das variáveis escalonadoras, o que pode ser feito com base em um conhecimento prévio do comportamento dinâmico do sistema. Em sistemas de controle de voo são utilizados em geral o número de Mach e a pressão dinâmica. Uma vez determinadas essas variáveis, os parâmetros de interesse do controlador implementado são calculados para diferentes condições de operação do sistema. Quando a planta controlada entra então em operação, o sistema de controle por ganho escalonado calibra ou sintoniza o controlador de acordo com a condição de operação. A estabilidade e o desempenho do sistema integrado quando em funcionamento para as diferentes condições de operação, bem como durante e após a transição entre esses pontos são comumente 
avaliados através de simulações. Como vantagem desses sistemas de controle temos a rápida adaptação dos parâmetros dos controladores frente às mudanças no processo. No entanto, como desvantagem temos o fato dos mesmos operarem na forma de compensadores em malha aberta, pois não há em sua implementação a realimentação do desempenho do sistema operado em malha fechada para os parâmetros do controlador de forma a compensar-se um escalonamento incorreto.

De acordo com (RADEMAKERS, 2004), o ganho escalonado mostra-se como a principal técnica de controle implementada nos sistemas de controle de voo atualmente, devido à sua aplicabilidade tanto à sistemas lineares como não-lineares variantes no tempo. Além do mais, essa técnica possibilita o controle de aeronaves em todo o envelope de voo através da seleção de diferentes pontos de operação, diferentemente do controle clássico o qual é válido apenas nas vizinhanças do ponto selecionado.

\subsection{MODELAGEM DO PILOTO}

O estudo de modelos dinâmicos do piloto humano também se mostra como uma área próspera, tendo sido alvo de pesquisa desde a década de 1940 com os estudos de Tustin na Inglaterra durante a Segunda Guerra Mundial. Paralelamente aos trabalhos de Tustin, mas de forma independente, ocorreram pesquisas no MIT (Massachusetts Institute of Technology) e no exército americano objetivando desenvolver modelos quase-lineares para sistemas de rastreamento de alvos com armas acionadas eletricamente. $\mathrm{O}$ campo de pesquisa de modelagem do piloto humano passou então por um desenvolvimento contínuo ao longo dos anos, com estágios de maior evolução como o ocorrido na década de 60 devido à corrida espacial e à Guerra Fria, tendo sido coletada uma vasta gama de dados experimentais (SCHMIDT, 2012). Dos trabalhos desenvolvidos, um dos primeiros modelos foi definido por Tustin (TUSTIN, 1947). Nesse modelo a função de transferência $\boldsymbol{Y}_{\boldsymbol{p}}(\boldsymbol{s})$ do piloto é definida como a relação entre o sinal de entrada do erro $\boldsymbol{e}(\boldsymbol{s})$ da variável controlada pelo piloto e o sinal de saída de controle do piloto para a aeronave $\boldsymbol{u}(\boldsymbol{s})$. A função de transferência pode então ser definida por:

$$
Y_{p}(s)=\frac{u(s)}{e(s)}=\frac{K_{p}(1+T s) e^{-\tau s}}{s}
$$


Na equação $2.1, \boldsymbol{K}_{\boldsymbol{p}}$ representa o ganho do piloto, estando esse parâmetro relacionado aos hábitos do mesmo no controle de uma determinada aeronave. A constante de tempo de antecipação $\boldsymbol{T}$, por sua vez, está relacionada à experiência do piloto e o atraso de tempo $\boldsymbol{\tau}$ é ocasionado principalmente pelo sistema neuromuscular do condutor. Outro trabalho que merece destaque foi o realizado por McRuer (MCRUER; KRENDEL, 1974), o qual originou o chamado Modelo Crossover, mostrando-se esse como um dos modelos mais utilizados. De acordo com esse modelo, o operador humano adapta sua função de transferência dependendo do comportamento dinâmico do veículo controlado. A função de transferência em malha aberta combinada do sistema piloto+veículo assume então o formato:

$$
Y_{p}(s) Y_{c}(s)=\frac{\omega_{c} e^{-\tau s}}{s}
$$

Onde $\boldsymbol{Y}_{\boldsymbol{c}}(\boldsymbol{s})$ representa a função de transferência do veículo controlado, $\boldsymbol{Y}_{\boldsymbol{p}}(\boldsymbol{s})$ a função de transferência do piloto, $\boldsymbol{\omega}_{\boldsymbol{c}}$ a chamada frequência de crossover e $\boldsymbol{\tau}$ um atraso total no tempo do sistema veículo+piloto. Esse atraso inclui o tempo transcorrido para o corpo humano identificar uma mudança na configuração do sistema e iniciar uma ação. Dessa forma há também uma influência da velocidade de resposta do sistema neuromuscular do piloto no tempo de resposta final. No entanto esse modelo é, em geral, válido apenas na região em torno da frequência de crossover, na qual o sistema do conjunto piloto + veículo se comporta como um integrador. A crossover é definida como a frequência na qual a função descrita pela equação 2.2 possui uma magnitude de $0 \mathrm{~dB}$ (frequência em que o gráfico de magnitude cruza o eixo de amplitudes de $0 \mathrm{~dB}$, fato que deu origem ao nome do modelo). Essa frequência tem seu valor dependente do sistema controlado, sendo incluído nesse montante o ganho $\boldsymbol{K}_{\boldsymbol{p}}$ empregado pelo piloto. A Tabela 1 apresenta um sumário das funções de transferência características aproximadas do piloto para diferentes formatos do sistema controlado. Cada uma das formas das funções de transferência especificadas nessa tabela apresenta uma aplicação específica no contexto do controle de aeronaves. Particularmente as formas 1, 2, 4 e 6 são aplicáveis no controle do ângulo de arfagem (pitch) de aeronaves, considerando-se em cada caso condições específicas de operação de voo. Essas formas possuem, portanto, aplicabilidade no desenvolvimento do trabalho. 
Tabela 1 - Sumário das funções de transferência características aproximadas do piloto

\begin{tabular}{|c|c|c|c|c|}
\hline Modelo & $\mathbf{Y}_{\mathbf{c}}$ & $\mathbf{Y}_{\mathbf{p}}$ & $\mathbf{Y}_{\mathbf{p}} \mathbf{Y}_{\mathbf{c}}$ & $\boldsymbol{\tau}_{\boldsymbol{e}}(\boldsymbol{s})$ \\
\hline $\mathbf{1}$ & $K_{c}$ & $\frac{K_{p} e^{-\tau_{1} s}}{s}$ & $\frac{\omega_{c} e^{-\tau_{e} s}}{s}$ & $\mathrm{ND}$ \\
\hline $\mathbf{2}$ & $\frac{K_{c}}{s}$ & $K_{p} e^{-\tau_{2} s}$ & $\frac{\omega_{c} e^{-\tau_{e} s}}{s}$ & 0.14 \\
\hline $\mathbf{3}$ & $\frac{K_{c}}{s(s+\alpha)}$ & $K_{p}(s+\alpha) e^{-\tau_{3} s}$ & $\frac{\omega_{c} e^{-\tau_{e} s}}{s}$ & 0.16 \\
\hline $\mathbf{4}$ & $\frac{K_{c}}{s^{2}}$ & $K_{p} s e^{-\tau_{3} s}$ & $\frac{\omega_{c} e^{-\tau_{e} s}}{s}$ & 0.43 \\
\hline $\mathbf{5}$ & $\frac{K_{c}}{(s-\lambda)}$ & $K_{p} e^{-\tau_{2} s}$ & $\frac{\omega_{c} e^{-\tau_{e} s}}{(s-\lambda)}$ & 0.07 \\
\hline $\mathbf{6}$ & $\frac{K_{c}}{(s+\alpha)(s-\lambda)}$ & $K_{p}(s+\alpha) e^{-\tau_{4} s}$ & $\frac{\omega_{c} e^{-\tau_{e} s}}{(s-\lambda)}$ & 0.20 \\
\hline
\end{tabular}

Fonte: Adaptado de (MCRUER; KRENDEL, 1974).

A partir do Modelo Crossover, McRuer desenvolveu ainda a função de modelagem do piloto apresentada na equação 2.3 , onde $\boldsymbol{T}_{\boldsymbol{I}}$ representa uma constante de tempo de retardo. Essa função é indicada quando a planta controlada tem sua resposta dominada por uma função de transferência de $2^{\mathrm{a}}$ ordem, a qual no ramo aeronáutico especificamente representa o modo de período curto. De fato, o modo fugóide em geral pode facilmente ser controlado pelo piloto, enquanto o modo de período curto apresenta maiores dificuldades em seu controle.

$$
Y_{p}(s)=\frac{u(s)}{e(s)}=\frac{K_{p} e^{-\tau s}}{T_{I} s+1}
$$

Baseando-se na metodologia do crossover, McRuer desenvolveu ainda o chamado Modelo de Precisão (Precision Model). Esse modelo objetiva cobrir uma maior faixa de frequências do que a permitida pelas funções do crossover, levando em consideração ainda a dinâmica do sistema neuromuscular humano. A função descritiva geral desse modelo pode ser definida por: 


$$
Y_{p}(s)=K_{p} e^{-\tau s} \frac{\left(T_{L} s+1\right)}{\left(T_{I} s+1\right)}\left(\frac{1}{\left(\frac{s^{2}}{\omega_{n}^{2}}+\frac{2 \zeta_{n}}{\omega_{n}} s+1\right)}\right)
$$

Onde além do ganho do piloto $\boldsymbol{K}_{\boldsymbol{p}}$ e do atraso $\boldsymbol{\tau}$ no tempo da resposta do mesmo, temos os termos $\boldsymbol{T}_{\boldsymbol{L}}$ e $\boldsymbol{T}_{\boldsymbol{I}}$ que representam as constantes de tempo de antecipação e de retardo do termo equalizador. Essa parte da função almeja modelar a habilidade do operador humano em ajustar a variável controlada, de forma a ser obtido um comportamento satisfatório do sistema piloto+veículo operado em malha fechada. Esse comportamento requerido pode estar ligado a parâmetros como relação entrada-saída, margem de estabilidade em malha fechada, capacidade de rejeição a distúrbios e entradas indesejadas e a capacidade de compensação de incertezas e variações de características da planta (LONE; COOKE, 2010). A última expressão entre parênteses da equação 2.4 representa o termo de modelagem do sistema neuromuscular de atuação do piloto. Nessa expressão $\boldsymbol{\omega}_{\boldsymbol{n}}$ e $\boldsymbol{\zeta}_{\boldsymbol{n}}$ representam respectivamente a frequência não amortecida e a razão de amortecimento do sistema neuromuscular do piloto.

O Modelo Crossover de McRuer serviu como base para o desenvolvimento de outros modelos do piloto humano classificados como quase-lineares, sendo ele mesmo classificado nessa categoria. O termo quase-linear é empregado nesse contexto para descrever os sistemas não-lineares que possuem uma relação entrada-saída que pode ser aproximada à de um sistema linear. A estrutura do modelo do piloto, a determinadas entradas, nesses sistemas pode assim ser dividida em dois elementos: uma função de transferência (conhecida como função descritiva) que modela o comportamento linear do piloto e um sinal adicionado de ruído (geralmente na forma de um ruído branco) à saída dessa função, conhecido como remnant. Esse sinal objetiva modelar qualquer outro comportamento não-linear do piloto presente na reposta final. Nesse contexto, no Modelo Crossover a dinâmica dada pela equação 2.2, na forma de uma função de transferência linear, é assim definida como o termo dominante e aplicável apenas para uma região de operação em torno da frequência $\omega_{c}$.

Os modelos até aqui descritos inserem-se em uma categoria maior denominada de modelos funcionais. Esses modelos buscam apenas representar funcionalmente o piloto, reproduzindo seus sinais de controle através de funções de transferência simplificadas. Os chamados modelos estruturais, por outro lado, buscam reproduzir o sistema de processamento de sinais interno dos seres humanos. Esses últimos buscam representar a influência dos sinais oriundos do sistema de percepção humana, como a visão e o sistema vestibular, no processo de tomada de decisão de controle. 
Dentre os modelos estruturais mais difundidos temos o proposto por Hess, introduzido na década de 70 (HESS, 1978) sendo o modelo então desenvolvido em (HESS, 1980) e revisado e ampliado posteriormente em (HESS, 1997). Nesse último trabalho, Hess propôs um modelo que possibilita a modelagem da capacidade do piloto em adaptar sua estratégia de controle dependendo da tarefa realizada, utilizando-se assim o sinal de erro ou de derivada do erro da variável controlada no ato da pilotagem. No modelo, esses sinais são obtidos por uma realimentação visual. Essa possibilidade de chaveamento exerce um papel central na iniciação e sustentação das oscilações do fenômeno de PIO. Nesse contexto, admite-se que para ocorrência do PIO, o piloto chaveia sua estratégia de controle normalmente operada utilizandose o erro para uma estratégia que utiliza a derivada do erro. Esse segundo modo de operação modela então uma situação de controle na qual o piloto opera a aeronave com um alto ganho, portanto mais propenso ao fenômeno. Nesse sistema há ainda elementos representativos da realimentação do sistema vestibular e da percepção proprioceptiva da posição do membro de acionamento do piloto.

Outro modelo estrutural bastante difundido foi o chamado Modelo Descritivo de Hosman (HOSMAN; STASSEN, 1998), o qual modela e analisa o grau de influência do sistema visual e do sistema vestibular do piloto no processo de tomada de decisões durante o ato da pilotagem. Nesse trabalho, Hosman realiza ainda a distinção entre os sistemas visuais central e periférico, inclui funções de transferência que modelam o utrículo e os canais semicirculares (órgãos do ouvido interno humano), os quais compõem o sistema vestibular humano, e modela o processo de percepção, detecção e controle desses sinais no sistema nervoso central através de ganhos. 


\section{CAPÍtulo 3}

\section{DESENVOLVIMENTO}

Nesse capítulo são desenvolvidos separadamente os sistemas constituintes do sistema de controle a ser utilizado nas simulações e nos ensaios. Esse sistema completo pode ser descrito pelo diagrama apresentado na Figura 4. Nesse diagrama tem-se que, a partir do sinal de erro entre a referência (Syntask) e a posição atual do modelo de aeronave considerado, o piloto atua no sistema gerando um sinal de comando, sendo esse sinal utilizado no controle dos modelos de referência. A saída de um desses modelos é então repassada ao sistema de controle MMRAC, que então envia um sinal de controle à aeronave controlada. O modelo de referência é selecionado pelo sistema de controle de ganho escalonado, o qual realiza essa seleção com base na saída do algoritmo ROVER. Cada um desses sistemas é então descrito nas seções subsequentes. Na seção 3.1 é desenvolvido o modelo matemático da aeronave, o qual será utilizado na definição dos modelos de referência. Na seção seguinte o sistema de detecção ROVER é definido, e então na última seção são descritos o sistema de controle M-MRAC integrado com o sistema os sistema de controle do tipo Regulador Quadrático Linear (LQR do inglês Linear Quadratic Regulator) e o algoritmo de supressão desenvolvido. 
Figura 4 - Diagrama do sistema de controle utilizado

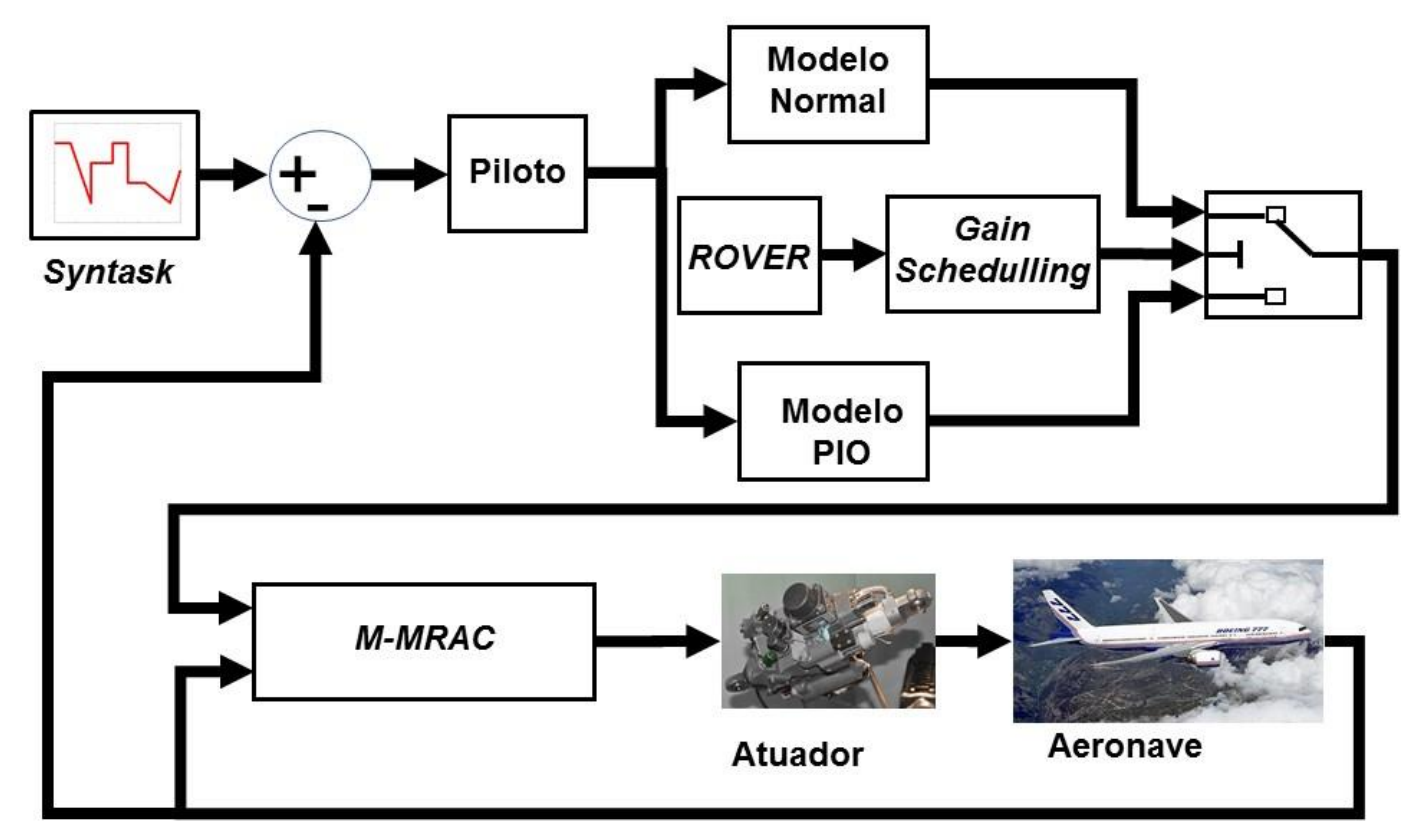

Fonte: Criada pelo autor.

\subsection{MODELAGEM DINÂMICA DE AERONAVES}

Uma aeronave modelada como um corpo rígido possui seis graus de liberdade, sendo três de translação (nos eixos $\mathrm{x}, \mathrm{y}$ e $\mathrm{z}$ ) e três de rotação, esses últimos definidos como os movimentos de rolagem (roll $-\boldsymbol{\phi})$, arfagem (pitch - $\boldsymbol{\theta})$ e guinada $($ yaw $-\boldsymbol{\psi})$. Comumente para a análise dinâmica de aeronaves adota-se o sistema de eixos mostrado na Figura 5, onde definese ainda a nomenclatura dos planos, forças e momentos resultantes. Nessa nomenclatura definese $\boldsymbol{L}=$ momento de rolagem, $\boldsymbol{M}=$ momento de arfagem, $\boldsymbol{N}=$ momento de guinada, $\boldsymbol{p}=$ velocidade angular de rolagem, $\boldsymbol{q}=$ velocidade angular de arfagem, $\boldsymbol{r}=$ velocidade angular de guinada, $[\boldsymbol{X}, \boldsymbol{Y}, \boldsymbol{Z}]=$ componentes da força aerodinâmica resultante e $[\boldsymbol{u}, \boldsymbol{v}, \boldsymbol{w}]=$ componentes da velocidade do centro de gravidade da aeronave relativa à atmosfera (ETKIN; REID, 1996). 
Figura 5 - Notação do sistema de eixos de uma aeronave

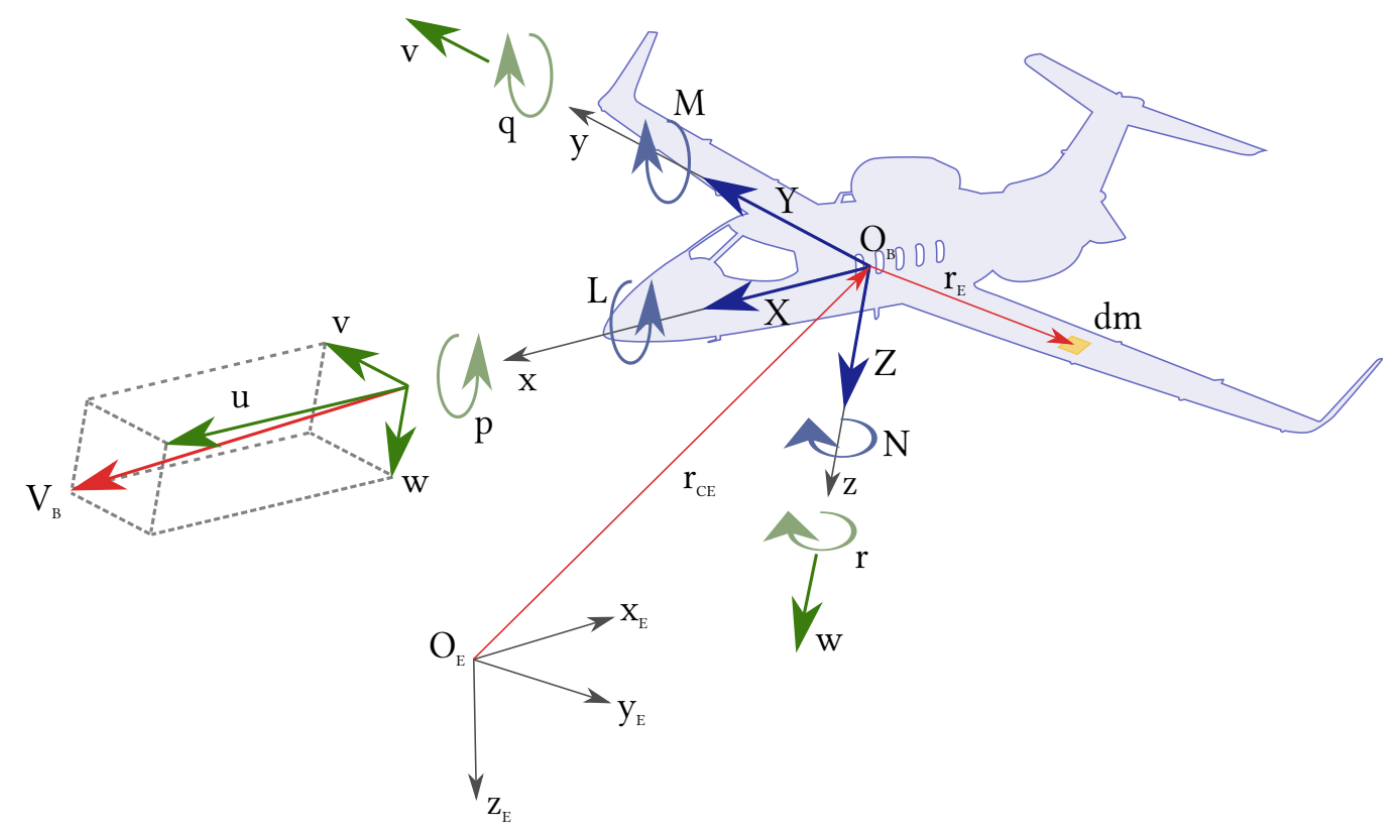

Fonte: Criada pelo autor.

As equações dinâmicas de aeronaves podem ser definidas se forem adotadas algumas hipóteses e considerações simplificadoras. Dentre elas considera-se o avião como um corpo rígido, despreza-se a influência da rotação dos rotores da aeronave, considera-se uma velocidade relativa do vento nula e que a movimentação da aeronave possa ser separada em duas partes. A primeira descreve uma movimentação longitudinal da aeronave na qual o CG do veículo se move em um plano vertical (movimento de arfagem). O segundo tipo de movimentação descreve a dinâmica lateral, na qual os movimentos de rolagem e guinada ocorrem de forma acoplada mantendo-se o ângulo de elevação constante. A partir das simplificações citadas, as equações gerais da dinâmica de movimentação das aeronaves podem ser definidas aplicando-se a teoria de pequenas perturbações às equações definidas para uma condição de voo estacionária de referência. Dessa forma, utilizando-se essa teoria, uma variável arbitrária $\mathrm{A}$ pode ser representada pela equação: $\boldsymbol{A}=\boldsymbol{A} \boldsymbol{\theta}+\boldsymbol{\Delta A}$, onde o primeiro termo representa um valor de referência e o segundo uma perturbação dessa condição. Para a dinâmica longitudinal as hipóteses citadas levam a um conjunto de equações diferencias que podem ser dadas no formato de espaço de estados:

$$
\begin{aligned}
& \dot{x}=A x+B u \\
& y=C x+D u
\end{aligned}
$$


Seguindo-se a abordagem proposta por Etkin (ETKIN; REID, 1996) considera-se $\left[\begin{array}{llll}\Delta \boldsymbol{u} & \boldsymbol{w} & \boldsymbol{q} & \boldsymbol{\Delta} \boldsymbol{\theta}_{0}\end{array}\right]^{T}$ como o vetor de estados e o ângulo requerido do profundor $\delta_{\mathrm{e}}$ como a entrada do sistema (para uma condição de propulsão constante). A saída por sua vez será aqui adotada como o vetor de estados. Para essa metodologia a aeronave pode então ser modelada da forma explicitada na equação 3.3. Nessas equações os termos $\boldsymbol{X}_{\boldsymbol{u}}, \boldsymbol{X}_{\boldsymbol{w}}, \boldsymbol{X}_{\boldsymbol{\delta}_{e}}, \boldsymbol{Z}_{\boldsymbol{u}}, \boldsymbol{Z}_{\boldsymbol{w}}, \boldsymbol{Z}_{\boldsymbol{q}}, \boldsymbol{Z}_{\boldsymbol{\delta}_{e}}, \boldsymbol{Z}_{\dot{w}}, \boldsymbol{M}_{\boldsymbol{u}}, \boldsymbol{M}_{q}, \boldsymbol{M}_{\boldsymbol{\delta}_{e}} \boldsymbol{e} \boldsymbol{M}_{\dot{\boldsymbol{w}}}$ definem as chamadas derivadas dimensionais (de estabilidade ou ainda de controle) longitudinais. Elas representam a influência das variáveis de estado e do sinal de entrada na resultante das forças aerodinâmicas e do momento de arfagem, podendo ser calculadas em termos dos dados geométricos e aerodinâmicos para uma determinada aeronave. Particularmente as derivadas $\boldsymbol{X}_{\boldsymbol{\delta}_{e}}, \boldsymbol{Z}_{\boldsymbol{\delta}_{e}}$ e $\boldsymbol{M}_{\boldsymbol{\delta}_{e}}$ são calculadas utilizandose os coeficientes aerodinâmicos adimensionais $\boldsymbol{C}_{\boldsymbol{x} \boldsymbol{\delta}_{e}}, \boldsymbol{C}_{\boldsymbol{z} \boldsymbol{\delta}_{e}}$ e $\boldsymbol{C}_{\boldsymbol{m} \boldsymbol{\delta}_{e}}$ através da equação 3.4. Os termos $\boldsymbol{m}, \boldsymbol{I}_{\boldsymbol{y}} \boldsymbol{g}, \boldsymbol{\theta}_{\boldsymbol{0}}, \boldsymbol{u}_{\boldsymbol{0}}, \boldsymbol{\rho}, \boldsymbol{S}$ e $\overline{\boldsymbol{c}}$ presentes nessas equações, por sua vez, representam respectivamente a massa, a componente em y do momento de inércia da aeronave, a aceleração da gravidade, o ângulo de arfagem de referência, a componente x da velocidade de referência de voo, a densidade do ar, área da asa e a corda média aerodinâmica.

$$
\begin{aligned}
& {\left[\begin{array}{c}
\Delta \dot{u} \\
\dot{w} \\
\dot{q} \\
\Delta \dot{\theta}
\end{array}\right]=\left[\begin{array}{cccc}
\frac{X_{u}}{m} & \frac{X_{w}}{m} & 0 & -g \cos \theta_{o} \\
\frac{Z_{u}}{m-Z_{\dot{w}}} & \frac{Z_{w}}{m-Z_{\dot{w}}} & \frac{Z_{q}+m u_{o}}{m-Z_{\dot{w}}} & \frac{-m g \sin \theta_{o}}{m-Z_{\dot{w}}} \\
\frac{1}{I_{y}}\left[M_{u}+\frac{M_{\dot{w}} Z_{u}}{\left(m-Z_{\dot{w}}\right)}\right] & \frac{1}{I_{y}}\left[M_{w}+\frac{M_{\dot{w}} Z_{u}}{\left(m-Z_{\dot{w}}\right)}\right] & \frac{1}{I_{y}}\left[\begin{array}{c}
\left.M_{q}+\frac{M_{\dot{w}}\left(Z_{q}+m u_{o}\right)}{\left(m-Z_{\dot{w}}\right)}\right] \\
0
\end{array}\right] & -\frac{M_{\dot{w}} m g \sin \theta_{o}}{I_{y}\left(m-Z_{\dot{w}}\right)} \\
0 & 1
\end{array}\right]\left[\begin{array}{c}
\Delta u \\
w \\
q \\
\Delta \theta
\end{array}\right]} \\
& +\left[\begin{array}{c}
\frac{X_{\delta_{e}}}{m} \\
\frac{Z_{\delta_{e}}}{m-Z_{\dot{w}}} \\
\frac{M_{\delta_{e}}}{I_{y}}+\frac{M_{\dot{w}}}{I_{y}} \frac{Z_{\delta_{e}}}{\left(m-Z_{\dot{w}}\right)} \\
0
\end{array}\right] \delta_{e} \\
& y=\left[\begin{array}{llll}
1 & 0 & 0 & 0 \\
0 & 1 & 0 & 0 \\
0 & 0 & 1 & 0 \\
0 & 0 & 0 & 1
\end{array}\right]\left[\begin{array}{c}
\Delta u \\
w \\
q \\
\Delta \theta
\end{array}\right]
\end{aligned}
$$

$$
X_{\delta_{e}}=C_{x \delta_{e}} \frac{1}{2} \rho u_{O}^{2} S
$$




$$
\begin{gathered}
Z_{\delta_{e}}=C_{z \delta_{e}} \frac{1}{2} \rho u_{O}^{2} S \\
M_{\delta_{e}}=C_{m \delta_{e}} \frac{1}{2} \rho u_{O}^{2} S \bar{c}
\end{gathered}
$$

As aeronaves assim modeladas possuem funções de transferência de $4^{\mathrm{a}}$ ordem, as quais relacionam a resposta de cada uma das variáveis de estado com a entrada do profundor. A resposta resultante pode em geral ser desmembrada em dois modos naturais, caracterizados por oscilações amortecidas. Um modo conhecido como fugóide de longo período e baixo amortecimento, e outro modo conhecido como modo de período curto caracterizado por um alto amortecimento. Esses modos podem ser obtidos através de uma análise dos autovalores da matriz A.

As derivadas de estabilidade a serem utilizadas como base para o estudo de diferentes modelos possíveis de aeronaves e sua susceptibilidade resultante ao PIO serão as da aeronave Boeing 747-100. Esse modelo de base será identificado a partir de agora como modelo A. As mesmas correspondem a uma condição de voo horizontal em cruzeiro em uma altitude de 40.000 pés (aproximadamente $12.192 \mathrm{~m}$ ) e uma velocidade de Mach 0,8. Os dados geométricos e aerodinâmicos necessários para o cálculo das derivadas de estabilidade dessa aeronave são apresentados na Tabela 2 e as derivadas dimensionais são apresentadas na Tabela 3, utilizandose unidades do SI.

Tabela 2 - Dados do modelo Boeing 747-100

\begin{tabular}{|c|c|}
\hline Massa $(\mathbf{k g})$ & $2,8876 \times 10^{5}$ \\
\hline $\boldsymbol{I}_{\boldsymbol{y}}\left(\boldsymbol{k g} \boldsymbol{m}^{\mathbf{2}}\right)$ & $0,449 \times 10^{8}$ \\
\hline $\boldsymbol{\theta}_{\mathbf{o}}(\mathbf{r a d})$ & 235,9 \\
\hline $\mathbf{u}_{\mathbf{0}}(\boldsymbol{m} / \boldsymbol{s})$ & 0,3045 \\
\hline $\boldsymbol{\rho}\left(\boldsymbol{k g} / \boldsymbol{m}^{\mathbf{3}}\right)$ & 511 \\
\hline $\mathbf{S}\left(\boldsymbol{m}^{\mathbf{2}}\right)$ & 8,324 \\
\hline$\overline{\boldsymbol{c}}(\boldsymbol{m})$ & $-3,818 \times 10^{-6}$ \\
\hline $\boldsymbol{C}_{\boldsymbol{x} \boldsymbol{\delta}_{\boldsymbol{e}}}$ & $-0,3648$ \\
\hline $\boldsymbol{C}_{z \delta_{e}}$ & $-1,444$ \\
\hline $\boldsymbol{C}_{\boldsymbol{m} \delta_{e}}$ & \\
\hline
\end{tabular}

Fonte: Adaptado de (ETKIN; REID, 1996). 
Tabela 3 - Derivadas dimensionais longitudinais da aeronave Boeing 747-100

\begin{tabular}{|c|c|c|c|}
\hline & $\boldsymbol{X}(\boldsymbol{N})$ & $\boldsymbol{Z}(\boldsymbol{N})$ & $\boldsymbol{M}(\mathbf{N m})$ \\
\hline $\boldsymbol{u}(\boldsymbol{m} / \boldsymbol{s})$ & $-1,982 \times 10^{3}$ & $-2,595 \times 10^{4}$ & $1,593 \times 10^{4}$ \\
\hline $\boldsymbol{w}(\boldsymbol{m} / \boldsymbol{s})$ & $4,025 \times 10^{3}$ & $-9,030 \times 10^{4}$ & $-1,563 \times 10^{5}$ \\
\hline $\boldsymbol{q}(\boldsymbol{r a d} / \boldsymbol{s})$ & 0 & $-4,524 \times 10^{5}$ & $-1,521 \times 10^{7}$ \\
\hline$\dot{\boldsymbol{w}}\left(\boldsymbol{m} / \boldsymbol{s}^{2}\right)$ & 0 & $1,909 \times 10^{3}$ & $-1,702 \times 10^{4}$ \\
\hline $\boldsymbol{\delta}_{\boldsymbol{e}}(\boldsymbol{r a d})$ & $-1,653 \times 10^{1}$ & $-1,5794 \times 10^{6}$ & $-5,204 \times 10^{7}$ \\
\hline
\end{tabular}

Fonte: Adaptado de (ETKIN; REID, 1996).

Utilizando-se esses dados são obtidas a matrizes apresentadas nas equações 3.5 e 3.6 para o modelo de base A. As características dos modos resultantes, por sua vez, para essa condição de voo são apresentadas na Tabela 4, explicitando-se a frequência natural $\omega_{n}$, o período $\boldsymbol{T}$ e a razão de amortecimento $\zeta$.

$$
\begin{gathered}
A=\left[\begin{array}{cccc}
-0,0069 & 0,0139 & 0 & -9,81 \\
-0,0905 & -0,3148 & 235,89 & 0 \\
0,0004 & -0,0034 & -0,428 & 0 \\
0 & 0 & 1 & 0
\end{array}\right] \\
B=\left[\begin{array}{c}
-0,0001 \\
-5,5060 \\
-1,1569 \\
0
\end{array}\right]
\end{gathered}
$$

Tabela 4 - Características dos modos do modelo A

\begin{tabular}{|c|c|c|c|c|c|}
\hline Modo & Nome & Autovalores & $\omega_{n}(\mathrm{rad} / \mathrm{s})$ & $T(s)$ & $\zeta$ \\
\hline 1 & Fugóide & $-0,0033 \pm 0,0672 i$ & 0,0673 & 93,4155 & 0,0489 \\
\hline 2 & Período & $-0,3716 \pm 0,8869 i$ & 0,9616 & 6,5338 & 0,3865 \\
& curto & & & & \\
\hline
\end{tabular}

Fonte: Adaptado de (ETKIN; REID, 1996). 
A partir desse modelo dois outros modelos derivados foram desenvolvidos: um com baixa propensão ao PIO (modelo B) e um modelo com mais alta propensão (modelo C). Esses modelos foram desenvolvidos com base nos resultados de (H.C. MOURA, G.S.P. ALEGRE, J.H. BIDINOTTO, 2018), trabalho no qual as derivadas de estabilidade são variadas a partir de um valor base e a susceptibilidade resultante do modelo de aeronave é avaliada com base em simulações de um sistema em malha fechada análogo ao aqui considerado. As derivadas dimensionais dos modelos considerados são apresentadas na Tabela 5, nas quais os valores em negrito representam derivadas que tiveram seus valores originais alterados. A características dos modos das respostas dos modelos B e C são apresentadas na Tabela 6. De forma a ser simulada uma planta com maior proximidade a uma aeronave real será incluído na mesma uma representação do sistema de acionamento servo hidráulico das superfícies de comando, especificamente o profundor. Esse modelo dos atuadores possui ainda uma limitação de velocidade de $40 \%$ s e uma limitação de posição de $30^{\circ}$, sendo esses valores escolhidos a partir de simulações realizadas e baseando-se no trabalho de (LIU, 2012). Esse sistema será modelado pela função de transferência simplificada $\boldsymbol{G}_{\boldsymbol{a} \boldsymbol{c}}$ (s) definida na equação 3.7, onde $\boldsymbol{\tau}$ representa a constante de tempo do sistema. Para as simulações será utilizado um valor de $\boldsymbol{\tau}=\frac{\mathbf{1}}{\mathbf{2 0}} \boldsymbol{s}$, sendo esse valor da ordem de grandeza em uma aeronave real (JOHNSON, 2002). Um diagrama representativo dessa modelagem é apresentado na Figura 6.

$$
G_{a c}(s)=\frac{1}{\tau s+1}
$$

Figura 6 - Modelo das superfícies de comando

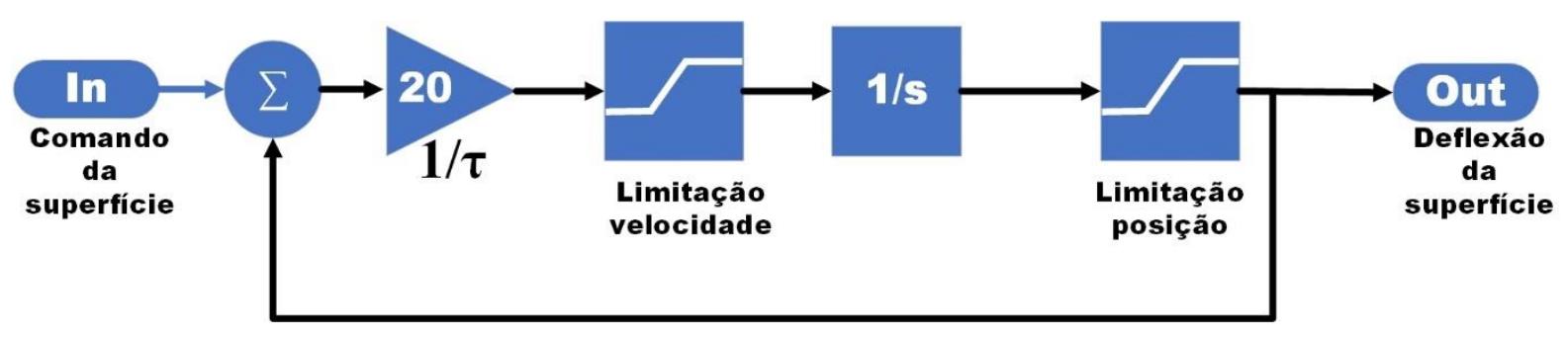

Fonte: adaptado de (SAFETY, 1997). 
Tabela 5 - Derivadas dimensionais longitudinais alteradas da aeronave Boeing 747-100 (Modelos B e C)

\begin{tabular}{|c|c|c|c|c|c|c|}
\hline & \multicolumn{2}{|c|}{$X(\boldsymbol{N})$} & \multicolumn{2}{c|}{$Z(\boldsymbol{N})$} & \multicolumn{2}{c|}{$M(\boldsymbol{N m})$} \\
\hline & B & C & B & C & B & C \\
\hline $\boldsymbol{u}(\boldsymbol{m} / \boldsymbol{s})$ & - & - & - & - & - & - \\
\hline $\boldsymbol{w}(\boldsymbol{m} / \boldsymbol{s})$ & - & - & $9,030 \times 10^{3}$ & - & - & - \\
\hline $\boldsymbol{q}(\boldsymbol{r a d} / \boldsymbol{s})$ & - & - & $1,610 \times 10^{8}$ & - & - & $1,171 \times 10^{7}$ \\
\hline$\dot{\boldsymbol{w}}\left(\boldsymbol{m} / \boldsymbol{s}^{2}\right)$ & - & - & - & - & - & $-8,510 \times 10^{4}$ \\
\hline $\boldsymbol{\delta}_{\boldsymbol{e}}(\boldsymbol{r a d})$ & - & - & $6,318 \times 10^{7}$ & $-3,2567 \times 10^{8}$ & $-5,204 \times 10^{8}$ & - \\
\hline
\end{tabular}

Fonte: Elaborada pelo autor.

Tabela 6 - Características dos modos (Modelo B e Modelo C)

\begin{tabular}{|c|c|c|c|c|c|c|}
\hline Modo & Nome & Modelo & Autovalores & $\omega_{n}(\mathrm{rad} / \mathrm{s})$ & $T(s)$ & $\zeta$ \\
\hline 1 & \multirow{2}{*}{ Fugóide } & $\mathrm{B}$ & $-0,0034 \pm 0,0326 i$ & 0,0328 & 191,6095 & 0,1026 \\
\cline { 3 - 7 } & & $\mathrm{C}$ & $-0,004 \pm 0,0754 i$ & 0,0755 & 83,2275 & 0,0531 \\
\hline 2 & \multirow{2}{*}{$\begin{array}{c}\text { Período } \\
\text { curto }\end{array}$} & $\mathrm{B}$ & $-0,3051 \pm 1,6362 i$ & 1,6644 & 3,7751 & 0,1833 \\
\cline { 3 - 7 } & & $\mathrm{C}$ & $-0,2499 \pm 0,8195 i$ & 0,8568 & 7,3337 & 0,2917 \\
\hline
\end{tabular}

Fonte: Elaborada pelo autor.

\subsection{ROVER}

O algoritmo ROVER (Realtime Oscillation Verifier) será implementado no trabalho utilizando-se o monitoramento de 4 parâmetros: amplitude e frequência da velocidade angular de arfagem, amplitude do sinal de comando do piloto e a diferença de fase entre esses dois sinais. Dessa forma serão criadas 4 flags de monitoramento dessas variáveis, às quais serão atribuídos o valor 1 quando as mesmas passarem dos limites estabelecidos na Tabela 7. Os valores apresentados foram estabelecidos com base nos trabalhos de (LIU, 2012) e (JOHNSON, 2002) e com base em simulações iniciais realizadas. 
Tabela 7 - Valores dos parâmetros do algoritmo ROVER

\begin{tabular}{|c|c|}
\hline Parâmetro & Valor limite \\
\hline Amplitude pico a pico velocidade angular de arfagem $(q)$ & $6^{\circ} / \mathrm{s}$ \\
\hline Frequência velocidade angular de arfagem & 0,85 a $10 \mathrm{rad} / \mathrm{s}$ \\
\hline Amplitude pico a pico do comando piloto $\left(\delta_{p}\right)$ & $1,0(50 \%$ do valor máximo 2$)$ \\
\hline Diferença de fase & $40^{\circ}$ \\
\hline
\end{tabular}

Fonte: Elaborada pelo autor.

Seguindo-se uma metodologia semelhante a esses trabalhos, a implementação do algoritmo inicia-se com o cálculo das amplitudes pico a pico de $\boldsymbol{q}$ e $\boldsymbol{\delta}_{\boldsymbol{p}}$. Para esse fim é utilizando o método de identificação dos picos, baseado no teste da derivada primeira para extremos relativos do Cálculo. Os picos máximos são identificados caso ocorra uma derivada positiva seguida de uma derivada negativa, como mostrado na Figura 7-a, e os picos mínimos caso ocorra uma derivada negativa seguida de uma derivada positiva no sinal monitorado, como explicitado na Figura 7- b. As derivadas são implementadas na forma aproximada de diferenças entre os valores dos sinais para um determinado intervalo de tempo considerado. Caso não ocorram novos picos, o algoritmo retém os valores dos últimos picos identificados como representado na Figura 7-c. A amplitude dos sinais é então calculada como a diferença entre o valor do último pico positivo e do último pico negativo identificados. 
Figura 7 - Representação do detector de picos do algoritmo ROVER: (a) Detecção dos picos de máximo; (b) Detecção dos picos de mínimo; (c) Retenção dos picos detectados

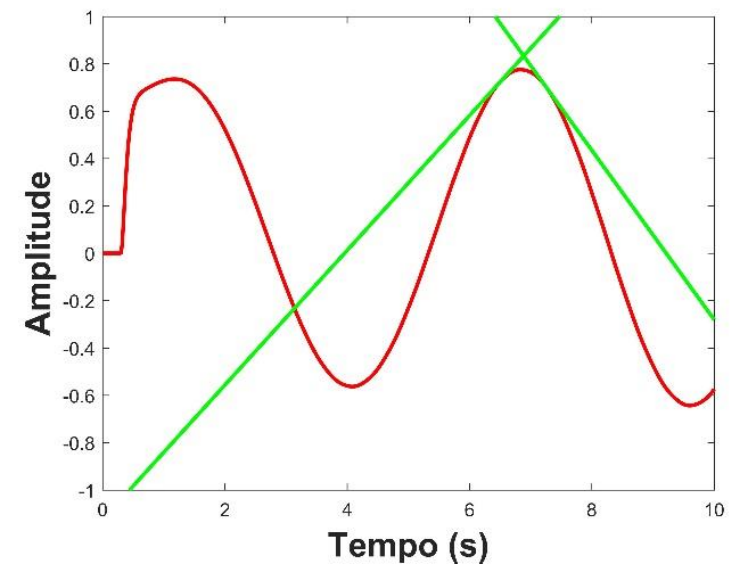

(a)

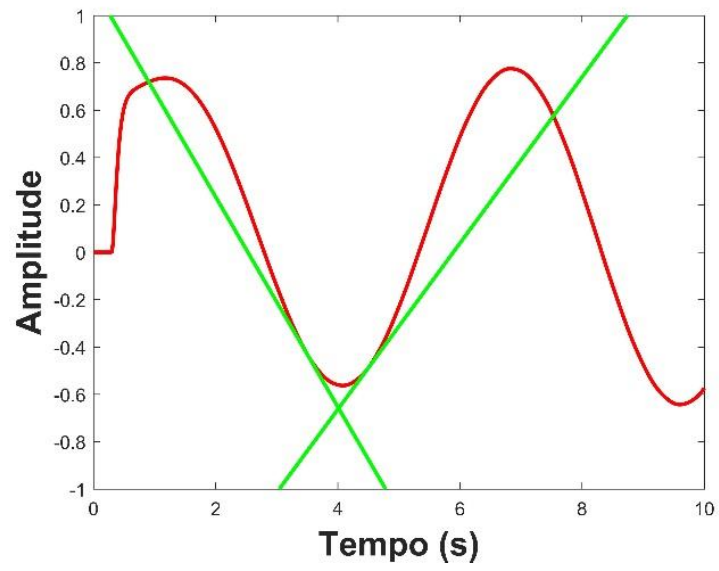

(b)

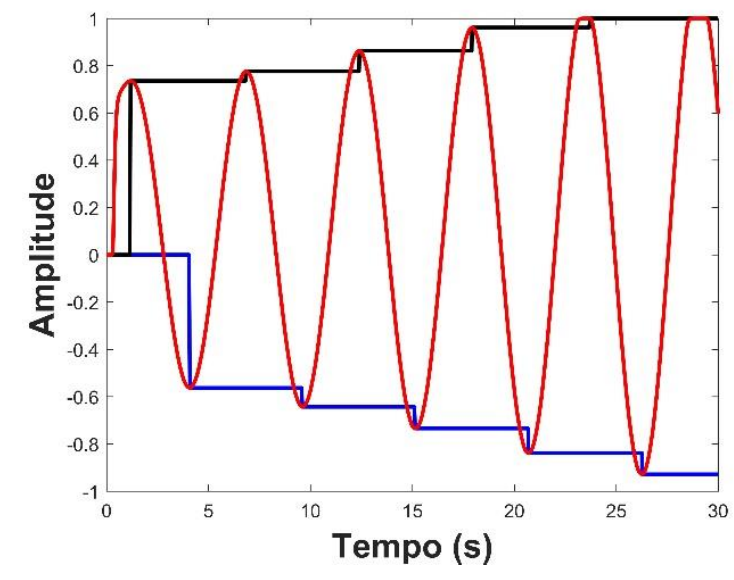

(c)

Fonte: Criada pelo autor.

O segundo parâmetro, a frequência da velocidade angular de arfagem é calculada a partir do valor da diferença dos instantes de tempo em que os picos máximo e mínimo foram detectados. Considerando-se que esses instantes de tempo sejam $\boldsymbol{t}_{\boldsymbol{m} \text { má }}$ e $\boldsymbol{t}_{\boldsymbol{m i n}}$ respectivamente, a frequência em $\mathrm{rad} / \mathrm{s}$ do sinal $\boldsymbol{q}$ é então calculada utilizando-se a equação 3.9. Um exemplo do cálculo desse parâmetro é apresentado na Figura 8, onde a partir dos valores de $\boldsymbol{t}_{\boldsymbol{m} \text { áx }}=\mathbf{8 , 0 8 9 \mathrm { s }}$ e $\boldsymbol{t}_{\min }=\mathbf{1 0}, \mathbf{8 9 s}$, aplicando-se a equação 3.9 temos $\omega=\mathbf{1}, 12 \mathrm{rad} / \mathrm{s}$.

$$
\omega=\frac{2 \pi}{T}=\frac{2 \pi}{2\left|t_{\max }-t_{\min }\right|}
$$


Figura 8 - Exemplificação do cálculo da frequência do sinal de velocidade angular no algoritmo ROVER

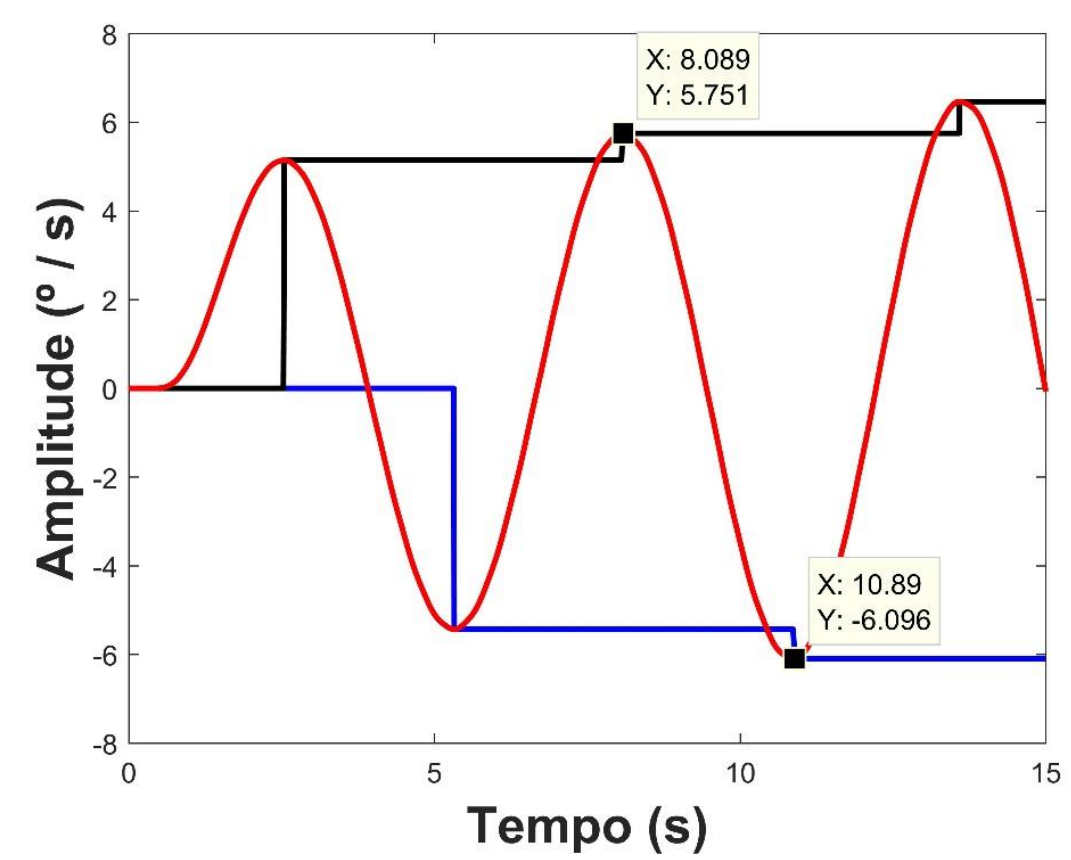

Fonte: Criada pelo autor.

A diferença de fase entre os sinais $\boldsymbol{q}$ e $\boldsymbol{\delta}_{\boldsymbol{p}}$ por sua vez é calculada a partir da informação dos instantes de tempo em que ocorre um pico máximo de $\boldsymbol{q}$, identificado por tquáx e o instante em que ocorre um pico mínimo de $\boldsymbol{\delta}_{\boldsymbol{p}}$, identificado por $\boldsymbol{t}_{\boldsymbol{\delta} p m i n}$. Essa inversão dos picos é necessária devido ao fato da convenção de sinais adotada para o modelo em espaço de estados da equação 3.3, na qual um comando positivo do piloto gera uma variação negativa do ângulo de arfagem da aeronave. A partir da informação desses instantes de tempo a diferença de fase $\boldsymbol{\varphi}$ em graus entre os sinais é então calculada com base no período de $\boldsymbol{q}$ utilizando-se a equação 3.10. Um exemplo do cálculo desse parâmetro é apresentado na Figura 9, onde a partir dos valores $\boldsymbol{t}_{\text {qmáx }}=\mathbf{1 3 , 6} s, \boldsymbol{t}_{\text {dpmin }}=\mathbf{9 , 6 0 8} s$ e $\boldsymbol{t}_{\text {qmin }}=\mathbf{1 0 , 8 9} \boldsymbol{s}$, obtém-se utilizando a equação $3.10 \mathrm{o}$ valor $\varphi=265,1513^{\circ}$.

$$
\begin{aligned}
& \varphi=360\left(\frac{t_{q_{\max }}-t_{\delta_{p_{\min }}}}{T}\right) \\
& =360\left(\frac{t_{q_{\text {máx }}}-t_{\delta_{p_{\min }}}}{2\left|t_{q_{\operatorname{má} x}}-t_{q_{\min }}\right|}\right)
\end{aligned}
$$


Figura 9 - Exemplificação do cálculo da diferença de fase entre o sinal de velocidade angular de arfagem e o comando do piloto

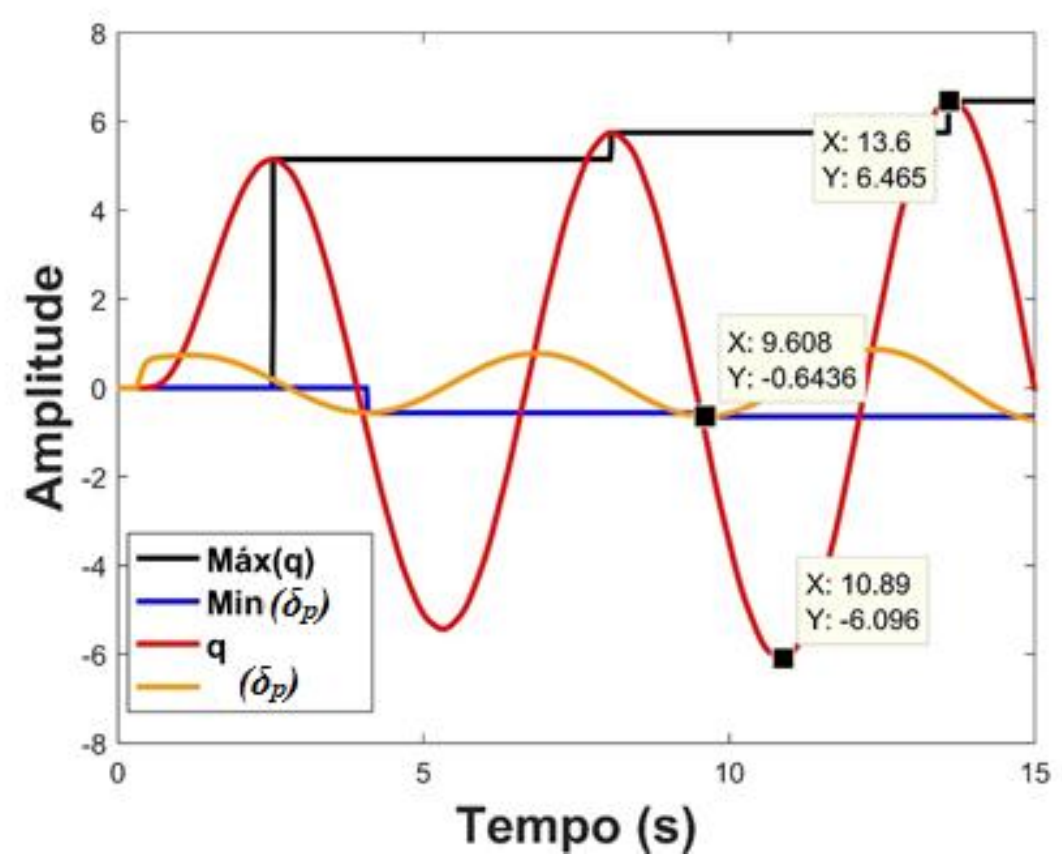

Fonte: Criada pelo autor.

\subsection{SISTEMA DE CONTROLE}

\subsubsection{Controlador MRAC}

De acordo com Eugene (2013), para sistemas de múltiplas entradas e múltiplas saídas (MIMO - Multi-input Multi-output ) pode-se definir um sistema de controle adaptativo MRAC direto utilizando-se a teoria da estabilidade de Lyapunov. Para isso definimos a planta em malha aberta no espaço de estados da forma:

$$
\begin{gathered}
\dot{x}(t)=A x(t)+B u(t) \\
x(0)=x_{0}
\end{gathered}
$$

onde $\boldsymbol{x} \in \boldsymbol{R}^{\boldsymbol{n}}$ representa o vetor de estados do sistema, $\boldsymbol{u} \in \boldsymbol{R}^{\boldsymbol{m}}$ representa a entrada de controle e $\boldsymbol{A} \in \boldsymbol{R}^{\boldsymbol{n} \boldsymbol{X} \boldsymbol{n}}$ e $\boldsymbol{B} \in \boldsymbol{R}^{\boldsymbol{n} \boldsymbol{X} \boldsymbol{m}}$ são matrizes constantes a priori desconhecidas. O objetivo do sistema é que a lei de controle adaptativa por realimentação possibilite que o estado $\boldsymbol{x}$ rastreie assintoticamente o estado $\boldsymbol{x}_{\boldsymbol{r} e f} \in \boldsymbol{\boldsymbol { R } ^ { n }}$ do modelo de referência definido por: 


$$
\begin{gathered}
\dot{x}_{r e f}(t)=A_{r e f} x_{r e f}(t)+B_{r e f} r(t) \\
x_{r e f}(0)=x_{0}
\end{gathered}
$$

onde $\boldsymbol{A}_{\text {ref }} \in \boldsymbol{R}^{\boldsymbol{n} X \boldsymbol{n}}$ define a matriz de Hurwitz, $\boldsymbol{B}_{r e f} \in \boldsymbol{R}^{\boldsymbol{n} \boldsymbol{X} \boldsymbol{m}}$ é uma matriz coluna de posto completo e $\boldsymbol{r}(\boldsymbol{t}) \boldsymbol{E} \boldsymbol{R}^{\boldsymbol{m}}$ representa o vetor de comando externo limitado. É requerido do sistema, durante o rastreamento do modelo de referência, que todos os sinais do sistema em malha fechada permaneçam uniformemente limitados. Dessa forma, para um comando de entrada $\boldsymbol{r}(\boldsymbol{t})$ limitado, a entrada de controle $\boldsymbol{u}(\boldsymbol{t})$ precisa ser escolhida de forma que o erro de rastreamento de estados:

$$
e(t)=x(t)-x_{\text {ref }}(t)
$$

tenda assintoticamente e uniformemente a zero da forma:

$$
\lim _{t \rightarrow \infty}\left\|x(t)-x_{r e f}(t)\right\|=0
$$

Caso a matriz $\boldsymbol{A}$ fosse conhecida, a lei de controle ideal de ganho fixo poderia ser calculada no formato da equação 3.15, sendo os ganhos $\boldsymbol{K}_{x}^{T}$ e $\boldsymbol{K}_{r}^{T}$ calculados na forma da equação 3.16 .

$$
\begin{gathered}
u=K_{x}^{T} x+K_{r}^{T} r \\
K_{x}^{T}=(B \Lambda)^{-1}\left(A_{r e f}-A\right) \\
K_{r}^{T}=(B \Lambda)^{-1} B_{r e f}
\end{gathered}
$$

Com a entrada de controle assim definida, o sistema operando em malha fechada pode ser equacionado da forma:

$$
\dot{x}(t)=\left(A+B \Lambda K_{x}^{T}\right) x(t)+\left(B \Lambda K_{r}^{T}\right) r(t)
$$

Se os ganhos da equação 3.15 forem calculados utilizando-se a equação 3.16, pode-se verificar que o sistema operando em malha fechada segue o modelo de referência. No entanto, 
como os termos $\boldsymbol{A}$ e $\boldsymbol{B}$ são em geral desconhecidos adota-se uma lei de controle alternativa da forma:

$$
u=\widehat{K}_{x}^{T} x+\widehat{K}_{r}^{T} r
$$

onde $\widehat{\boldsymbol{K}}_{\boldsymbol{x}} \in \boldsymbol{R}^{n \boldsymbol{x} \boldsymbol{m}}$ e $\widehat{\boldsymbol{K}}_{\boldsymbol{r}} \in \boldsymbol{R}^{\boldsymbol{m} \boldsymbol{X}^{\boldsymbol{m}}}$ são estimativas das matrizes ideais de ganho $\boldsymbol{K}_{\boldsymbol{x}}$ e $\boldsymbol{K}_{\boldsymbol{r}}$ respectivamente. $\mathrm{O}$ erro entre as estimativas e os valores ideais desses parâmetros é definido para cada um dos termos, da forma $\Delta \boldsymbol{K}_{\boldsymbol{x}}=\widehat{\boldsymbol{K}}_{\boldsymbol{x}}-\boldsymbol{K}_{\boldsymbol{x}}$ e $\boldsymbol{\Delta} \boldsymbol{K}_{\boldsymbol{r}}=\widehat{\boldsymbol{K}}_{\boldsymbol{r}}-\boldsymbol{K}_{\boldsymbol{r}}$. As estimativas para esses parâmetros são geradas com o controlador em operação utilizando-se a análise de Lyapunov inversa. Através dessa teoria, estabelece-se que caso os ganhos estimados sejam calculados da forma apresentada na equação 3.19, pode-se definir uma função de Lyapunov $\boldsymbol{V}\left(\boldsymbol{e}, \boldsymbol{\Delta} \boldsymbol{K}_{\boldsymbol{x}}, \boldsymbol{\Delta} \boldsymbol{K}_{\boldsymbol{r}}\right)$ a qual possui derivada semi-definida negativa da forma $\dot{\mathbf{V}}=-\mathbf{e}^{\mathbf{T}} \mathbf{Q} \mathbf{e} \leq \mathbf{0}$ e uma derivada segunda limitada da forma $\ddot{V}=-\mathbf{2} \boldsymbol{e}^{T} \boldsymbol{Q} \dot{\boldsymbol{e}}$. Consequentemente a dinâmica do erro em malha fechada é uniformemente estável e tende assintoticamente, globalmente e uniformemente à origem como definido pela equação 3.14. Os termos $\boldsymbol{\Gamma}_{\boldsymbol{x}}$ e $\boldsymbol{\Gamma}_{\boldsymbol{r}}$ representam as matrizes da taxa de adaptação do sistema. A prova detalhada desses resultados pode ser encontrada em (EUGENE; KEVIN, 2013).

$$
\begin{gathered}
\dot{\hat{K}}_{x}=-\Gamma_{x} x e^{T} P B \\
\dot{\hat{K}}_{r}=-\Gamma_{r} r(t) e^{T} P B \\
P=P^{T}>0 \text { satisfaz a equação algébrica de Lyapunov para } \\
\text { alguma matriz } Q=Q^{T}>0: \\
P A_{\text {ref }}+A_{r e f}^{T} P=-Q
\end{gathered}
$$

\subsubsection{Controlador M-MRAC}

De forma a aprimorar a resposta transitória do sistema MRAC tradicional, esse trabalho seguirá a metodologia dos sistemas M-MRAC. Para tanto, de acordo com (STEPANYAN; KRISHNAKUMAR, 2012), o sinal de erro da equação 3.13 é calculado da forma $\boldsymbol{e}_{\boldsymbol{m}}(\boldsymbol{t})=\boldsymbol{x}(\boldsymbol{t})$ $\boldsymbol{x}_{\boldsymbol{m}}(\boldsymbol{t})$, utilizando-se agora o modelo de referência modificado definido por: 


$$
\begin{gathered}
\dot{x}_{m}(t)=A_{m} x_{m}(t)+B_{m} r(t)+\lambda e_{m}(t) \\
x_{m}(0)=x_{0}
\end{gathered}
$$

onde $\lambda>0$ representa um parâmetro de projeto. Nota-se, comparando-se as equações 3.12 e 3.20, que a diferença entre os modelos reside na inclusão do termo de erro, onde os mesmos igualamse para $\boldsymbol{\lambda}=\mathbf{0}$. Com a inclusão desse parâmetro, o qual deve ser dependente das matrizes da taxa de adaptação do sistema, pode-se provar utilizando-se novamente a teoria de estabilidade de Lyapunov que tanto o erro de rastreamento original quanto o modificado tendem assintoticamente a zero como almejado. O parâmetro $\lambda$ pode ser calculado da forma:

$$
\lambda=\sqrt{2 \alpha \Gamma_{r} \lambda_{\text {máx }}\left(B_{m}^{T} P B_{m}\right)}
$$

onde $\boldsymbol{\alpha}=\left\|\boldsymbol{x}_{\mathbf{0}}\right\|^{2}+\boldsymbol{s u p}_{\boldsymbol{t}}\|\boldsymbol{r}(\boldsymbol{t})\|^{2}, \lambda_{\text {máx }}$ representa um parâmetro de ajuste e $\boldsymbol{P}$ é solução da equação de Lyapunov apresentada na equação 3.19 utilizando-se a matriz $\boldsymbol{A}_{\boldsymbol{m}}$. Uma comparação da resposta do sistema MRAC com o sistema M-MRAC pode ser vista na Figura 10. Desses gráficos pode-se notar que esse sistema de controle originalmente pode induzir a planta controlada a oscilações de alta amplitude quando em rastreamento do modelo de referência, com uma frequência próxima à do fenômeno de $\mathrm{PIO}$ da ordem 1,6 rad/s, sem porém, ocorrer o fenômeno de fato. Com o sistema M-MRAC, no entanto, essas oscilações passam então a ter baixa amplitude e alta frequência, da ordem $12 \mathrm{rad} / \mathrm{s}$, não interferindo portanto no estudo desse trabalho.

Figura 10 - Exemplificação da atuação do sistema M-MRAC
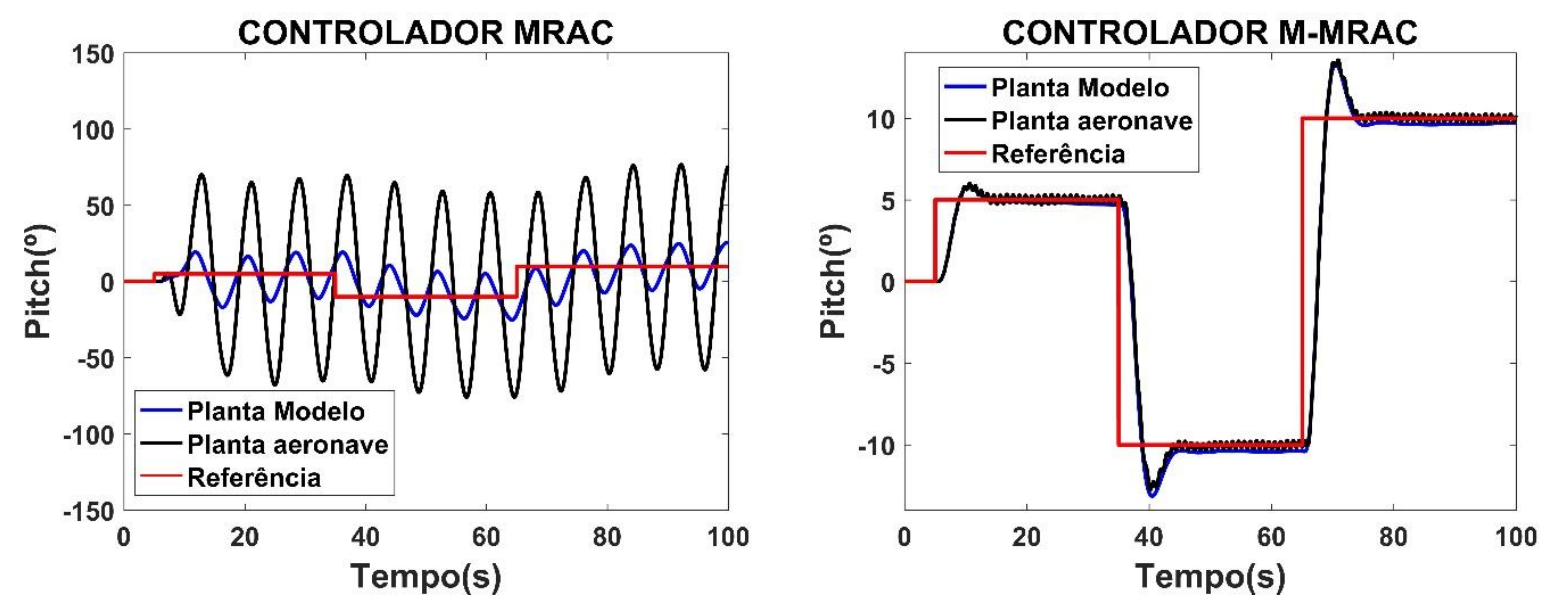

Fonte: Criada pelo autor. 


\subsubsection{Controlador Regulador Linear Quadrático (LQR)}

Os modelos de referência original e modificados apresentados nas equações 3.12 e 3.20 respectivamente, podem ser definidos em malha aberta ou em malha fechada. Nesse trabalho os modelos de referência serão implementados em malha fechada utilizando-se um controlador LQR para fechar a malha. Como vantagens dessa abordagem, tem-se a possibilidade de modificação da resposta original da planta modelo para uma resposta almejada, bem como a garantia de que a mesma opere de forma estável.

Diferentemente da abordagem clássica de projeto de controladores, na qual os ganhos são ajustados de forma a ser obtida uma localização almejada dos polos do sistema em malha fechada, os controladores ótimos buscam otimizar uma função custo de forma a alcançar o melhor desempenho possível para as condições consideradas. Em particular, o controlador LQR mostra-se como um dos mais utilizados.

Para sua implementação busca-se, para um dado sistema MIMO linear da forma $\dot{x}=$ $\mathbf{A x}+\mathbf{B u}\left(\mathbf{x} \in \mathbb{R}^{\mathbf{n}} \mathbf{e} \mathbf{u} \in \mathbb{R}^{\mathbf{m}}\right)$, uma lei de controle da forma $\boldsymbol{u}=\mathbf{-} \boldsymbol{K} \boldsymbol{x}$ a qual minimiza a função custo quadrática definida por:

$$
J=\int_{0}^{\infty}\left(x^{T} Q x+u^{T} R u\right) d t
$$

onde $\boldsymbol{Q}$ e $\boldsymbol{R}$ são matrizes simétricas, positivas e semi-definidas de dimensões apropriadas. A escolha dessas matrizes deve basear-se no conhecimento do sistema a ser controlado. Uma escolha simples é utilizar matrizes diagonais, nas quais os elementos da diagonal principal determinam quanto cada estado (elementos da diagonal de $\boldsymbol{Q}$ ) e cada entrada (elementos da diagonal de $\boldsymbol{R}$ ) contribui para o valor total da função custo (ÅSTRÖM; MURRAY, 2008). A solução desse problema fornece o valor de $\boldsymbol{K}$ da forma:

$$
K=R^{-1} B^{T} P
$$

Para uma matriz $\boldsymbol{P} \in \boldsymbol{R}^{n \times n}$ positiva definida e simétrica que satisfaz a equação algébrica de Riccati dada por: 


$$
P A+A^{T} P-P B R^{-1} B^{T} P+Q=0
$$

No entanto o problema LQR é baseado na minimização de um conjunto de sinais, comumente denominados de saídas controladas, no menor intervalo de tempo possível. Modificações são necessárias para a aplicação desse método em sistemas cujo objetivo principal seja o rastreamento de uma referência. Uma das modificações utilizadas incorpora ao sistema um novo estado $z$ de erro entre a referência e saída da planta controlada da forma:

$$
\dot{z}=r-C_{l q r} x
$$

onde $\boldsymbol{C}_{\boldsymbol{l} \boldsymbol{r}}$ representa uma matriz de dimensões apropriadas, a qual é dependente das dimensões da referência. O sistema é então alterado para uma forma aumentada com a inclusão do novo estado $z$ da forma:

$$
\left[\begin{array}{l}
\dot{x} \\
\dot{z}
\end{array}\right]=\left[\begin{array}{cc}
A & 0_{n \times m} \\
-C_{l q r} & 0_{m \times m}
\end{array}\right]\left[\begin{array}{l}
x \\
z
\end{array}\right]+\left[\begin{array}{c}
B \\
0_{m \times m}
\end{array}\right] u+\left[\begin{array}{c}
0_{n \times m} \\
I_{m \times m}
\end{array}\right] r
$$

onde $\boldsymbol{I}$ representa uma matriz identidade de ordem $\mathrm{m}$. Utilizando-se as matrizes aumentadas definidas na equação 3.26, busca-se então uma lei de controle da forma $\boldsymbol{u}=-\left[\begin{array}{ll}\boldsymbol{K}_{\boldsymbol{x}} & \boldsymbol{K}_{\boldsymbol{z}}\end{array}\right]\left[\begin{array}{l}\boldsymbol{x} \\ \boldsymbol{z}\end{array}\right]$ de modo que a função custo da equação 3.22 seja minimizada. O controlador LQR considerado ainda apresenta um sistema anti-windup do tipo back calculation de forma evitar o carregamento do elemento de integração presente no controlador quando o modelo de atuador estiver nos seus limites de saturação.

\subsubsection{Supressão adaptativa do PIO: Ganho escalonado}

O algoritmo de supressão desenvolvido utiliza a técnica de ganho escalonado, de forma a alternar entre duas plantas o modelo de referência a ser utilizado no sistema de controle MMRAC. Dessa forma são definidos para o sistema dois pontos de operação: um na condição de operação normal do sistema (baixo ganho do piloto) e outro na condição de ocorrência do PIO (alto ganho). Como variáveis escalonadoras são consideradas a saída do algoritmo ROVER e o valor máximo da velocidade angular de arfagem $\boldsymbol{q}$. O algoritmo então funciona da seguinte maneira: quando detectada uma saída de valor igual a 4 do algoritmo ROVER o sistema alterna 
do modo de operação normal para o modo de PIO, repassando a saída do modelo de referência definido para o PIO para o sistema M-MRAC. A partir desse momento é então monitorado o valor máximo absoluto da varíavel $q$ e enquanto o mesmo estiver na faixa de $q \geq \mathbf{1 , 8 8 5} \% \mathrm{~s}$ sistema permanece na condição de PIO. Esse valor foi escolhido com base em simulações iniciais realizadas no sistema completo. Quando essa variável diminui a um valor abaixo do limite estabelecido o sistema então volta à operação normal, sendo repassada a saída do modelo de referência da condição normal de operação para o restante do sistema de controle. De forma a não se obter um chaveamento excessivo entre os modelos, foi estabelecido ainda um intervalo de tempo mínimo de $8 \boldsymbol{s}$ no qual o sistema permanece na condição de PIO, sendo repassadas as saídas do sistema de baixa propensão nesse caso. Com o sistema assim definido, garante-se que não ocorra um chaveamento excessivo entre as plantas, condição na qual o sistema completo poderia tornar-se instável ou muito oscilatório. Nas simulações e ensaios realizados foi utilizado o modelo de dinâmica A como planta controlada, os modelos C (maior susceptibilidade ao PIO) ou A como planta de referência na condição normal de operação e o modelo B (baixa susceptibilidade ao fenômeno) como modelo de referência na condição de PIO. Dessa forma almeja-se que no modo de operação de utilização da planta B consiga-se a supressão das oscilações. 


\section{CAPÍtUlo 4}

\section{MATERIAIS E MÉTODOS}

Nesse capítulo são apresentados os materiais e métodos utilizados nas simulações e nos ensaios realizados com voluntários, empregando-se o sistema descrito nas seções anteriores.

\subsection{MATERIAIS}

Como exposto anteriormente o projeto utilizou as ferramentas computacionais provenientes de softwares comerciais como o MATLAB. Desse software foram utilizadas a interface de programação e de interação com o usuário e a toolbox de identificação de sistemas (System Identification Toolbox). A primeira foi utilizada nos ensaios e nas simulações realizadas. A segunda ferramenta foi utilizada especificamente na estimação dos principais parâmetros dos modelos do piloto, sendo utilizado para tanto os modelos dinâmicos disponíveis na mesma.

Nos ensaios realizados bem como em algumas simulações desenvolvidas foi utilizada ainda a integração do MATLAB com o software Open-Source de simulação de voo FlightGear. Optou-se pela utilização desse software simulador pelo mesmo ser livre e gratuito, além do fato de o mesmo possibilitar uma fácil integração com o MATLAB e com modelos de dinâmica de voo definidos externamente. Com o auxílio do MATLAB foi ainda implementada uma interface de simulação do horizonte artificial como a mostrada na Figura 11-a. A tela programada foi então utilizada nos ensaios realizados com o simulador de voo de forma a apresentar ao piloto a orientação espacial dos modelos dinâmicos da aeronave considerados, bem como a referência de posicionamento das tarefas de rastreamento a ser realizada. O voluntário piloto deveria então seguir a referência de posicionamento utilizando o joystick mostrado na Figura 11-b, simulando o sidestick de uma aeronave FBW real. A implementação dessa tela no software MATLAB foi preferida devido à maior facilidade que o mesmo possibilita na aquisição e posterior análise dos dados provenientes dos ensaios. 
Figura 11 - (a) Horizonte artificial desenvolvido (b) Joystick utilizado nos ensaios

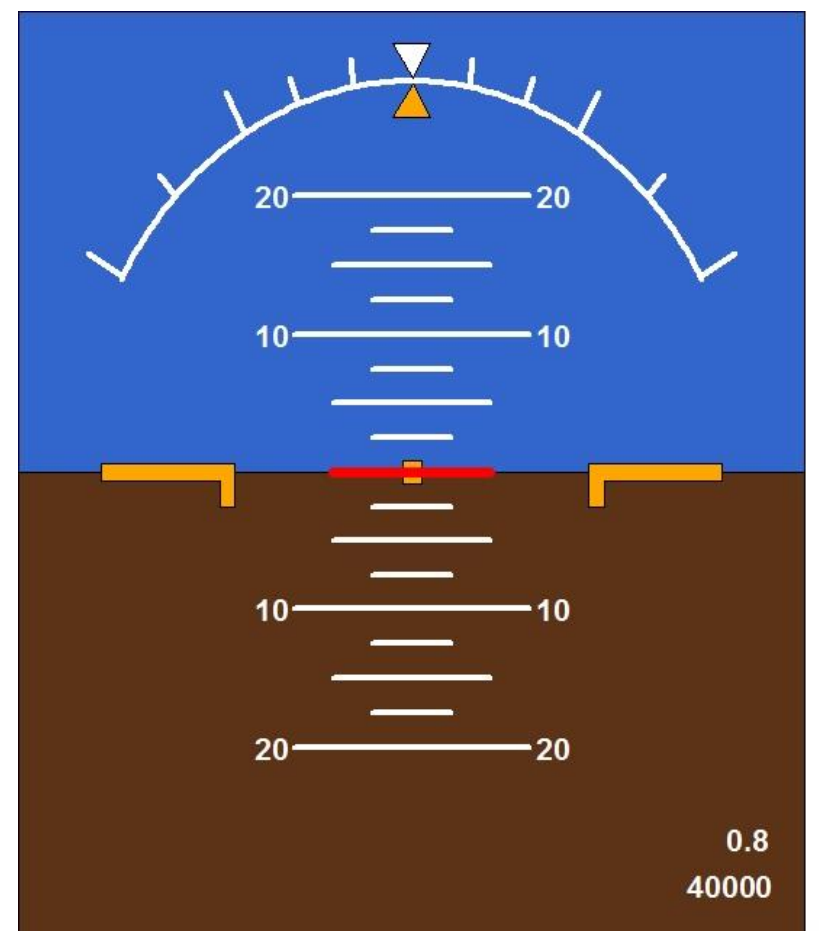

(a)

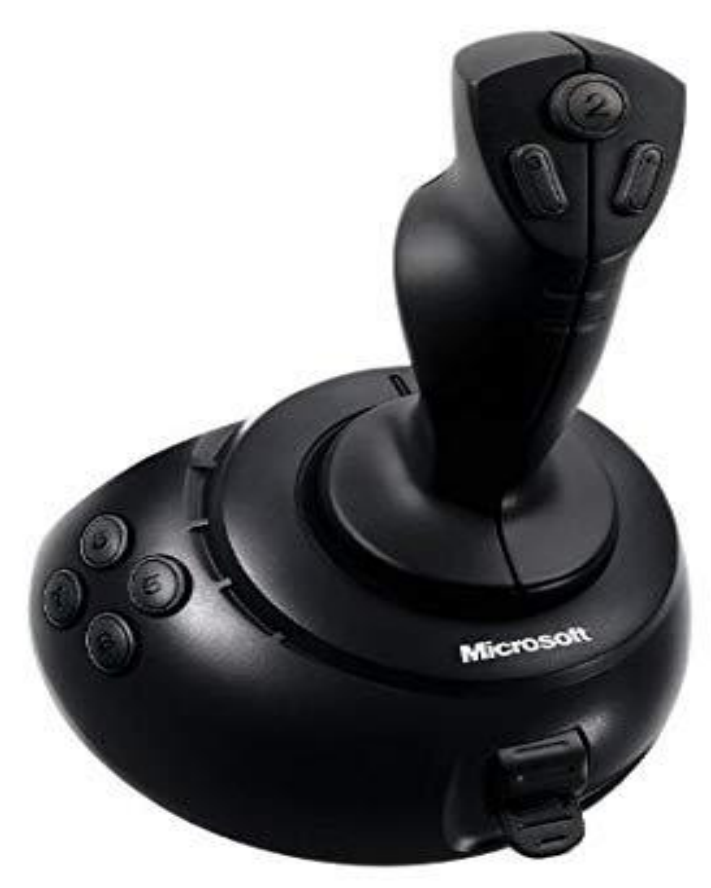

(b)

\subsection{METODOLOGIA}

Na primeira etapa desse projeto, foram estimados os parâmetros de algumas funções de transferência do piloto através de ensaios realizados com operadores humanos. Os dados coletados então foram utilizados na identificação dos parâmetros utilizando-se a toolbox de identificação de sistemas do MATLAB. Para a seleção dos modelos a serem adotados nas simulações considerou-se as limitações dos formatos das funções de modelagem disponibilizadas pela toolbox. Particularmente essa ferramenta disponibiliza funções de transferência de até $3^{a}$ ordem, possibilitando ainda a inclusão de um integrador e de um retardo no tempo. Além do mais, caso a função possua um zero deve ser incluído pelo menos um polo, não localizado na origem, na mesma. Levando-se em conta essas restrições foram considerados, para as simulações e consequente estimação dos parâmetros, os modelos de Tustin apresentado na equação 2.1, o modelo de Crossover descrito pela equação 2.3 e o Modelo de Precisão descrito pela equação 2.4. Nesses ensaios, voltados para a coleta de dados necessários para a estimação, foi simulada a aplicação de uma função degrau ao piloto, implementada através de uma referência do ângulo de arfagem da aeronave. A planta controlada nesse caso consistiu no 
modelo em espaço de estados A apresentado na seção 3.1. Considerando-se o fato de que a dinâmica da aeronave simulada e consequentemente do piloto poderia mudar dependendo do sentido do ângulo de referência, foram considerados nos ensaios um ângulo positivo inicialmente e então um ângulo negativo, a partir de uma referência nula, aplicados em um determinado instante de tempo. Foi requerido ainda do voluntário participante que controlasse a aeronave simulada em um modo normal de pilotagem em uma primeira etapa e então em uma segunda etapa um modo de pilotagem de alto ganho, de forma a simular-se uma condição de PIO. Para esses ensaios iniciais, uma interface foi desenvolvida de forma a possibilitar o ajuste dos parâmetros dos ensaios quando necessário, como a mostrada na Figura 12. As posições de referência almejada e a atual da aeronave foram apresentadas ao piloto utilizando-se o horizonte artificial ilustrado na Figura 11-a. Nessa etapa de ensaios, incluindo os próximos a serem descritos bem como nas simulações, foi adotada uma mesma taxa de amostragem de $40 \mathrm{~Hz}$.

Figura 12 - Janela de controle dos ensaios

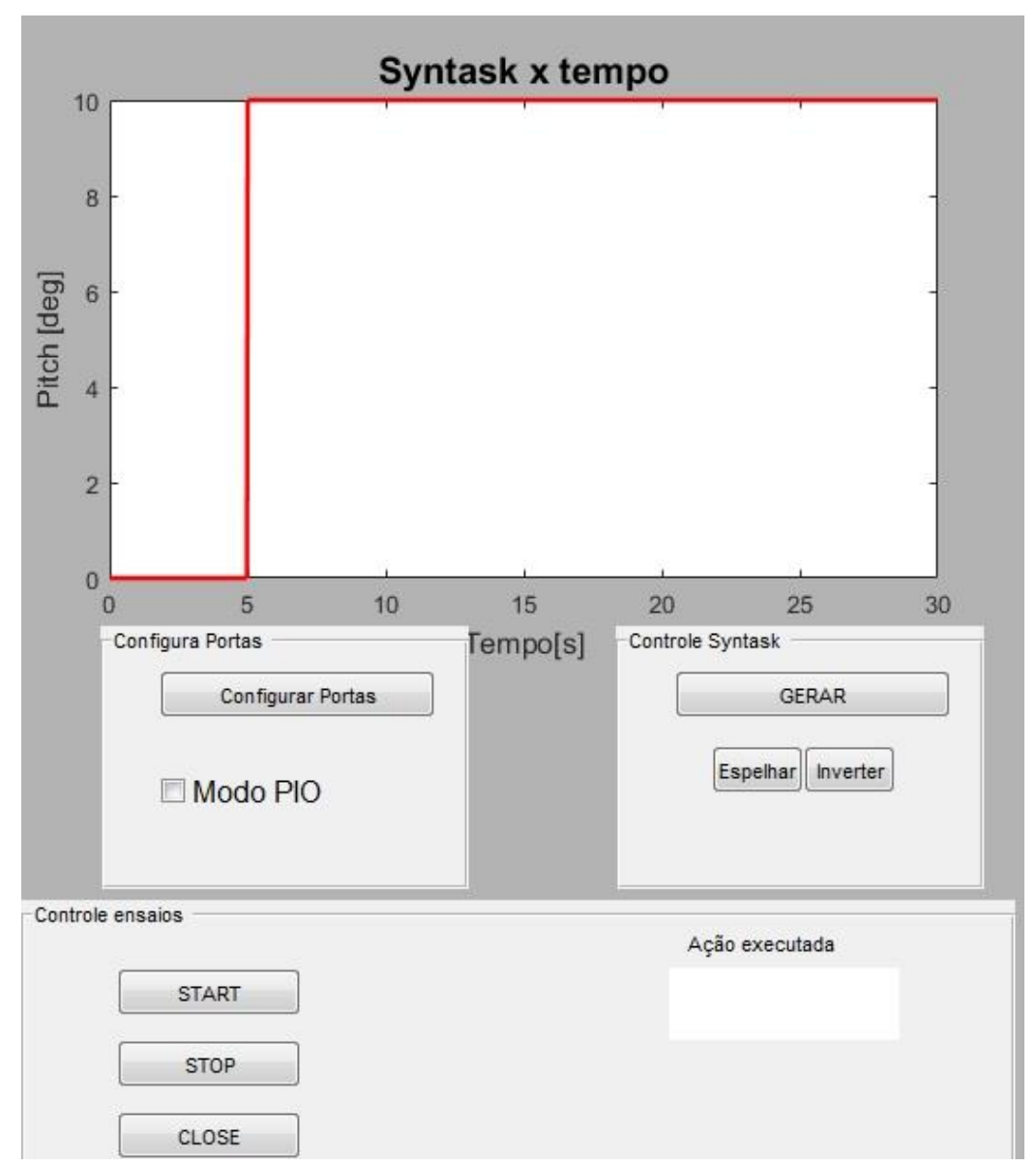

Na segunda etapa do trabalho, os modelos de piloto obtidos com os ensaios foram utilizados na realização de simulações, empregando-se códigos desenvolvidos no software 
MATLAB. Inicialmente os modelos A, B e C de dinâmica da aeronave foram simulados considerando-se o sistema operando em malha fechada com o controlador LQR. Os três modelos de piloto foram utilizados operando nas condições de baixo e alto ganho de forma a fechar a malha externa do sistema. O algoritmo ROVER foi também utilizado objetivando-se mensurar o nível de PIO obtido em cada simulação. Posteriormente o sistema M-MRAC desenvolvido foi então simulado isoladamente, considerando-se como planta controlada tanto o modelo A em espaço de estados quanto os modelos dinâmicos implementados no software de simulação de voo FlightGear. Como plantas modelos do sistema de referência foram aplicadas as plantas B e C nessas simulações. O algoritmo ROVER novamente foi aplicado de forma a medir o nível de PIO obtido no sistema completo. Finalmente, o algoritmo de supressão, integrando o sistema M-MRAC, o controle de ganho escalonado e o detector ROVER foi simulado. Nessas simulações foram considerados os modelos de piloto operando apenas na condição de alto ganho de forma a testar a eficácia do sistema em suprimir ou mitigar as oscilações do PIO.

$\mathrm{Na}$ terceira e última etapa foram realizados ensaios seguindo-se as mesmas etapas realizadas nas simulações descritas. Dessa forma, foram realizados ensaios testando-se os modelos separadamente, o sistema M-MRAC e o algoritmo de supressão. Como planta controlada foram consideradas nessa etapa tanto os modelos em espaço de estados quanto o modelo do software FlightGear. A posição atual dos sistemas simulados bem como a referência Syntask foram apresentadas ao piloto através do horizonte artificial desenvolvido da Figura 11a. O piloto então deveria controlar o sistema através de um joystick. Considerando-se o fato de que os operadores humanos podem memorizar a sequência de ângulos da referência e antecipar seus comandos, o sinal de Syntask original considerado foi alterado nos ensaios subsequentes de forma a se evitar esse fenômeno seguindo-se uma metodologia semelhante à aplicada em (CELERE, 2008). Para tanto o mesmo foi modificado invertendo-se a sequência das referências e refletindo-se a mesma em torno da origem como mostrado na Figura 13. 
Figura 13 - Espelhamento e inversão da Syntask
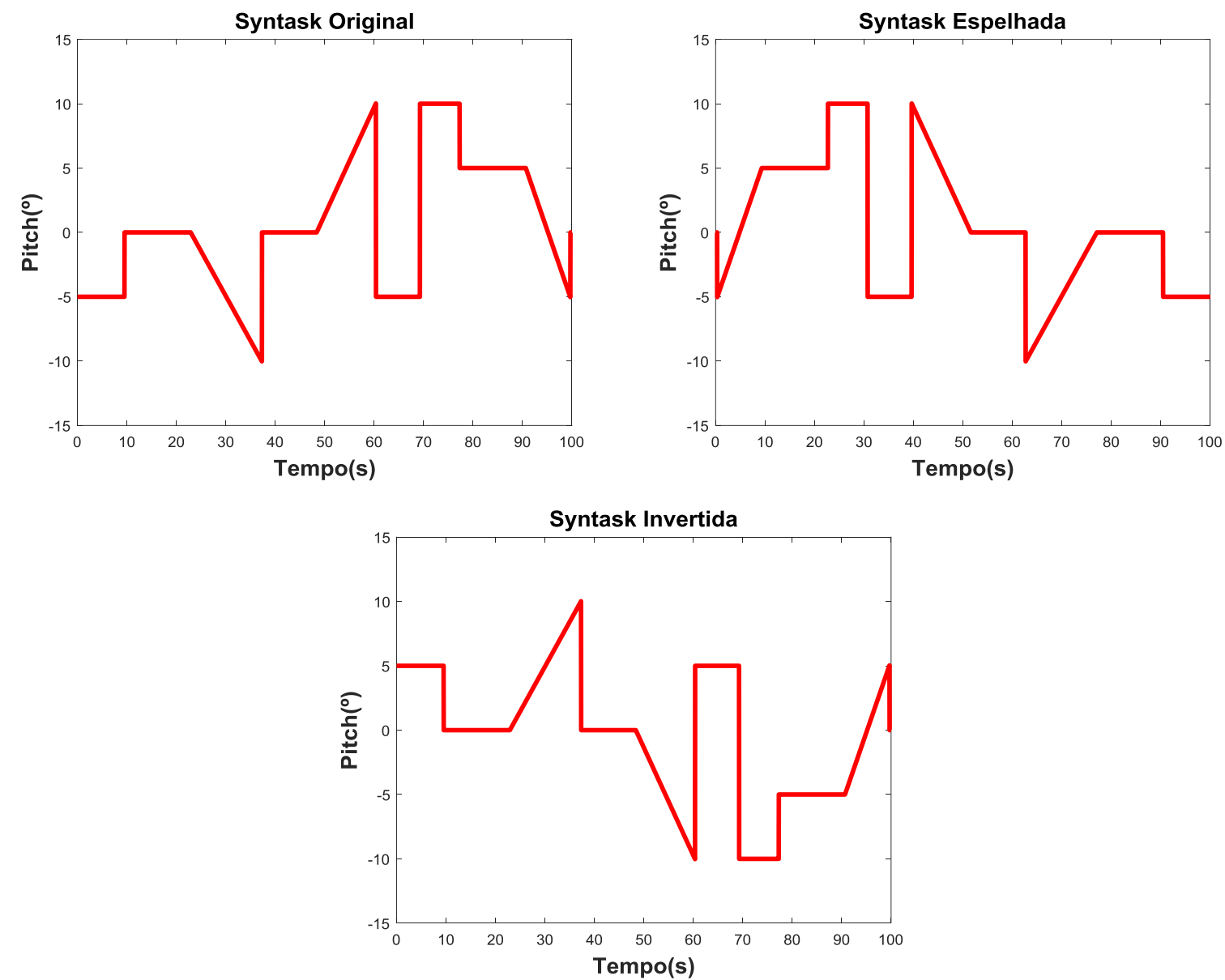


\section{CAPÍtULO 5}

\section{RESULTADOS E DISCUSSÃO}

Nesse capítulo são apresentados os resultados obtidos nos ensaios e nas simulações, bem como uma explanação e análise de cada um desses resultados. Inicialmente na seção 5.1, são apresentados os dados obtidos nos ensaios com voluntários para estimação dos parâmetros dos modelos do piloto, bem como os modelos obtidos com esses dados. Na seção 5.2 são então apresentados os dados obtidos com as simulações iniciais dos modelos de aeronave A, B e C controlados pelos modelos de piloto considerados. Na seção 5.3 apresentam-se então os resultados das simulações do sistema M-MRAC e na seção 5.4 do sistema de supressão, com todos os modelos em espaço de estados. Nas seções 5.5 e 5.6 o sistema M-MRAC e algoritmo de supressão são novamente simulados, considerando-se agora como planta controlada o modelo de aeronave implementado no software FlightGear. Na seção 5.7 iniciam-se então os ensaios com um operador humano, controlando inicialmente os modelos em espaço de estados isoladamente. O sistema M-MRAC em espaço de estados é então utilizado em ensaios na seção 5.8, e o algoritmo de supressão na seção 5.9. Nas seções 5.10 e 5.11 os ensaios são então repetidos, considerando-se agora a utilização do modelo implementado no software de simulação de voo.

De forma a facilitar o entendimento dos resultados obtidos, a divisão das seções de apresentação dos mesmos é apresentada na Tabela 8. Nessa tabela os resultados de cada seção são divididos de acordo com o tipo de sistema utilizado. Cabe ressaltar que o sistema completo de supressão consiste na junção das técnicas LQR, M-MRAC e Gain Scheduling. 
Tabela 8 - Divisão dos Resultados

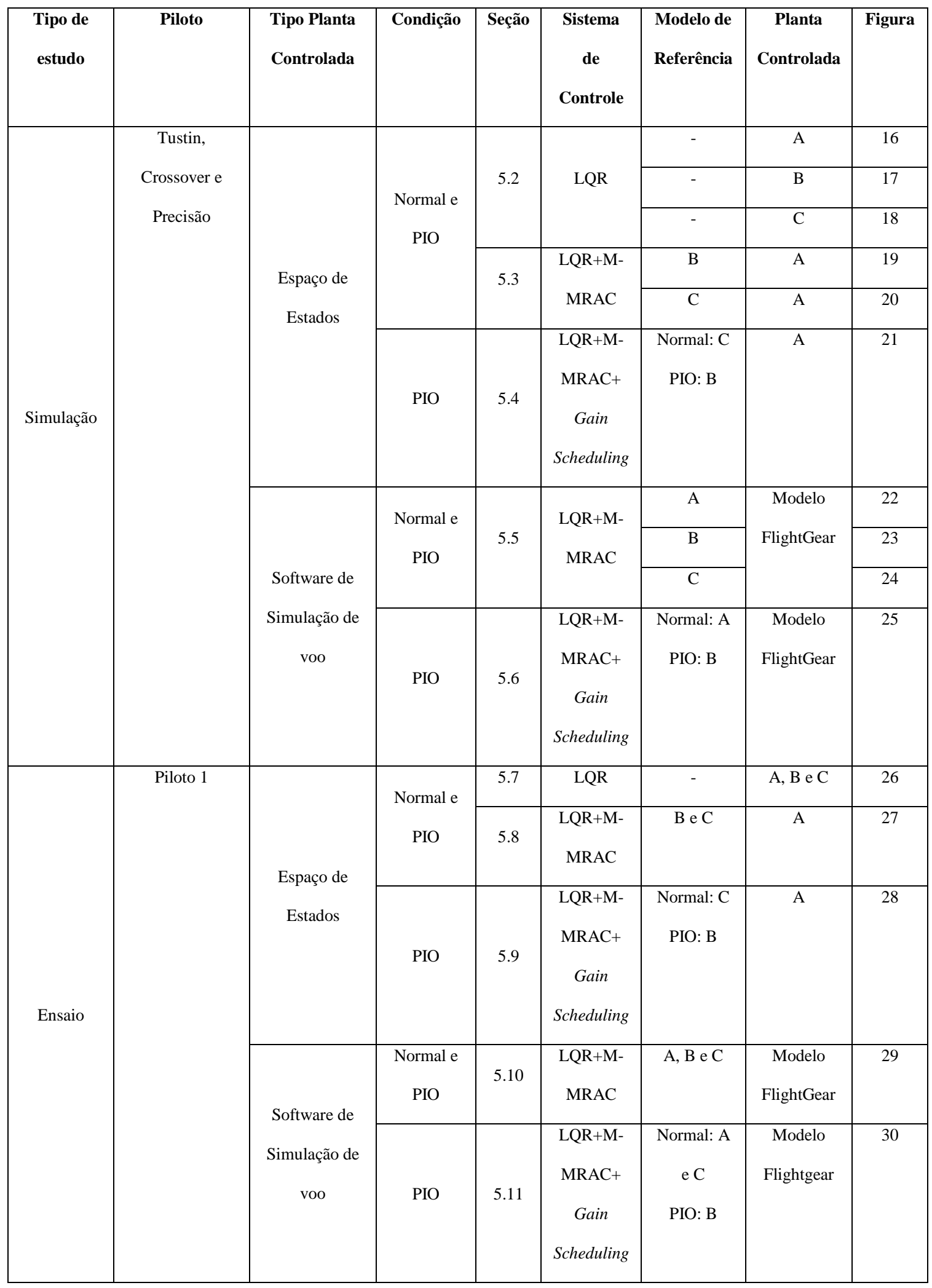

Fonte: Elaborada pelo autor. 


\subsection{ENSAIOS PARA ESTIMAÇÃO DOS MODELOS DO PILOTO}

$\mathrm{Na}$ primeira etapa do projeto três voluntários identificados como Pilotos 1,2 e 3 realizaram o controle do modelo A da aeronave no espaço de estados com o auxílio do software $M A T L A B$ e de um joystick, utilizando-se uma taxa de aquisição de $40 \mathrm{~Hz}$. Os pilotos participantes consistiam em voluntários adultos sem conhecimento de pilotagem. Considerando-se o fato de que a aeronave simulada apresenta uma dinâmica dependente do sentido de movimentação de arfagem, ascendente ou descendente, a dinâmica do piloto consequentemente modifica-se. Dessa forma, nessa etapa dos ensaios foram consideradas incialmente uma referência na forma de um degrau positivo e posteriormente uma referência de degrau negativo. Primeiramente foi solicitado que fosse realizada uma pilotagem mais precisa e com pouco ganho, sendo o resultado apresentado na Figura 14 para os três pilotos. Nesse gráfico é ainda explicitado o instante de tempo em que o voluntário passou a atuar no sistema, sendo esse o parâmetro de atraso de tempo $\boldsymbol{\tau}$ considerado nos modelos. Foi então solicitado dos voluntários uma pilotagem de alto ganho de forma a induzir o sistema ao PIO. A resposta do modelo de aeronave simulado nessa condição é apresentada na Figura 15 para os três pilotos participantes dos ensaios. 
Figura 14 - Resposta modelo aeronave controlada na condição de pilotagem normal
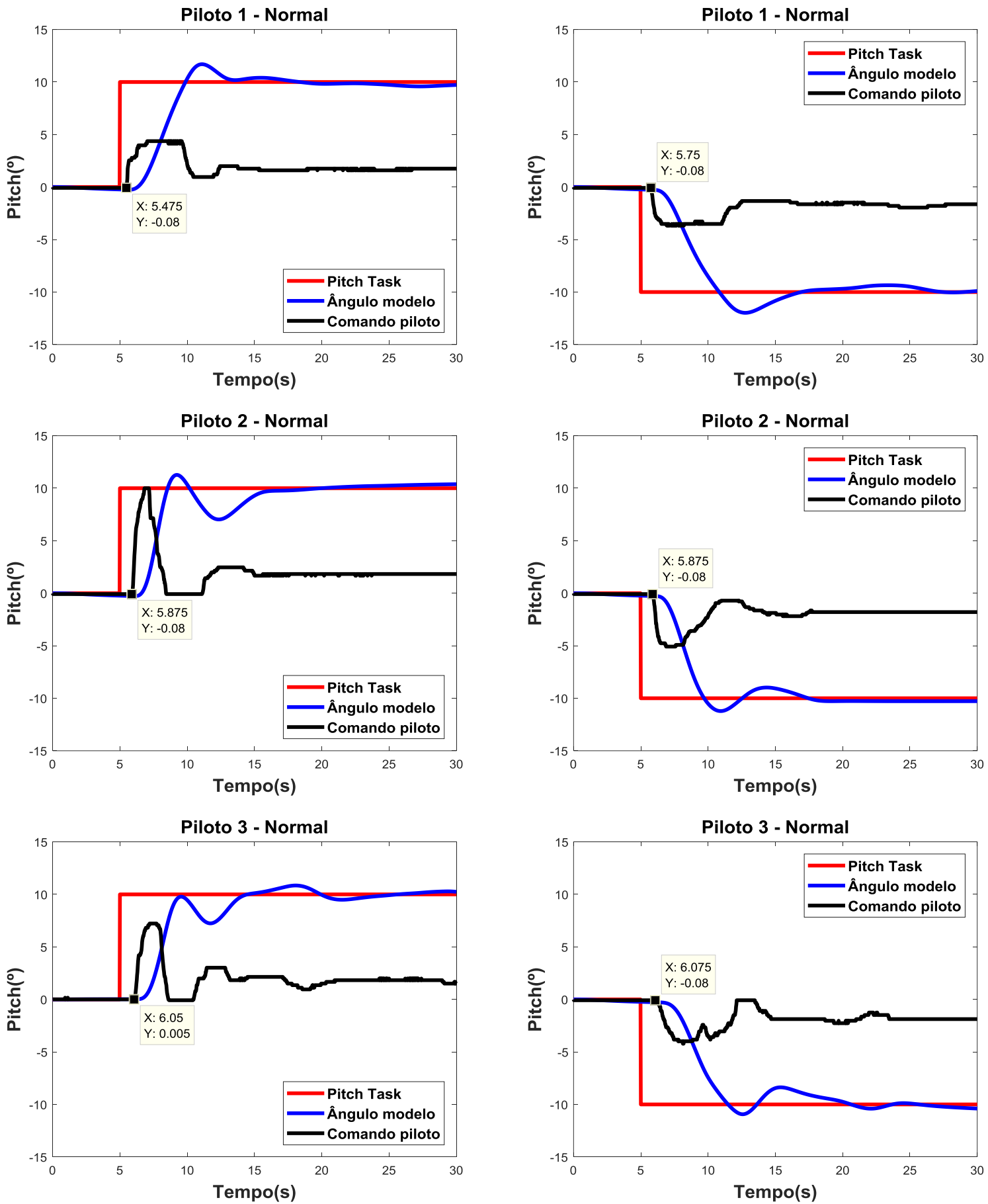
Figura 15 - Resposta modelo aeronave controlado pelo piloto 1 na condição de pilotagem de alto ganho (PIO)
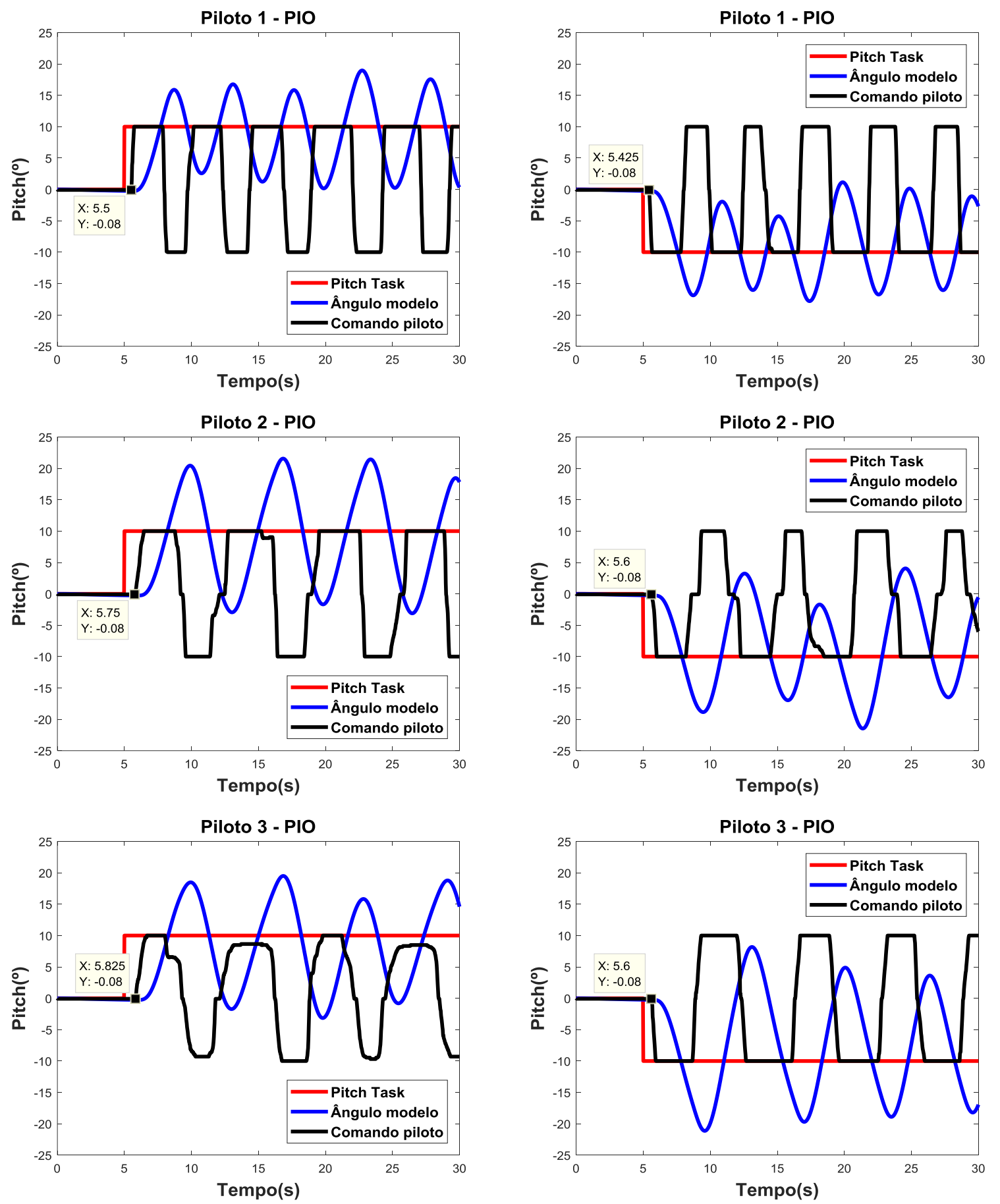

De posse dos dados da resposta da aeronave e do comando do piloto, os mesmos foram utilizados de forma a estimar-se os parâmetros dos modelos de piloto considerados utilizandose a toolbox de identificação de sistemas do MATLAB. Os resultados obtidos são apresentados na Tabela 9 para a condição normal de operação (baixo ganho) e na Tabela 10 na condição de alto ganho (PIO). Os dados apresentados nessa tabela foram calculados através da realização 
de uma média aritmética simples de cada parâmetro obtido para os três pilotos. Para cada piloto foi realizada uma sequência de ensaios até a obtenção de resultados satisfatórios, tendo sido considerado, no entanto, ao final apenas os valore obtidos dos parâmetros para o melhor ensaio realizado. Os valores individuais de cada parâmetro obtidos podem ser encontrados no Apêndice A.

Comparando-se as Tabelas 9 e 10 podemos inferir que a mudança do comportamento do operador humano da condição normal de operação para a condição de PIO provoca uma mudança nos valores dos parâmetros dos modelos considerados. Os principais parâmetros modificados incluem o ganho puro $\boldsymbol{K}_{\boldsymbol{p}}$, bem como as constantes de tempo de antecipação e de retardo.

Tabela 9 - Parâmetros estimados dos modelos obtidos nos ensaios na condição normal

\begin{tabular}{|c|c|c|c|c|c|c|}
\hline \multirow{2}{*}{ Modelo Piloto } & \multicolumn{6}{|c|}{ Parâmetros Modelos Condição Normal } \\
\cline { 2 - 7 } & $\mathbf{K}_{\mathbf{P}}$ & $\mathbf{T}_{\mathbf{L}}$ & $\mathbf{T}_{\mathbf{I}}$ & $\zeta_{\boldsymbol{n}}$ & $\boldsymbol{\omega}_{\boldsymbol{n}}(\mathbf{r a d} / \mathbf{s})$ & $\boldsymbol{\tau}(\mathbf{s})$ \\
\hline Tustin & $\mathbf{0 , 3 7 1 5}$ & $\mathbf{5 , 3 5 2 8}$ & $\mathbf{1 e - 0 6}$ & - & - & $\mathbf{0 , 8 5 0 0}$ \\
\hline Crossover & $\mathbf{2 , 8 8 2 0}$ & - & $\mathbf{0 , 2 3 3 3}$ & - & - & $\mathbf{0 , 8 5 0 0}$ \\
\hline Preciso & $\mathbf{4 , 9 4 7 5}$ & $\mathbf{6 , 5 2 5 3}$ & $\mathbf{1 0}$ & $\mathbf{0 , 6 4 6 0}$ & $\mathbf{1 8 , 1 2 1 7}$ & $\mathbf{0 , 8 5 0 0}$ \\
\hline
\end{tabular}

Tabela 10 - Parâmetros estimados dos modelos obtidos nos ensaios na condição PIO

\begin{tabular}{|c|c|c|c|c|c|c|}
\hline \multirow{2}{*}{ Modelo Piloto } & \multicolumn{6}{|c|}{ Parâmetros Modelos Condição PIO } \\
\cline { 2 - 7 } & $\mathbf{K}_{\mathbf{P}}$ & $\mathbf{T}_{\mathbf{L}}$ & $\mathbf{T}_{\mathbf{I}}$ & $\zeta_{\boldsymbol{n}}$ & $\boldsymbol{\omega}_{\boldsymbol{n}}(\mathbf{r a d} / \mathbf{s})$ & $\boldsymbol{\tau}(\mathbf{s})$ \\
\hline Tustin & $\mathbf{1 , 0 4 2 3}$ & $\mathbf{6 , 0 3 9 0}$ & $\mathbf{1 e - 0 6}$ & - & - & $\mathbf{0 , 6 1 6 7}$ \\
\hline Crossover & $\mathbf{6 , 4 7 0 6}$ & - & $\mathbf{0 , 1 5 6 2}$ & - & - & $\mathbf{0 , 6 1 6 7}$ \\
\hline Preciso & $\mathbf{5 , 9 6 4 0}$ & $\mathbf{1 , 0 0 9 5}$ & $\mathbf{0 , 8 8 7 5}$ & $\mathbf{0 , 8 0 0 0}$ & $\mathbf{2 2 , 2 9 1 6}$ & $\mathbf{0 , 6 1 6 7}$ \\
\hline
\end{tabular}

De posse dos valores dos parâmetros, as funções de transferência de modelagem podem então serem obtidas. O modelo de Tustin, apresentado na equação 2.1, foi o primeiro modelo de piloto analisado. Devido à necessidade da inclusão de um polo adicional ao sistema na toolbox, o modelo considerado passou a ser representado como descrito pela equação 5.1. Em consequência ainda da dificuldade do sistema de identificação em obter o valor real do atraso de tempo do piloto, esse termo foi estimado diretamente no gráfico de comando. Para as condições de alto e baixo ganho foram admitidos os seguintes intervalos de variação das variáveis: $0,1 \leq K_{P} \leq+\infty, T_{I}=0,0,1 \leq T_{L} \leq 6,1$. Essas faixas de valores, bem como as seguintes adotadas para os outros modelos de piloto, foram definidas com base nos valores 
utilizados nos trabalhos de referência utilizados como em (JIRGL; HAVLIKOVA; BRADAC, 2015) e (BORIL; JALOVECKY, 2012), e então refinados com base em simulações preliminares realizadas com os valores obtidos.

$$
Y_{p}(s)=\frac{u(s)}{e(s)}=\frac{K_{p}\left(1+T_{L} s\right) e^{-\tau s}}{s\left(1+T_{I} s\right)}
$$

Trabalhando-se com uma taxa de amostragem de $40 \mathrm{~Hz}$ e utilizando-se o método de discretização do segurador de ordem zero, o modelo de Tustin na condição normal de operação (baixo ganho) é apresentado na equação 5.2 e o modelo discretizado com as mesmas configurações na condição de alto ganho (PIO) obtido é apresentado na equação 5.3.

$$
\begin{aligned}
& Y_{p}(z)=\frac{u(z)}{e(z)}=\frac{z^{-34}(1,989 z-1,979)}{z-1} \\
& Y_{p}(z)=\frac{u(z)}{e(z)}=\frac{z^{-25}(6,303 z-6,277)}{z-1}
\end{aligned}
$$

O segundo modelo analisado, o Modelo Crossover, é novamente apresentado na equação 5.4. Para a condição de baixo ganho foram admitidos os seguintes intervalos de variação das variáveis: $0,1 \leq K_{P} \leq+\infty$ e $5 \leq T_{I} \leq 10$. Já para a condição de alto ganho foram considerados os intervalos: $0,1 \leq K_{P} \leq+\infty$ e $0 \leq T_{I} \leq 0,3$.

$$
Y_{p}(s)=\frac{u(s)}{e(s)}=\frac{K_{p} e^{-\tau s}}{T_{I} s+1}
$$

Trabalhando-se novamente com uma taxa de amostragem de $40 \mathrm{~Hz}$ e utilizando-se o método de discretização do segurador de ordem zero, o modelo de Crossover na condição normal de operação (baixo ganho) pode ser obtido como o apresentado na equação 5.5. O modelo discretizado com as mesmas configurações na condição de alto ganho (PIO) obtido é apresentado na equação 5.6. 


$$
\begin{gathered}
Y_{p}(z)=\frac{u(z)}{e(z)}=\frac{z^{-34}(0,2928)}{z-0,8984} \\
Y_{p}(z)=\frac{u(z)}{e(z)}=\frac{z^{-25}(0,3348 z+0,6221)}{z-0,8521}
\end{gathered}
$$

O terceiro modelo analisado, o Modelo de Precisão, é novamente apresentado na equação 5.7. Para a condição de baixo ganho foram admitidos os seguintes intervalos de variação das variáveis: $0 \leq K_{P} \leq+\infty, 0,1 \leq T_{L} \leq 10,0,1 \leq T_{I} \leq 10,0,5 \leq \zeta_{n} \leq 0,8$ e $16,6667 \leq \boldsymbol{\omega}_{n} \leq 25$. Para a condição de alto ganho foram admitidos os seguintes intervalos de variação das variáveis: $0 \leq K_{P} \leq 10,0 \leq T_{L} \leq 2, \quad 0 \leq T_{I} \leq 1, \quad 0,5 \leq \zeta_{n} \leq 0,8$, $16,6667 \leq \omega_{n} \leq 25$.

$$
Y_{p}(s)=K_{p} e^{-\tau s} \frac{\left(T_{L} s+1\right)}{\left(T_{I} s+1\right)}\left(\frac{1}{\left(\frac{s^{2}}{\omega_{n}^{2}}+\frac{2 \zeta_{n}}{\omega_{n}} s+1\right)}\right)
$$

De modo análogo aos casos anteriores e utilizando-se as mesmas condições, o Modelo de Precisão foi discretizado, sendo a função obtida na condição normal de operação (baixo ganho) apresentada na equação 5.8 e a função discretizada na condição de alto ganho (PIO) obtida na equação 5.9 .

$$
\begin{gathered}
Y_{p}(z)=\frac{u(z)}{e(z)}=\frac{z^{-34}\left(0,2708 z^{2}-0,04705 z-0,2218\right)}{z^{3}-2,402 z^{2}+1,958 z-0,5555} \\
Y_{p}(z)=\frac{u(z)}{e(z)}=\frac{z^{-25}\left(0,1051 z^{3}+0,915 z^{2}-0,7586 z-0,2282\right)}{z^{3}-2,182 z^{2}+1,586 z-0,3986}
\end{gathered}
$$

\subsection{SIMULAÇÃO DE MODELOS EM ESPAÇO DE ESTADOS}

Nessa etapa os modelos de aeronave considerados foram simulados utilizando-se os modelos de piloto obtidos, programados com os valores dos parâmetros estimados dos ensaios. Os modelos são simulados considerando-se os modelos de piloto nas condições normais e de 
PIO, operando em malha fechada com o controlador LQR. Na Figura 16 é apresentada a resposta do modelo original (modelo A) nas condições de alto e baixo ganho para os três modelos de piloto considerados. No gráfico é apresentada a resposta do ângulo de arfagem do modelo, em conjunto com a referência e a saída do algoritmo ROVER indicando a existência do PIO. A saída desse algoritmo, a qual assume os valores 0 ou 1, foi multiplicada por um fator de 10 de forma a facilitar a visualização dos resultados. No gráfico ainda é apresentado o nível de PIO da saída do sistema calculado como a porcentagem do tempo total de simulação em que ele fica ativo. Nas Figuras 17 e 18 são apresentados os resultados das simulações nas mesmas condições dos modelos de baixa (modelo B) e alta (modelo C) propensão respectivamente.

Analisando os gráficos obtidos pode-se observar que os três modelos de piloto implementados puderam recriar corretamente as condições de operação normal (baixa ativação do algoritmo ROVER) e de PIO (alta ativação do algoritmo ROVER). Dessa forma, os parâmetros obtidos nos ensaios apresentam valores corretamente estimados para cada caso. É possível observar ainda dos gráficos da Figura 18, como almejado, que o modelo $\mathrm{C}$ da aeronave em espaço de estados implementado apresenta uma alta propensão ao fenômeno de PIO para os três modelos de piloto considerados, induzindo o sistema a oscilações de alta amplitude características do fenômeno. Esse fato é corroborado pelo maior nível de ativação do algoritmo ROVER para esse modelo, em comparação com os outros dois implementados. O modelo B, por outro lado, apresenta uma baixa propensão ao PIO, levando o ROVER a um nível de ativação nulo ou próximo do nulo. Pequenas oscilações podem ainda ser observadas nos gráficos da Figura 17 instantes após a mudança do ângulo de referência, sendo, no entanto, de baixa amplitude e de pequena duração. Essas oscilações não são, portanto, continuamente sustentadas, a qual seria uma condição necessária para ocorrência do PIO. O modelo A por fim apresenta uma propensão média a alta ao fenômeno, produzindo em sua resposta oscilações sustentadas como observado na Figura 16. 
Figura 16 - Resposta das simulações do modelo A da aeronave comandado pelos modelos de piloto
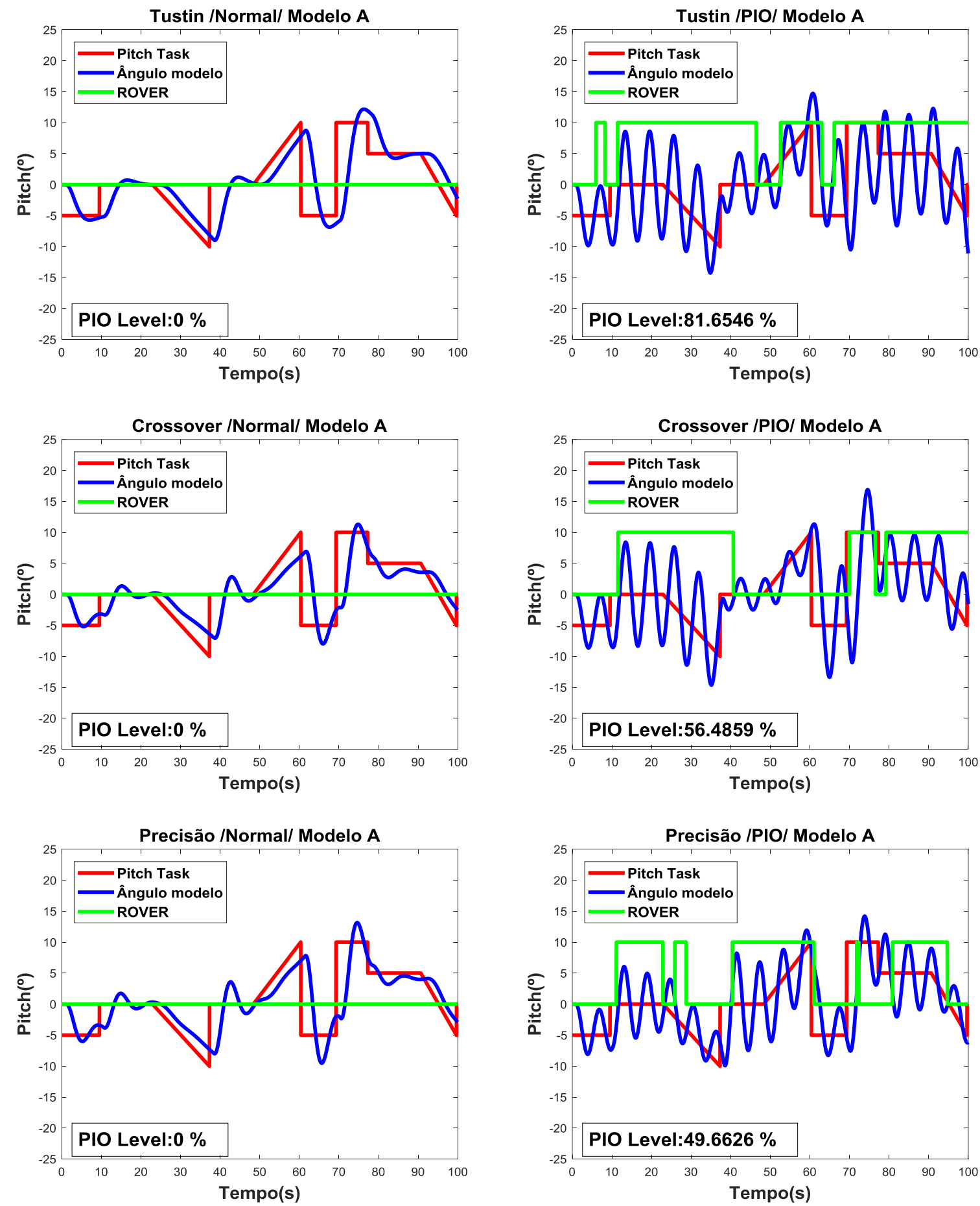
Figura 17 - Resposta das simulações do modelo B da aeronave comandado pelos modelos de piloto
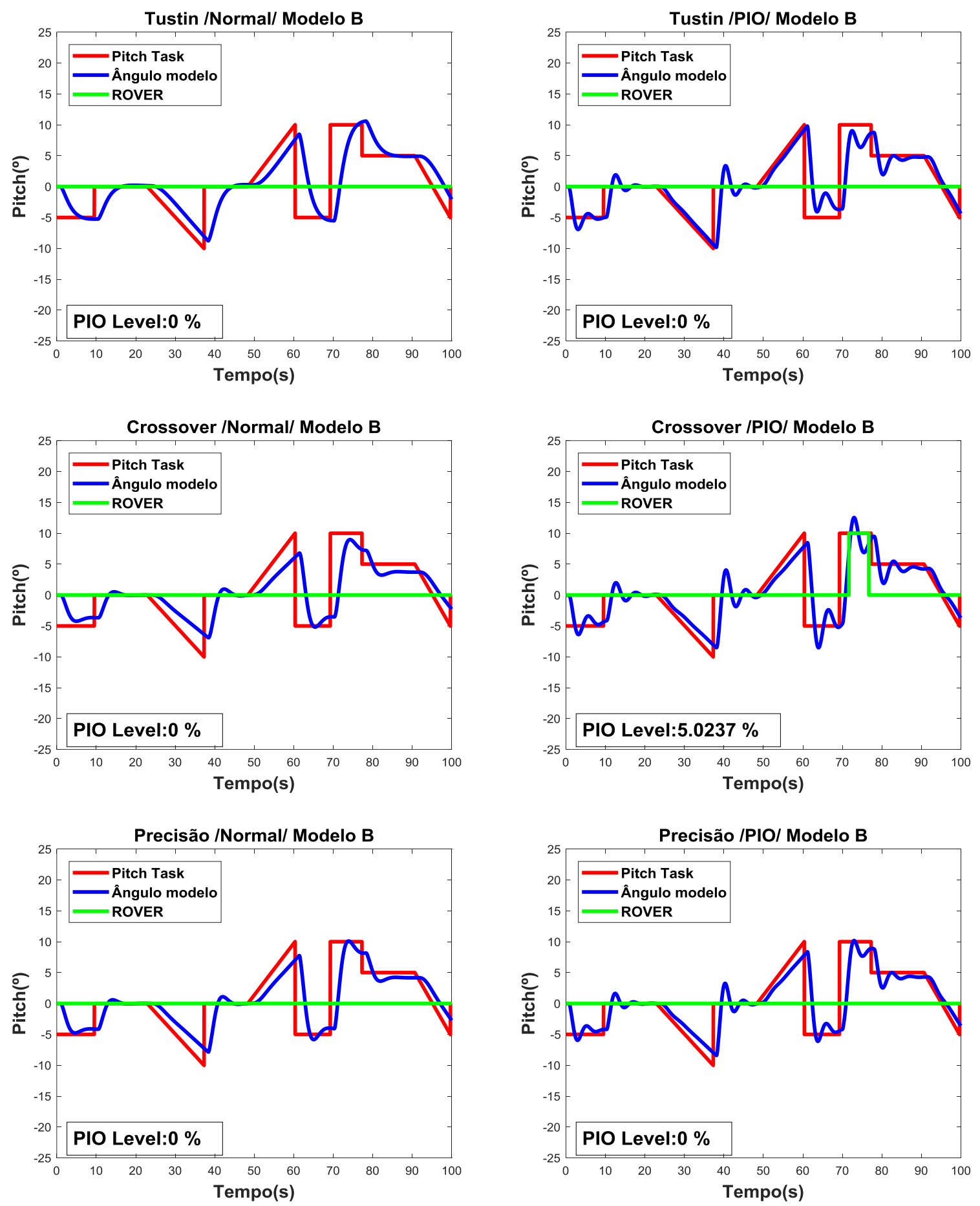
Figura 18 - Resposta das simulações do modelo $\mathrm{C}$ da aeronave comandado pelos modelos de piloto
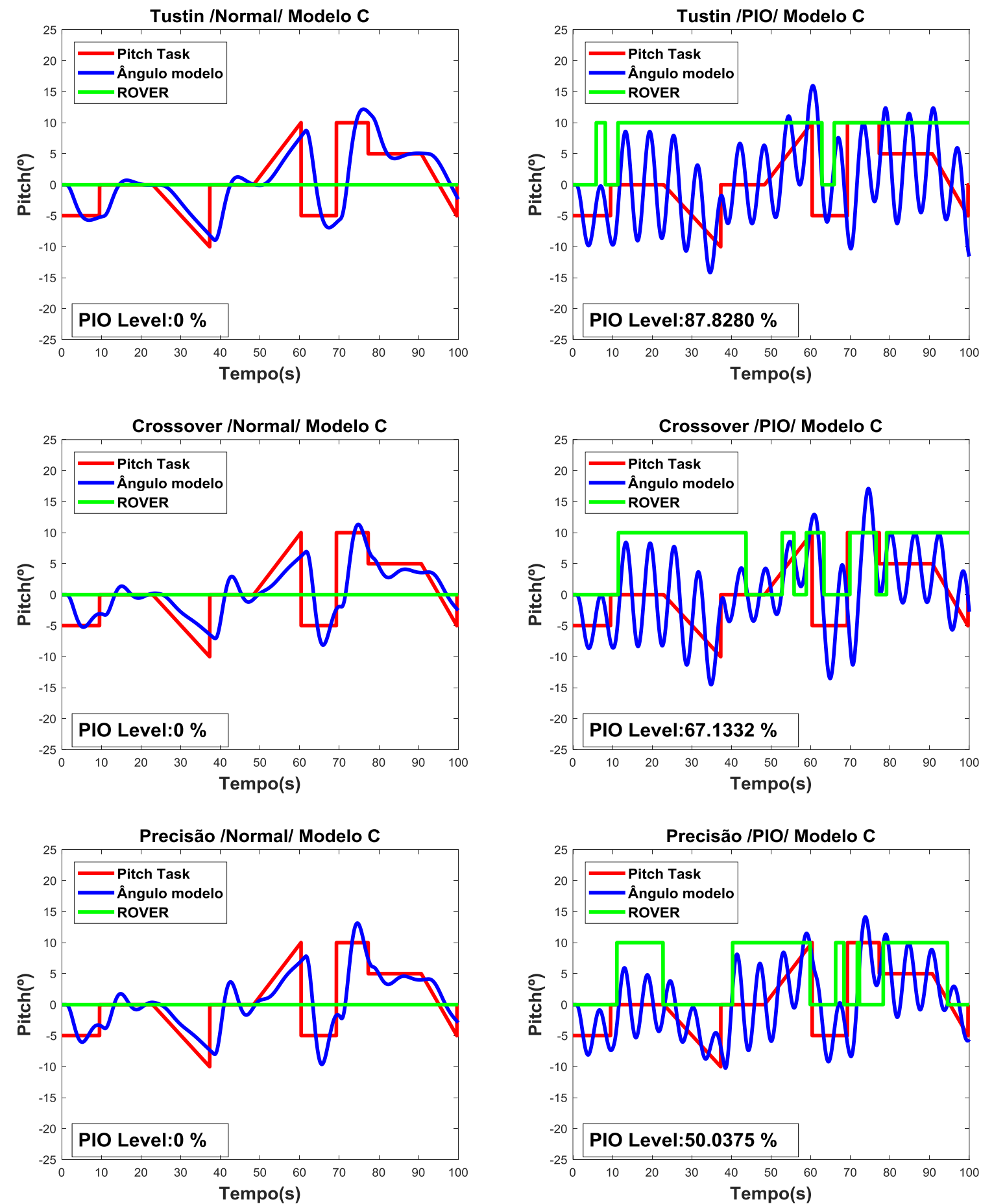


\subsection{SIMULAÇÃO DO SISTEMA M-MRAC: PLANTA EM ESPAÇO DE ESTADOS}

Nessa etapa o sistema M-MRAC implementado foi simulado considerando-se os modelos de piloto obtidos. Nesse estágio a planta controlada consiste no modelo A e o modelo de referência foi considerado como sendo os modelos B ou C, sendo os resultados obtidos apresentados nas Figuras 19 e 20 respectivamente. Esses gráficos apresentam a resposta da planta controlada bem como dos modelos de referência, e explicitam ainda a saída do algoritmo ROVER e o nível do PIO obtido, sendo o último calculado de forma análoga ao caso anterior.

Dos resultados obtidos da Figura 19, pode-se observar que o sistema M-MRAC implementado, de fato, conseguiu alterar a dinâmica da planta controlada, modelo A, induzindo a mesma a seguir a dinâmica do modelo de baixa propensão B. Como resultado, a tendência da planta controlada ao fenômeno de PIO foi reduzida, seguindo agora a tendência do modelo de referência. Dessa forma, pode-se notar apenas pequenas oscilações nos gráficos de respostas sendo, no entanto, não sustentadas, característica originalmente do modelo de referência. Essa característica do sistema assim implementado serviu como base para o desenvolvimento do algoritmo de supressão. Para as simulações com o modelo de referência C da Figura 20, é possível constatar que a tendência às oscilações do PIO do sistema controlado manteve-se alta. No entanto, a dinâmica de funcionamento do sistema M-MRAC interferiu na capacidade do sistema ROVER em detectar as oscilações, levando-o a um nível de ativação baixo se comparado com os resultados da seção anterior, com as plantas A e C controladas individualmente. Esse fato é oriundo ainda da tendência dos sistemas MRAC em produzir oscilações no sistema durante o rastreamento da dinâmica do modelo de referência. Esse comportamento pode ser aprimorado utilizando-se uma maior taxa de amostragem no sistema, o que possibilitaria a aplicação de um maior valor do parâmetro $\lambda$, reduzindo-se consequentemente essas oscilações. Por fim, pode-se verificar dos gráficos dessa seção que os modelos de piloto considerados puderam induzir o sistema controlado, bem como o modelo de referência ao PIO. Na condição normal de operação, por outro lado, não houveram oscilações características do fenômeno, como almejado, fato que ressalta novamente a eficácia da estimação dos parâmetros dos modelos de pilotos considerados. 
Figura 19 - Resposta das simulações em espaço de estados do sistema M-MRAC para o modelo de referência $B$
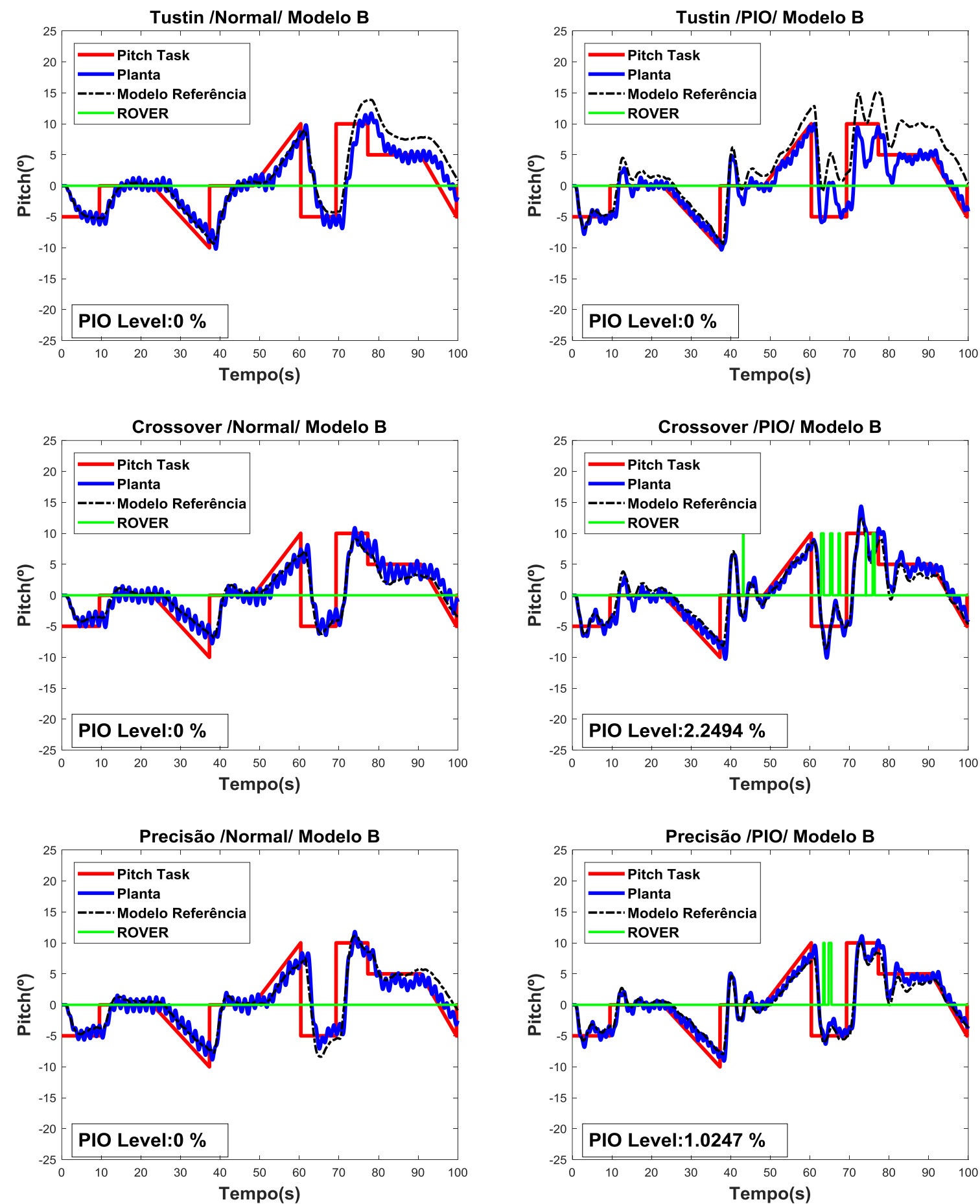
Figura 20 - Resposta das simulações em espaço de estados do sistema M-MRAC para o modelo de referência $\mathrm{C}$
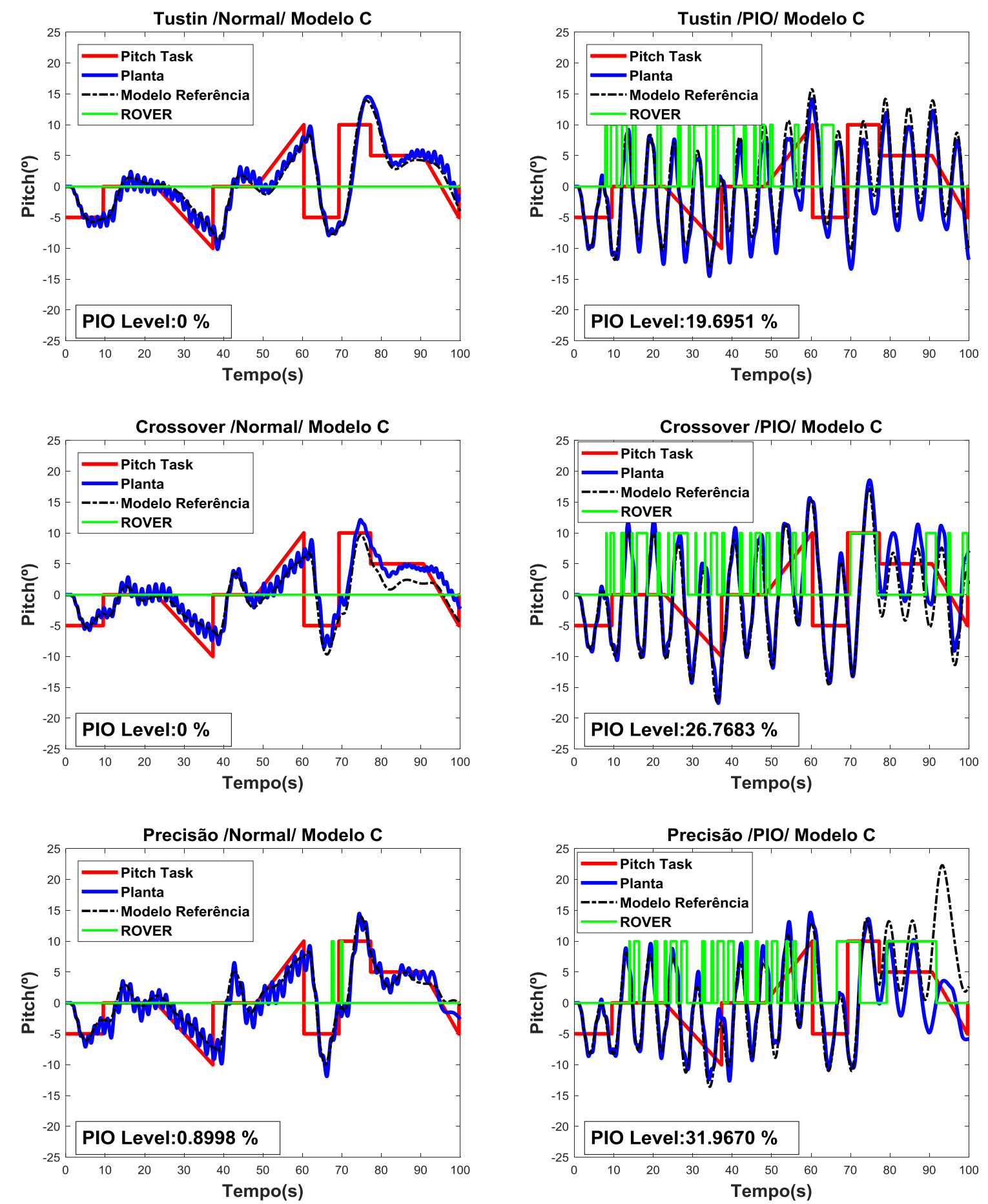


\subsection{SIMULAÇÃO DO SISTEMA DE SUPRESSÃO: PLANTA EM ESPAÇO DE ESTADOS}

Nessa etapa o sistema de supressão implementado foi simulado considerando-se os modelos de piloto obtidos na condição de alto ganho apenas, de forma a testar-se a eficácia do algoritmo. Nesse estágio a planta controlada consiste no modelo A e o modelo de referência foi considerado como sendo os modelos B ou C para as condições de PIO e normal de operação respectivamente. Os resultados obtidos são apresentados na Figura 21, onde são ilustradas a reposta da planta controlada bem como dos modelos de referência. A saída do algoritmo ROVER e o nível do PIO obtido são novamente apresentados, sendo o último calculado de forma análoga aos casos anteriores.

Como pode ser observado dos gráficos de resposta da Figura 21, o sistema de supressão implementado pode reduzir as oscilações do PIO, diminuindo consequentemente o nível de ativação do ROVER, em relação às oscilações notadas nos resultados da seção anterior com o sistema M-MRAC atuando isoladamente. Dessa forma o modelo de referência B de baixa propensão, ativado após a detecção do ROVER, possibilitou a modificação da dinâmica do sistema controlado diminuindo as oscilações. Pode-se notar ainda que quando o sistema encontra-se na condição normal de operação a planta controlada segue a dinâmica do modelo C de alta propensão.

Outro fator característico do sistema implementado, que pode ser observado nos gráficos dessa seção, concerne ao fato de que o piloto controla o modelo da aeronave indiretamente através do sinal de erro entre a referência e a resposta dessa planta controlada. Consequentemente, os modelos de referência não realizam um rastreamento direto do sinal Syntask, podendo inclusive ter uma tendência de afastamento do mesmo como pode ser observado. No entanto, essa dinâmica não interfere na capacidade da planta controlada realizar o rastreamento do sinal Syntask seguindo a dinâmica do modelo de referência ativado.

Outra característica desse sistema está presente no acoplamento resultante entre as dinâmicas dos modelos de referência, uma vez que o mesmo sinal de comando do piloto é repassado a ambos. Dessa forma, a dinâmica de um modelo de referência influencia no comportamento do piloto, alterando consequentemente a dinâmica do outro modelo de referência fazendo com que eles apresentem um formato de resposta semelhante, mas de amplitudes diferentes. 
Figura 21 - Resposta das simulações em espaço de estados do sistema de supressão
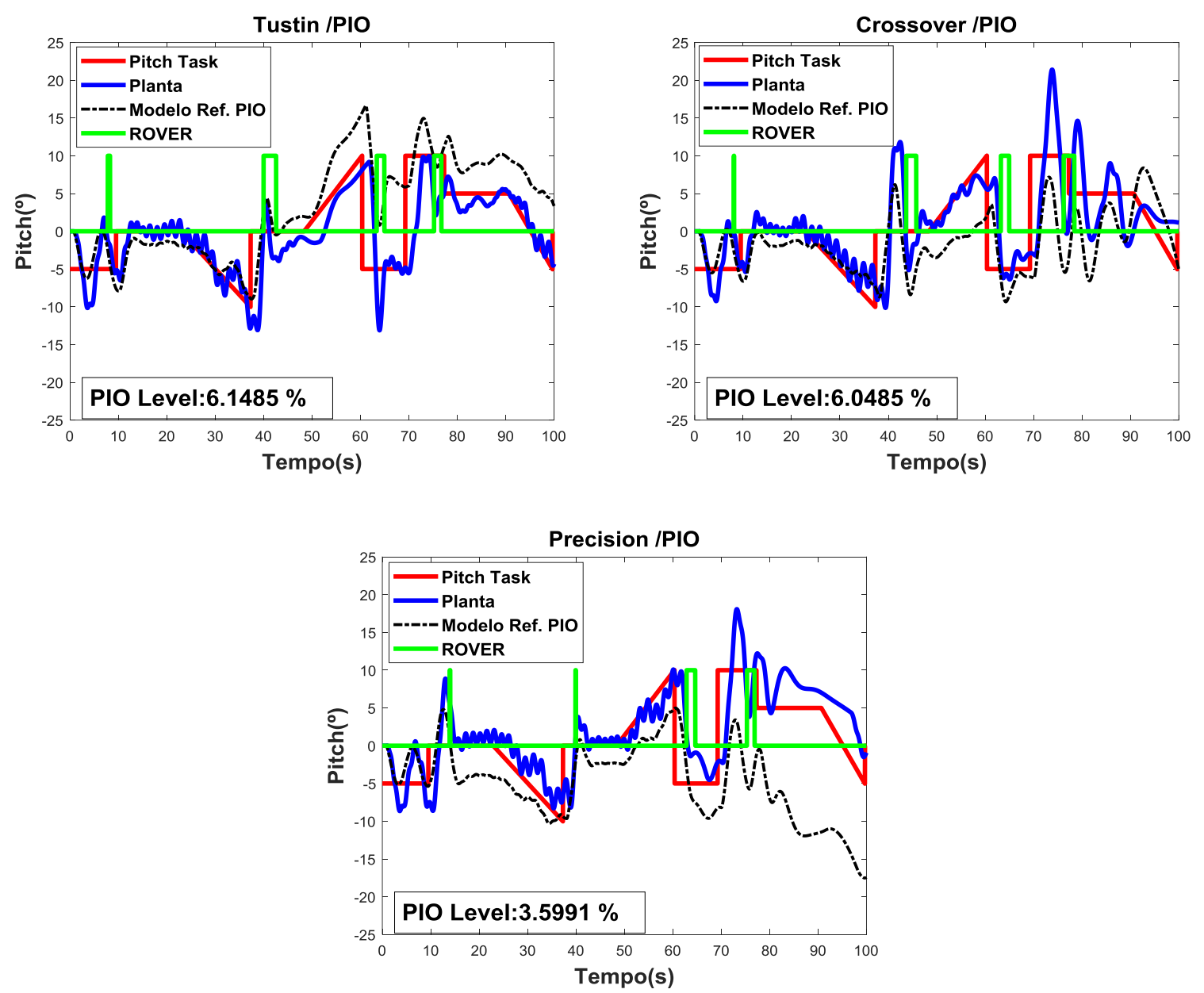

\subsection{SIMULAÇÃO DO SISTEMA M-MRAC: FLIGHTGEAR}

Nesse estágio o sistema M-MRAC implementado foi simulado considerando-se os modelos de piloto obtidos. Nessas simulações a planta controlada consiste no modelo de dinâmica de aeronave implementado no software FlightGear e o modelo de referência foi considerado como sendo os modelos A, B ou C, sendo os resultados obtidos apresentados nas Figuras 22, 23 e 24 respectivamente. Nos gráficos são apresentados ainda a saída do algoritmo ROVER e o nível do PIO obtido, sendo o último calculado de forma análoga aos casos anteriores.

Novamente o sistema M-MRAC desenvolvido possibilitou que a planta controlada seguisse a dinâmica dos modelos de referência considerados. O modelo A também mostrou-se nessas simulações como um modelo de média a alta propensão, possuindo inclusive um nível de PIO do algoritmo ROVER maior que o modelo C para o caso do Modelo de piloto Crossover. 
O modelo B, por outro lado, mostrou-se novamente como o modelo de mais baixa propensão ao fenômeno, com um nível de ativação praticamente nulo para os três modelos de piloto considerados. Por fim o modelo $\mathrm{C}$ apresentou-se novamente como o modelo de mais alta propensão, induzindo a dinâmica do modelo de aeronave implementado no software FlightGear a uma maior propensão às oscilações do PIO.

Figura 22 - Resposta das simulações do sistema M-MRAC integrado com o software FlightGear para o modelo de referência A
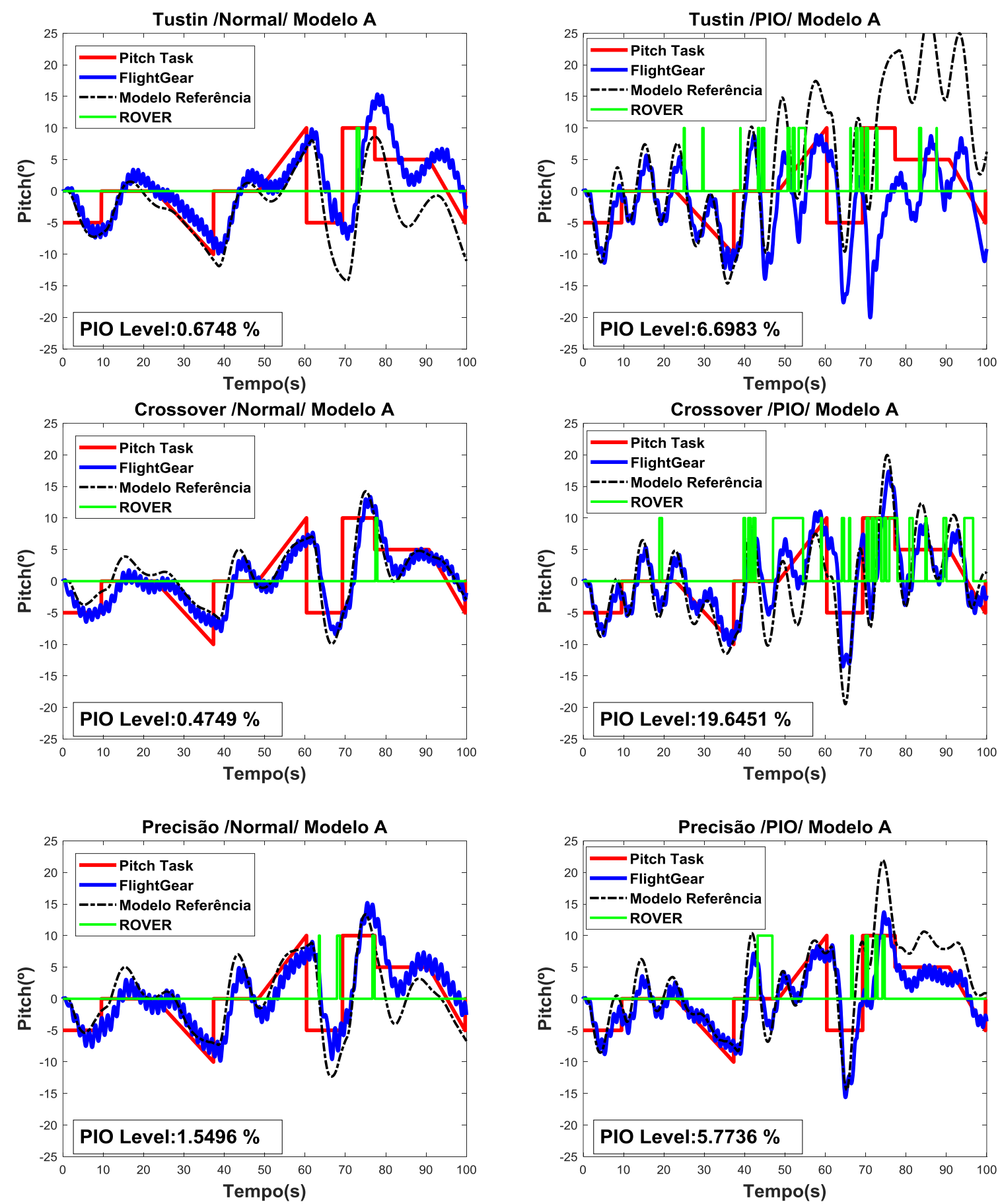
Figura 23 - Resposta das simulações do sistema M-MRAC integrado com o software FlightGear para o modelo de referência B
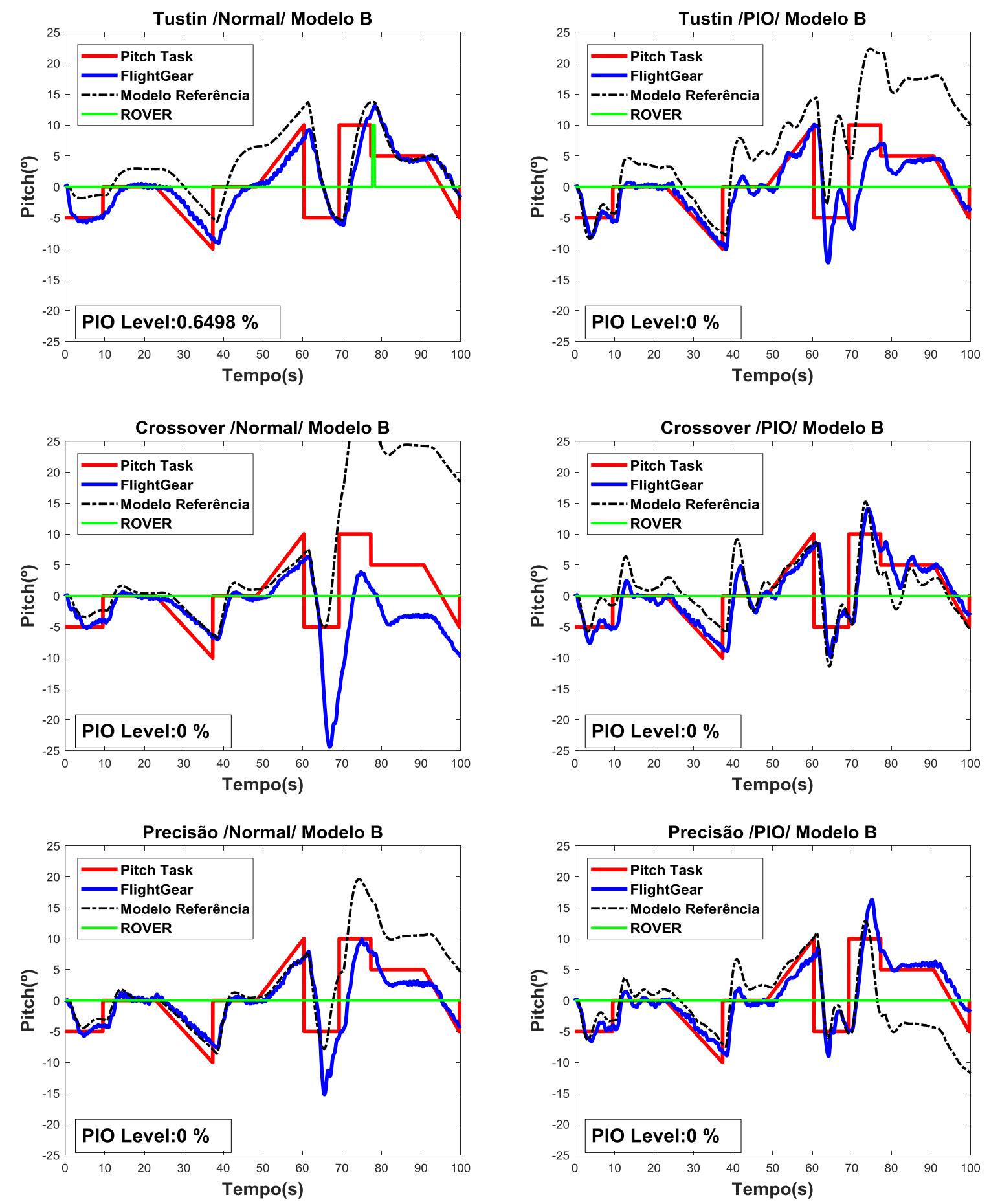
Figura 24 - Resposta das simulações do sistema M-MRAC integrado com o software FlightGear para o modelo de referência C
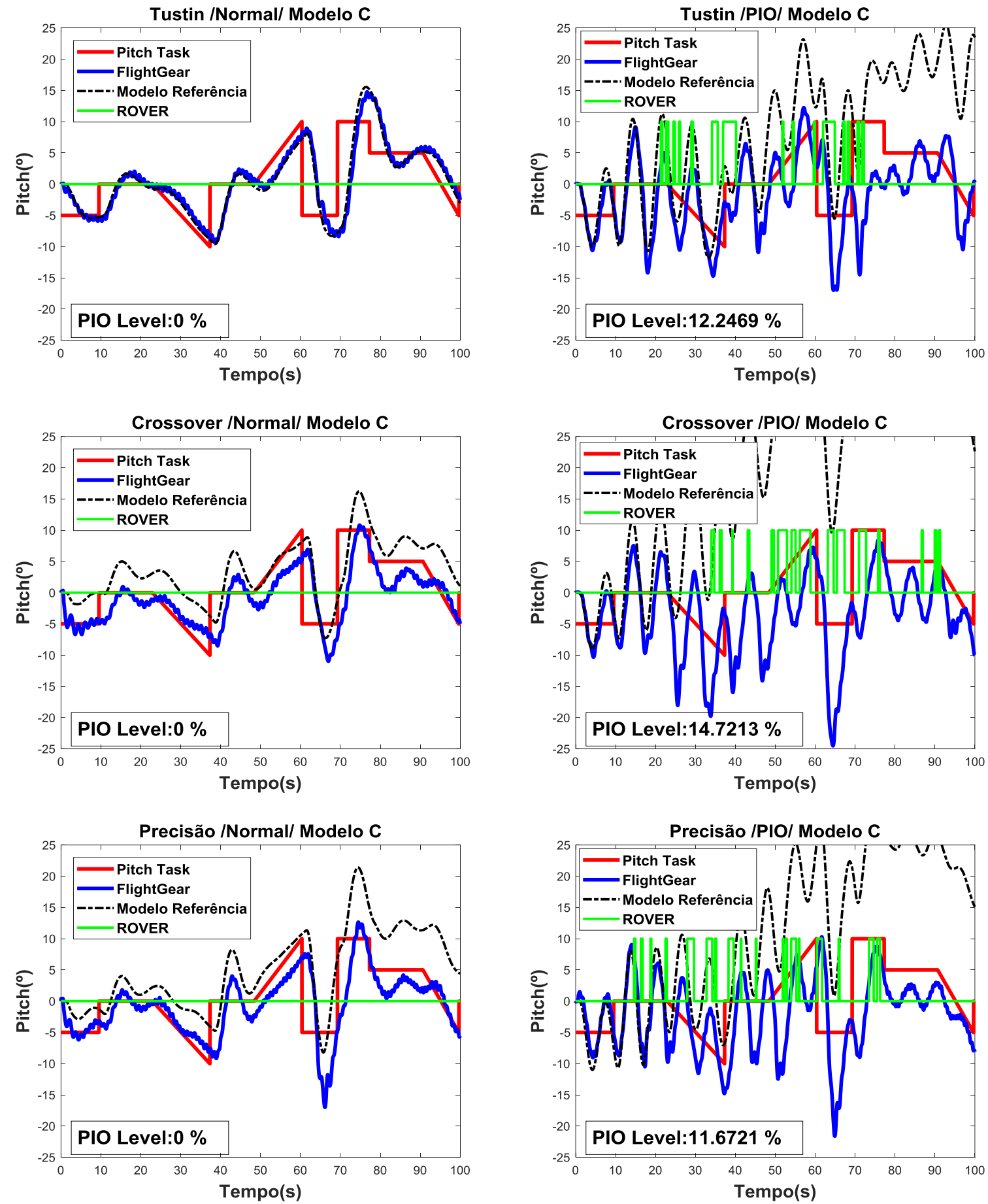


\subsection{SIMULAÇÃO DO SISTEMA DE SUPRESSÃO: FLIGHTGEAR}

Nessa etapa o sistema de supressão implementado foi simulado considerando-se os modelos de piloto obtidos. Nesse estágio a planta controlada consiste no modelo de dinâmica de aeronave implementado no software FlightGear e o modelo de referência foi considerado como sendo os modelos B, na condição de PIO, ou os modelos A e C para a condição normal de operação. Os resultados obtidos são apresentados nos gráficos da Figura 25.

Como esperado, o sistema de supressão implementado possibilitou a redução da amplitude e da duração das oscilações características do PIO, levando consequentemente a um decréscimo do nível de ativação do ROVER. Dessa forma, uma vez detectado o fenômeno, a atuação do modelo de baixa propensão possibilitou a redução da presença dessas oscilações. Em geral ainda, o modelo $\mathrm{C}$ quando considerado um modelo de referência, levou o sistema controlado a um maior nível de ativação do ROVER. As oscilações ainda presentes após a atuação do sistema de supressão poderiam ser ainda mais reduzidas se o nível de sensibilidade de ativação do algoritmo de detecção fosse diminuído. No entanto, para esse caso deve ser feita uma análise de trade-off entre a sensibilidade do algoritmo às oscilações e a qualidade de controle pelo piloto do sistema resultante, pois um chaveamento excessivo do sistema pode levar o mesmo à instabilidade. 
Figura 25 - Resposta das simulações do sistema de supressão integrado com o software

FlightGear
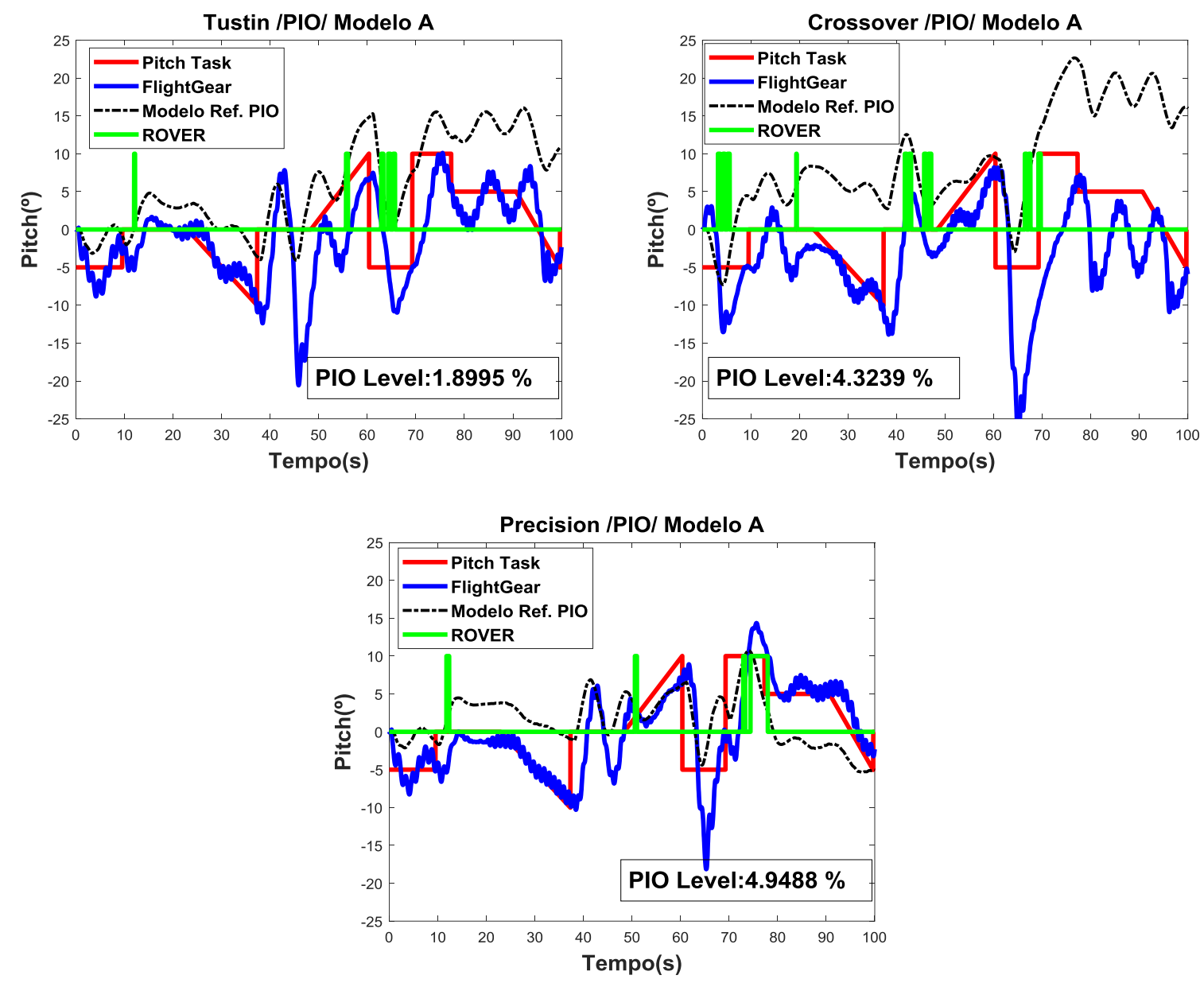

\subsection{ENSAIOS DOS MODELOS EM ESPAÇO DE ESTADOS}

Nesse estágio os modelos de aeronave considerados foram utilizados na realização de ensaios com um operador humano controlando o sistema com o auxílio de um joystick. Os modelos foram testados considerando-se o piloto operando nas condições normais e de PIO, estando o sistema completo em malha fechada com o controlador LQR. Na Figura 26 são apresentadas as respostas dos modelos A, B e C nas condições de alto e baixo ganho. De forma a evitar-se a antecipação da posição de referência pelo piloto na realização de ensaios seguidos, o sinal de Syntask sofreu um espelhamento e uma inversão para os ensaios com os modelos B e $\mathrm{C}$ respectivamente. 
Dos gráficos apresentados nessa figura pode-se notar que o piloto conseguiu induzir corretamente os sistemas controlados às condições de baixo ganho e de alto ganho (PIO). Como esperado ainda, o modelo $\mathrm{C}$ apresentou novamente uma maior susceptibilidade ao fenômeno de PIO se comparado aos modelos A e B , tanto para a condição normal de operação quanto para a condição de PIO. O modelo B, novamente, mostrou-se como o sistema de menor propensão às oscilações do fenômeno, sendo obtido inclusive, um nível de ativação nulo do algoritmo ROVER para ambas as condições de operação consideradas. De acordo com relatos do Piloto 1, notou-se nos ensaios dessa seção que essa menor propensão foi alcançada devido ao fato da dinâmica do modelo B responder de forma mais ágil aos comandos do piloto, apresentando dessa forma uma atenuação do efeito de limitação de posição e de velocidade do modelo de atuadores. Assim, como esperado, pode-se inferir de que de fato uma das causas do fenômeno de PIO resulta dos atrasos presentes no sistema controlado. Esses resultados validam ainda os modelos de piloto implementados, pois os modelos B e C foram montados variandose as derivadas de estabilidade originais do modelo A e avaliando-se o nível de ativação do ROVER para os modelos de piloto considerados. Dessa forma, considerando-se os resultados apresentados nessa seção, a susceptibilidade dos modelos implementados pode ser confirmada com a aplicação do sistema em ensaios com pilotos reais. Por fim, o modelo A mostrou-se como um modelo de média a alta propensão ao fenômeno, por apresentar um nível de ativação algoritmo ROVER na mesma ordem de grandeza do modelo $\mathrm{C}$ de alta propensão. 
Figura 26 - Resposta dos ensaios dos modelos de aeronave comandados pelo operador
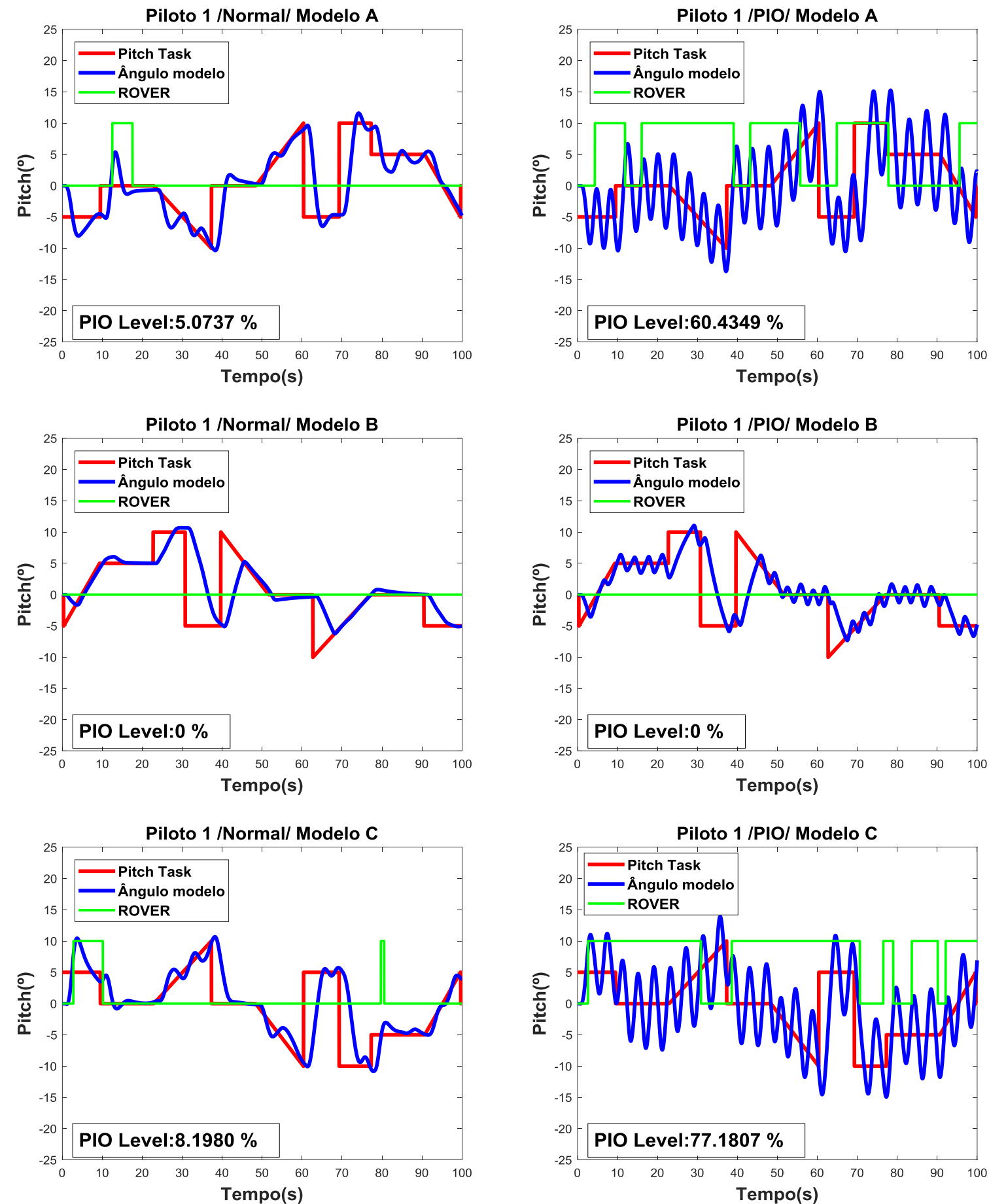


\subsection{ENSAIOS DO SISTEMA M-MRAC: PLANTA EM ESPAÇO DE ESTADOS}

Nessa etapa o sistema M-MRAC implementado foi utilizado na realização de ensaios controlados por um operador humano, atuando nas condições de baixo e alto ganho (PIO). Nesse estágio a planta controlada consiste no modelo A e o modelo de referência foi considerado como sendo os modelos B ou C, sendo os resultados obtidos apresentados na Figura 27.

Dos gráficos obtidos pode-se notar novamente que a atuação do sistema M-MRAC com o modelo de referência $B$ possibilitou a modificação da dinâmica original da planta $A$, reduzindo sua propensão ao fenômeno de PIO. O algoritmo ROVER apresentou para esse caso um nível de ativação nulo, tanto na condição normal de operação quanto na condição de PIO. O modelo C, por outro lado, quando empregado como modelo de referência levou o sistema A a uma alta propensão ao fenômeno. Novamente o nível de atuação do ROVER não foi maior para esse caso devido à influência do algoritmo M-MRAC no sistema de detecção como observado na seção 5.3. As oscilações residuais de baixa amplitude e alta frequências oriundas do sistema M-MRAC podem novamente ser reduzidas aumentando-se a taxa de amostragem do sistema, o que possibilitaria um aumento do parâmetro $\lambda$. 
Figura 27 - Resposta dos ensaios em espaço de estados do sistema M-MRAC com o operador humano
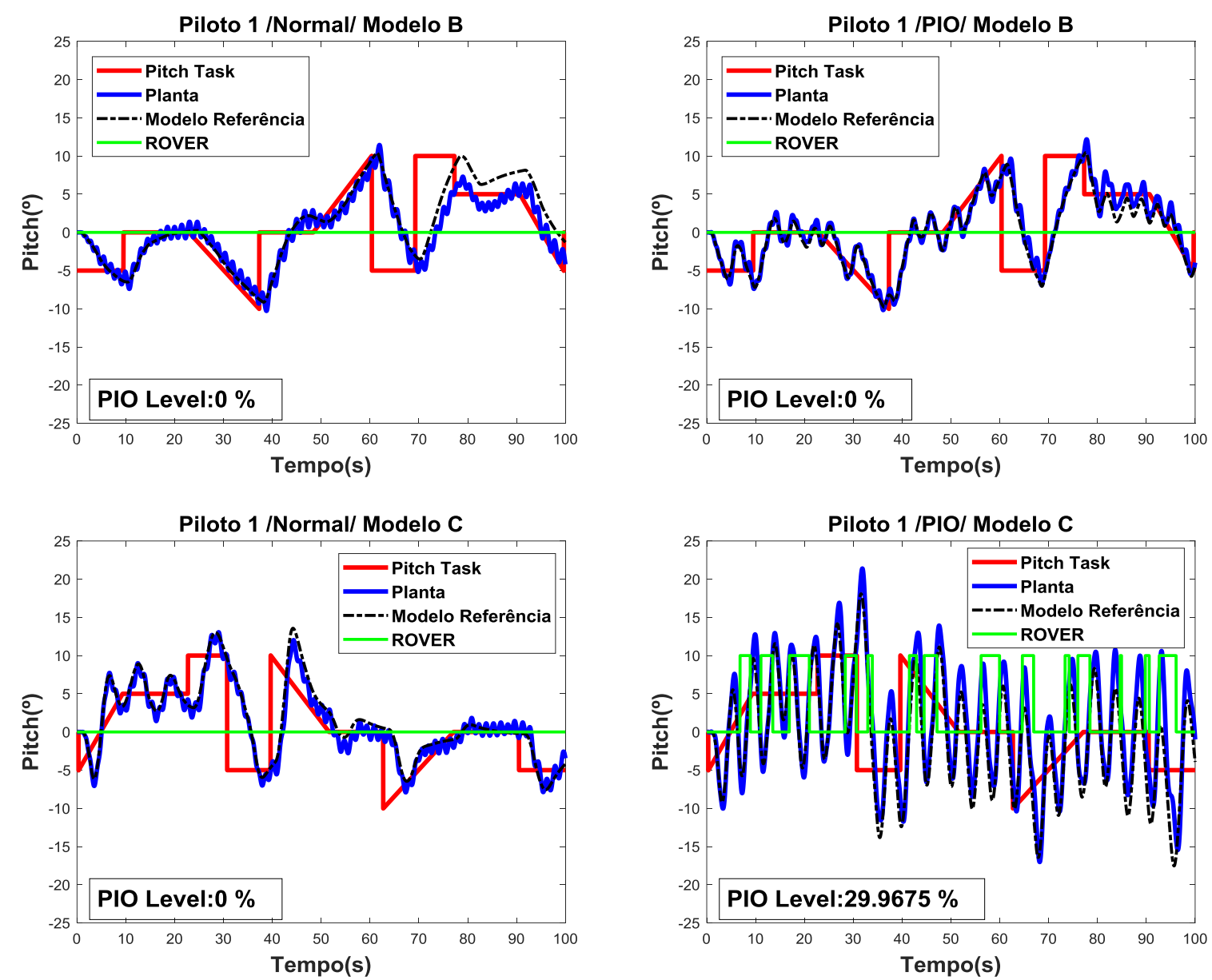

\subsection{ENSAIOS DO SISTEMA DE SUPRESSÃO: PLANTA EM ESPAÇO DE ESTADOS}

Nessa etapa o sistema de supressão implementado foi utilizado na realização de ensaios com um operador humano controlando o processo. Nesse estágio a planta controlada consiste no modelo A e o modelo de referência foi considerado como sendo os modelos B ou C para as condições de PIO e normal de operação respectivamente. Os resultados obtidos são apresentados na Figura 28.

Analisando de forma qualitativa esses gráficos podemos notar que o sistema de supressão conseguiu de fato diminuir a amplitude das oscilações do PIO instantes após sua detecção pelo algoritmo ROVER. No entanto, esse algoritmo ainda apresentou um nível alto de ativação da mesma ordem de grandeza do sistema M-MRAC atuando isoladamente, como o da 
seção 5.8. Como pode ser observado no gráfico, a ativação do ROVER ocorreu na maioria dos casos instantes após uma mudança do ângulo de referência da Syntask, quando ocorre um sobressinal no sistema. Esse comportamento do algoritmo ROVER pode ser minimizado reduzindo-se seu nível de sensibilidade à detecção da amplitude das oscilações, aumentando-se assim o nível da amplitude pico a pico da velocidade angular de arfagem a ser detectado. Novamente um trade-off deve ser realizado entre esse nível de detecção e a eficácia do sistema em suprimir as oscilações.

Figura 28 - Resposta do ensaio em espaço de estados do sistema de supressão

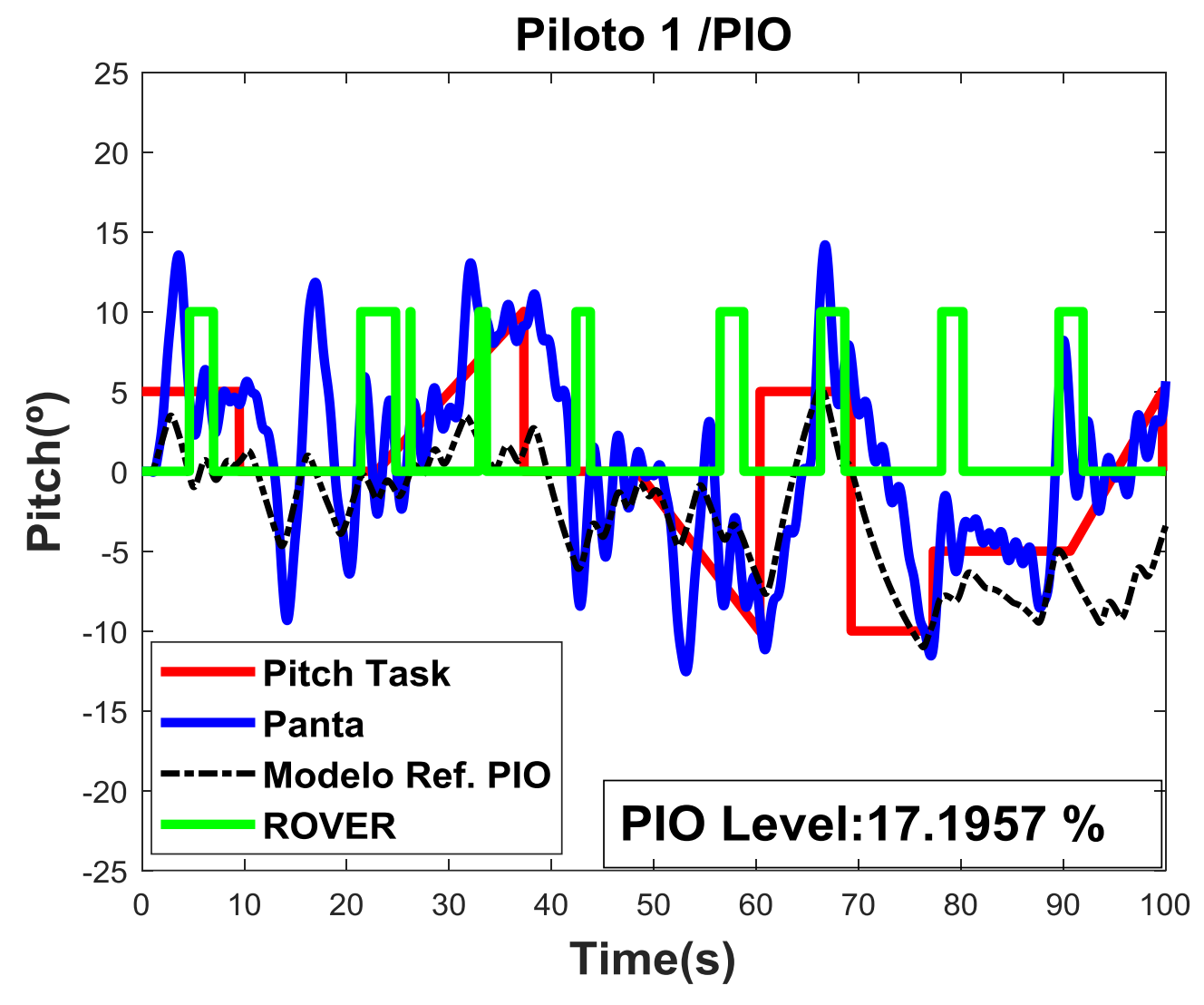




\subsection{ENSAIOS DO SISTEMA M-MRAC: FLIGHTGEAR}

Nesse estágio o sistema M-MRAC implementado foi utilizado na realização de ensaios controlados por um operador humano. Nesses ensaios a planta controlada consiste no modelo de dinâmica de aeronave implementado no software FlightGear e o modelo de referência foi considerado como sendo os modelos A, B ou C, sendo os resultados obtidos apresentados na Figura 29.

Como explicitado nos gráficos apresentados, o sistema M-MRAC implementado conseguiu de forma eficaz alterar a dinâmica do modelo de aeronave implementado no software simulador de voo. O piloto participante dos ensaios conseguiu também reproduzir as condições de baixo e alto ganho (PIO) no sistema controlado, sendo obtido um nível nulo de ativação do ROVER para a condição normal de operação (baixo ganho). De forma análoga aos casos anteriores, o modelo $\mathrm{C}$ apresentou para esses ensaios uma maior susceptibilidade às oscilações do PIO com um nível de ativação do algoritmo ROVER da ordem de $21 \%$. O modelo B por outro lado, como almejado, apresentou também uma baixa propensão ao fenômeno, sendo obtido um nível ativação nulo do ROVER para as condições de operação normal e PIO. O modelo original A mostrou-se novamente como um sistema de média a alta propensão às oscilações do PIO, com um nível de ativação do ROVER de cerca de $17 \%$, sendo portanto da mesma ordem de grandeza do sistema C. Um maior nível de ativação do algoritmo de detecção pode ser obtido aumentando-se sua sensibilidade à detecção da amplitude das oscilações. No entanto, essa sensibilidade deve ser ajustada com cautela de forma a não comprometer o sistema de supressão de oscilações, o qual utiliza a mesma estrutura do sistema apresentado nessa seção. 
Figura 29 - Resposta dos ensaios do sistema M-MRAC integrado com o software FlightGear
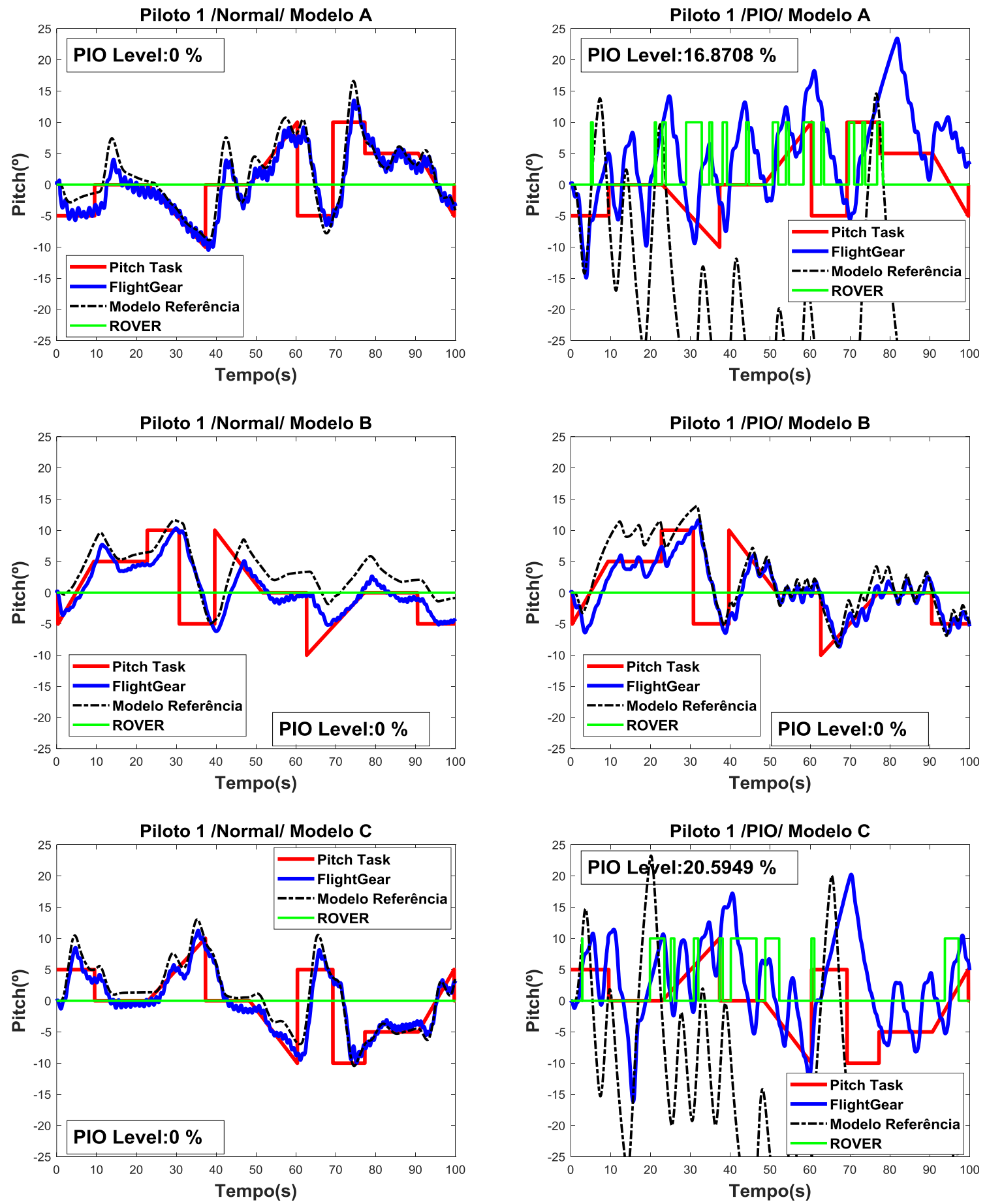


\subsection{ENSAIOS DO SISTEMA DE SUPRESSÃO: FLIGHTGEAR}

Nessa etapa final o sistema de supressão implementado foi utilizado na realização de ensaios com um operador humano, operando apenas na condição de PIO (alto ganho) de forma a testar-se a eficácia do sistema em suprimir (ou mitigar as oscilações). A planta controlada consiste no modelo de dinâmica de aeronave implementado no software FlightGear e o modelo de referência foi considerado como sendo os modelos B, na condição de PIO, ou os modelos A e C para a condição normal de operação. Os resultados obtidos são apresentados na Figura 30.

Dos gráficos apresentados pode-se inferir de forma qualitativa que o sistema de supressão conseguiu de forma eficaz mitigar as oscilações do PIO, reduzindo sua amplitude instantes após sua detecção pelo algoritmo ROVER. Uma análise quantitativa pode ser realizada a partir do nível de detecção das oscilações pelo algoritmo de detecção. Dessa análise pode-se concluir que algoritmo de supressão de fato foi eficaz em sua atuação, reduzindo o nível do ROVER de cerca de 17\%, para o sistema M-MRAC atuando isoladamente, para 7\% para o modelo A, e de cerca de $21 \%$ para $6 \%$ para o modelo B. O modelo A apresentou ainda um maior nível de oscilação pelo ROVER, fato que ressalva novamente o fato de que esse modelo enquadra-se na classificação de um sistema de alta propensão, semelhantemente ao modelo C.

Figura 30 - Resposta dos ensaios do sistema de supressão integrado com o software FlightGear
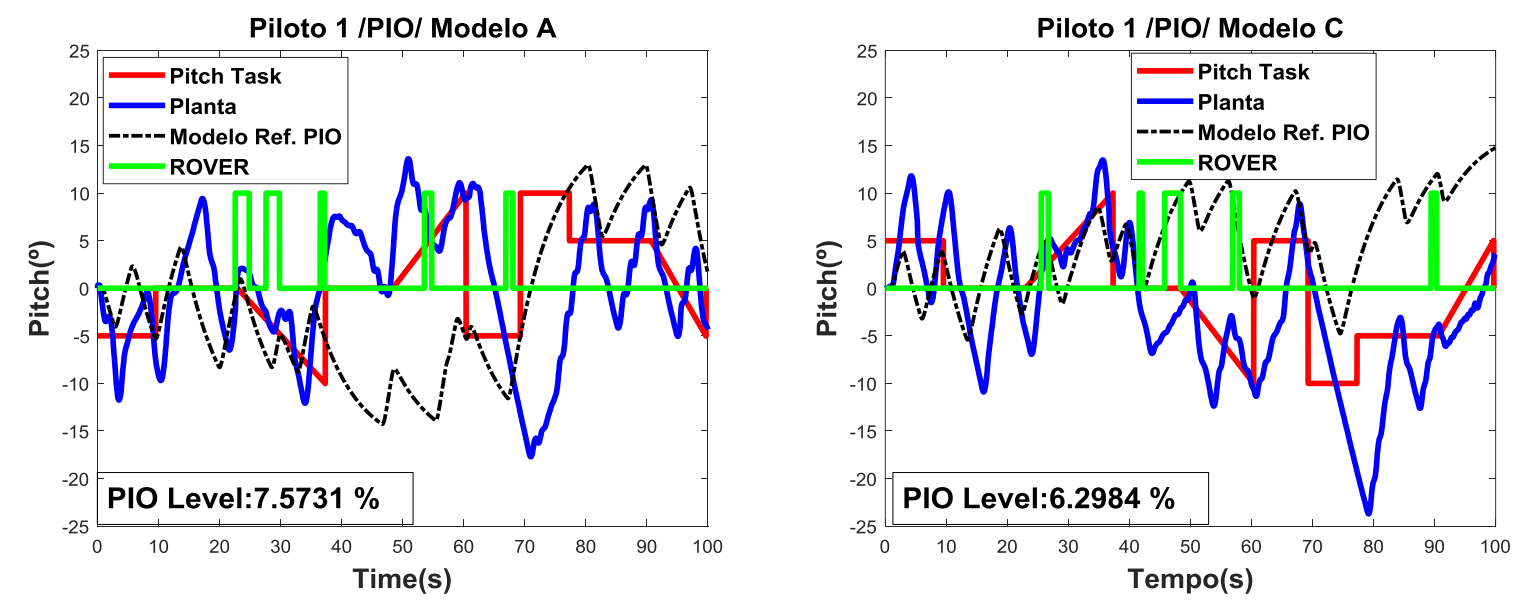


\section{CAPítulo 6}

\section{CONCLUSÕES}

Dos resultados obtidos, tanto das simulações quanto dos ensaios, foi possível atestar-se a susceptibilidade dos modelos A, B e C ao fenômeno de PIO. Os modelos B e C mostraramse de fato como modelos de baixa e alta propensão ao fenômeno respectivamente. O modelo A, por sua vez, mostrou-se como um modelo de alta propensão ao fenômeno também, ao produzir oscilações da mesma ordem de grandeza que o modelo C. Com base nessas respostas, a eficácia do algoritmo M-MRAC em alterar a dinâmica do modelo de aeronave controlado, de forma a induzi-lo a seguir um modelo de referência, pode ser verificada. Dessa forma, foi possível aumentar sua susceptibilidade ao fenômeno adotando-se o modelo $\mathrm{C}$ ou diminuí-la adotandose o modelo B.

Partindo-se desses resultados então, o sistema de supressão foi validado, sendo possível verificar sua atuação ao reduzir o nível das oscilações características do PIO tanto nas simulações quanto nos ensaios. Como resultados secundários obtidos, os modelos de piloto levantados mostraram-se eficazes em controlar o sistema completo e induzir a planta controlada, representando a aeronave, às condições de operação normal e de PIO. Foi notado ainda, com exceção do sistema LQR básico da seção 5.2, que o modelo de piloto Crossover se mostrou, em geral, mais propenso a induzir o sistema simulado às oscilações características do PIO. Esse comportamento foi notado inclusive nas simulações do modelo de aeronave B de baixa propensão quando este foi simulado separadamente, com o algoritmo LQR apenas, ou quando atuava como modelo de referência para o algoritmo M-MRAC.

O algoritmo ROVER implementado também mostrou-se eficaz em detectar em tempo real as oscilações do PIO, contribuindo para o funcionamento do algoritmo completo. No entanto, dos resultados obtidos foi verificado que o sistema M-MRAC interferiu no funcionamento do algoritmo ROVER, devido ao seu comportamento transitório oscilatório. Esse comportamento, porém, pode ser minimizado adotando-se uma maior taxa de amostragem no sistema e possivelmente um maior valor do parâmetro $\lambda$, o que possibilitaria uma maior redução dessas oscilações sem comprometer a estabilidade e o funcionamento do sistema. 
Por fim, o arranjo experimental proposto para a realização dos ensaios possibilitou que o piloto voluntário participante dos ensaios conseguisse controlar a aeronave e efetuar o rastreamento da referência apresentada pelo horizonte artificial em todos os tipos de sistemas implementados. Além do mais, foram obtidos nos ensaios resultados semelhantes aos obtidos nas simulações com respeito à propensão dos modelos e à eficácia do algoritmo de supressão, fato o qual possibilitou a validação dos resultados antes obtidos nas simulações. Dos relatos do piloto, foi observado ainda que a maior ou menor propensão do modelo de aeronave controlado ao PIO correlacionou-se com a velocidade de resposta desse frente aos comandos do piloto repassados. Esse fato está em consonância com o relatado nas referências bibliográficas utilizadas, o que ressalta novamente a validade do estudo e dos experimentos realizados.

Considerando-se os resultados obtidos, os trabalhos futuros possíveis incluem aqueles nos quais o sistema completo seja implementado em uma linguagem de programação mais rápida como a Linguagem $\mathrm{C}$, ou se possível, em um hardware dedicado. Essa implementação possibilitaria a adoção de taxas de amostragem mais altas, o que aprimoraria o sistema como um todo. Em possíveis trabalhos ainda, poderiam ser realizados mais ensaios com pilotos humanos, de forma a avaliar-se a qualidade de voo tanto dos modelos de referência atuando isoladamente quanto do sistema completo com a supressão. Esses ensaios podem inclusive ser realizados em uma plataforma móvel de simulação de voo como a presente no laboratório, de forma a reproduzir com maior fidelidade o ambiente de voo de uma aeronave real. 


\section{REFERÊNCIAS}

ASHKENAS, I. L. et al. Pilot-Induced Oscillations: their cause and analysis (S. T. I. N. C. I. CA, Ed.)NATIONAL TECHNICAL INFORMATION SERVICE, 1964.

ÅSTRÖM, K. J.; MURRAY, R. M. Feedback systems : an introduction for scientists and engineers. Princeton university press, p. 190-200, 2008.

ASTROM, K. J.; WITTENMARK, B. Adaptive Control. Reading, Mass: Reading, Mass. Addison-Wesley, 2. ed., p.185-260,1934.

BAILEY, R. E.; SMITH, R. E.; SHAFER, M. F. In-flight investigation of pilot-induced oscillation suppression filters during the fighter approach and landing task. Proceedings, Annual Symposium - Society of Flight Test Engineers, 1982.

BORIL, J. ; JALOVECKY, R. Experimental identification of pilot response using measured data from a flight simulator. In: IFIP International Conference on Artificial Intelligence Applications and Innovations. Springer, Berlin, Heidelberg, p. 126-135, 2012.

CELERE, A. L. Método para a avaliação do ganho empregado pelo piloto em ensaios de pio. Tese (Doutorado) - Universidade de São Paulo, Escola de Engenharia de São Carlos, 2008.

ETKIN, B.; REID, L. D. Dynamics of flight stability and control. New York: New York Wiley, 3. ed., 1996.

H.C. MOURA, G.S.P. ALEGRE, J.H. BIDINOTTO, E. M. B. Pio susceptibility in fly-by-wire systems. 31st Congress of the International Council of the Aeronautical Sciences. Belo Horizonte, Brasil: 2018

HESS, R. A. Dual-loop model of the human controller. Journal of Guidance and Control, v. 1, n. 4, p. 7, 1978.

HESS, R. A. Structural model of the adaptive human pilot. Journal of Guidance and Control, v. 3, n. 5, p. 416-423, 1980.

HESS, R. A. Unified Theory for Aircraft Handling Qualities and Adverse Aircraft-Pilot Coupling - NASA/CR-1997-207115, Journal of Guidance, Control and Dynamics, 1997.

HOSMAN, R.; STASSEN, H. Pilot's perception in the control of aircraft motions. Control Engineering Practice, v. 7, n. 11, p. 1421-1428, 1998.

JIRGL, M. ; HAVLIKOVA, M.; BRADAC, Z. The dynamic pilot behavioral models. Procedia engineering, v. 100, p. 1192-1197, 2015. 
JOHNSON, D. A. Suppression of Pilot-Induced Oscillation (PIO). [s.1.] AIR FORCE INST OF TECH WRIGHT-PATTERSON AFB OH, 2002.

KHARISOV, E.; HOVAKIMYAN, N.; ASTROM, K. J. Comparison of several adaptive controllers according to their robustness metrics. AIAA Paper No. AIAA-2010-8047, 2010.

LIU, Q. Pilot-induced oscillation detection and mitigation. Dissertação (mestrado) Cranfield University, 2012.

LONE, M. M.; COOKE, A. K. Review of pilot modelling techniques. 48th AIAA Aerospace Sciences Meeting Including the New Horizons Forum and Aerospace Exposition, 2010

MCRUER, D. T. Pilot-Induced Oscillations and Human Dynamic Behavior - NASA-CR4683, 1995.

MCRUER, D. T.; KRENDEL, E. S. Mathematical models of human pilot behavior. ADVISORY GROUP FOR AEROSPACE RESEARCH AND DEVELOPMENT NEUILLYSUR-SEINE (FRANCE), 1974.

MITCHELL, D. G.; ARENCIBIA, A. J.; MUNOZ, S. Real-time detection of pilot-induced oscillations. AIAA Atmospheric Flight Mechanics Conference and Exhibit, 2004

MITCHELL, D. G.; KISH, B. A.; SEO, J. S. A flight investigation of pilot-induced oscillation due to rate limiting. Aerospace Conference, IEEE, 1998

RADEMAKERS, N. G. M. Control of a tailless fighter using gain-scheduling. Traineeship report, Eindhoven University of Technology, Netherlands, 2004.

SAFETY, N. R. C. (U. S. ). C. ON THE E. OF A.-P. C. ON F. Aviation Safety and Pilot Control: Understanding and Preventing Unfavorable Pilot-Vehicle Interactions. [s.l.] National Academies Press, 1997.

SCHMIDT, D. Modern flight dynamics. McGraw-Hill Higher Education, 1. ed., p. 789 - 808, 2012.

SHAFER, M. F. et al. Flight test experience with pilot-induced-oscillation suppression filters - NASA-TM-86028 AIAA Atmospheric Flight Mech. Conf., Sponsoring Organization: NASA Hugh L. Dryden Flight Research Center|NASA Ames Research Center, 1984.

SMITH, J. W.; BERRY, D. T. Analysis of longitudinal pilot-induced oscillation tendencies of YF-12 aircraft - NASA-TN-D-7900, Sponsoring Organization: NASA Flight Research Center, 1975.

SMITH, J. W.; EDWARDS, J. W. Design of a nonlinear adaptive filter for suppression of shuttle pilot-induced oscillation tendencies - NASA-TM-81349, Sponsoring Organization: NASA Dryden Flight Research Center, 1980. 
STANDARD, M. Flying qualities of piloted airplanes. Mil-STD-1797A (USAF). Department of Defense, USA, 1987.

STEIN, G.; HARTMANN, G. Adaptive control laws for F-8 flight test. Automatic Control, IEEE Transactions on, v. 22, n. 5, p. 758-767, 1977.

STEPANYAN, V.; KRISHNAKUMAR, K. MRAC Revisited: Guaranteed Performance with Reference Model Modification. American Control Conference, 2010

STEPANYAN, V.; KRISHNAKUMAR, K. On the robustness properties of M-MRAC. AIAA Infotech at Aerospace Conference and Exhibit 2012. Anais...Mission Critical Technologies Inc, NASA Ames Research Center, Moffett Field, CA 94035, United States: 2012. Disponível em: <https://www.scopus.com/inward/record.uri?eid=2-s2.084880832114\&partnerID=40\&md5=613660c4913e86aa57a9f5b314a66307>

TUSTIN, A. The nature of the operator's response in manual control, and its implications for controller design. Journal of the Institution of Electrical Engineers-Part IIA: Automatic Regulators and Servo Mechanisms, v. 94, n. 2, p. 190-206, 1947.

WANG, C.; SANTONE, M.; CAO, C. Pilot-induced oscillation suppression by using L1 adaptive control. Journal of Control Science and Engineering, v. 2012, 2012. 


\section{APÊNDICE A}

\section{A DADOS DOS ENSAIOS DE ESTIMAÇÃO}

Nessa seção são apresentados os dados obtidos, em forma de tabela, dos ensaios com pilotos de forma a obter os valores dos parâmetros dos modelos considerados. Os dados são organizados por piloto (identificados por 1,2 ou 3), por modo de operação (normal ou PIO) e por sentido da referência (positivo ou negativo). Para cada uma das condições são apresentados ainda os valores obtidos do cálculo da média aritmética dos mesmos.

Tabela 11 - Parâmetros estimados do Modelo de Tustin obtidos dos ensaios com pilotos

\begin{tabular}{|c|c|c|c|c|}
\hline \multirow[t]{2}{*}{ Piloto } & \multicolumn{4}{|c|}{ Parâmetros Modelo piloto de Tustin } \\
\hline & $\overline{K_{\mathbf{P}}}$ & $\mathbf{T}_{\mathbf{L}}$ & $\mathbf{T}_{\mathbf{I}}$ & $\tau(\mathbf{s})$ \\
\hline 1- Normal Positivo & 0,47243 & 3,9678 & 1e-06 & 0,475 \\
\hline 2- Normal Positivo & 0,43026 & 6,1 & 1e-06 & 0,875 \\
\hline 3- Normal Positivo & $\mathbf{0 , 3 1 3 5 3}$ & 6,1 & 1e-06 & 1,05 \\
\hline Normal Positivo Média & $\mathbf{0 , 4 0 5 4}$ & 5,3893 & 1e-06 & $\mathbf{0 , 8 0 0 0}$ \\
\hline 1- Normal Negativo & 0,4193 & 3,7485 & 1e-06 & 0,75 \\
\hline 2- Normal Negativo & 0,34667 & 6,1 & 1e-06 & 0,875 \\
\hline 3- Normal Negativo & 0,24694 & 6,1 & 1e-06 & 1,075 \\
\hline Normal Negativo Média & $\mathbf{0 , 3 3 7 6}$ & 5,3162 & 1e-06 & 0,9000 \\
\hline Normal Média Final & $\mathbf{0 , 3 7 1 5}$ & 5,3528 & 1e-06 & $\mathbf{0 , 8 5 0 0}$ \\
\hline 1- PIO Positivo & 1,2187 & 6,1 & 1e-06 & 0,5 \\
\hline 2- PIO Positivo & 0,91669 & 6,1 & 1e-06 & $\mathbf{0 , 7 5}$ \\
\hline 3- PIO Positivo & 0,92084 & 6,1 & 1e-06 & $\mathbf{0 , 8 2 5}$ \\
\hline PIO Positivo Média & 1,0187 & 6,1 & 1e-06 & 0,6917 \\
\hline 1- PIO Negativo & 1,2576 & 6,1 & 1e-06 & 0,425 \\
\hline 2- PIO Negativo & 0,96393 & 6,0341 & 1e-06 & 0,6 \\
\hline 3- PIO Negativo & 0,97625 & 5,8 & 1e-06 & 0,6 \\
\hline PIO Negativo Média & 1,0659 & 5,9780 & 1e-06 & 0,5417 \\
\hline PIO Média & 1,0423 & 6,0390 & 1e-06 & 0,6167 \\
\hline
\end{tabular}


Tabela 12 - Parâmetros estimados do Modelo Crossover obtidos dos ensaios com piloto

\begin{tabular}{|c|c|c|c|}
\hline \multirow{2}{*}{ Piloto } & \multicolumn{3}{|c|}{ Parâmetros Modelo piloto Crossover } \\
\cline { 2 - 4 } & KP $_{\mathbf{P}}$ & $\mathbf{T}_{\mathbf{I}}$ & $\tau$ (s) \\
\hline 1- Normal Positivo & $\mathbf{2 , 8 4 7 8}$ & $\mathbf{0 , 3}$ & $\mathbf{0 , 4 7 5}$ \\
\hline 2- Normal Positivo & $\mathbf{3 , 6 2 4 8}$ & $\mathbf{0 , 1}$ & $\mathbf{0 , 8 7 5}$ \\
\hline 3- Normal Positivo & $\mathbf{2 , 8 1 2 7}$ & $\mathbf{0 , 1}$ & $\mathbf{1 , 0 5}$ \\
\hline Normal Positivo Média & $\mathbf{3 , 0 9 5 1}$ & $\mathbf{0 , 1 6 6 7}$ & $\mathbf{0 , 8 0 0 0}$ \\
\hline 1- Normal Negativo & $\mathbf{2 , 5 6 9}$ & $\mathbf{0 , 3}$ & $\mathbf{0 , 7 5}$ \\
\hline 2- Normal Negativo & $\mathbf{3 , 0 2 9 6}$ & $\mathbf{0 , 3}$ & $\mathbf{0 , 8 7 5}$ \\
\hline 3- Normal Negativo & $\mathbf{2 , 4 0 8}$ & $\mathbf{0 , 3}$ & $\mathbf{1 , 0 7 5}$ \\
\hline Normal Negativo Média & $\mathbf{2 , 6 6 8 8 7}$ & $\mathbf{0 , 3}$ & $\mathbf{0 , 9 0 0 0}$ \\
\hline Normal Média Final & $\mathbf{2 , 8 8 1 9 8 5}$ & $\mathbf{0 , 2 3 3 3 5}$ & $\mathbf{0 , 8 5}$ \\
\hline 1- PIO Positivo & $\mathbf{7 , 7 3 7 9}$ & $\mathbf{0 , 1}$ & $\mathbf{0 , 5}$ \\
\hline 2- PIO Positivo & $\mathbf{5 , 8 7 7 6}$ & $\mathbf{0 , 1 8 0 2 8}$ & $\mathbf{0 , 7 5}$ \\
\hline 3- PIO Positivo & $\mathbf{5 , 7 3 1}$ & $\mathbf{0 , 1}$ & $\mathbf{0 , 8 2 5}$ \\
\hline PIO POSITIVO Média & $\mathbf{6 , 4 4 8 8 3}$ & $\mathbf{0 , 1 2 6 7 6}$ & $\mathbf{0 , 6 9 1 7}$ \\
\hline 1- PIO Negativo & $\mathbf{7 , 9 0 9 3}$ & $\mathbf{0 , 1}$ & $\mathbf{0 , 4 2 5}$ \\
\hline 2- PIO Negativo & $\mathbf{5 , 9 9 0 8}$ & $\mathbf{0 , 1 5 7 0 7}$ & $\mathbf{0 , 6}$ \\
\hline 3- PIO Negativo & $\mathbf{5 , 5 7 6 8}$ & $\mathbf{0 , 3}$ & $\mathbf{0 , 6}$ \\
\hline PIO Negativo Média & $\mathbf{6 , 4 9 2 3}$ & $\mathbf{0 , 1 8 5 6 9}$ & $\mathbf{0 , 5 4 1 7}$ \\
\hline PIO Média Final & $\mathbf{6 , 4 7 0 5 6 5}$ & $\mathbf{0 , 1 5 6 2 2 5}$ & $\mathbf{0 , 6 1 6 7}$ \\
\hline
\end{tabular}


Tabela 13 - Parâmetros estimados do Modelo de Precisão obtidos dos ensaios com pilotos

\begin{tabular}{|c|c|c|c|c|c|c|}
\hline \multirow{2}{*}{ Piloto } & \multicolumn{6}{|c|}{ Parâmetros Modelo piloto de Precisão } \\
\cline { 2 - 7 } & KP & $\mathbf{T}_{\mathbf{L}}$ & $\mathbf{T}_{\mathbf{I}}$ & $\zeta_{\boldsymbol{n}}$ & $\boldsymbol{\omega}_{\boldsymbol{n}}(\mathbf{r a d} / \mathbf{s})$ & $\boldsymbol{\tau}$ (s) \\
\hline 1- Normal Positivo & $\mathbf{4 , 1 5 0 3}$ & $\mathbf{6 , 8 2 2 7}$ & $\mathbf{1 0}$ & $\mathbf{0 , 6 6 5 1 3}$ & $\mathbf{1 6 , 7 0 3 1}$ & $\mathbf{0 , 4 7 5}$ \\
\hline 2- Normal Positivo & $\mathbf{3 , 6 6 3 3}$ & $\mathbf{9 , 9 9 7}$ & $\mathbf{1 0}$ & $\mathbf{0 , 5 1 5 3 7}$ & $\mathbf{1 6 , 6 6 6}$ & $\mathbf{0 , 8 7 5}$ \\
\hline 3- Normal Positivo & $\mathbf{3 , 8 5 4 9}$ & $\mathbf{7 , 3 8 7}$ & $\mathbf{1 0}$ & $\mathbf{0 , 5 9 5 2 7}$ & $\mathbf{1 7 , 0 3 0 0}$ & $\mathbf{1 , 0 5}$ \\
\hline Normal Média & $\mathbf{3 , 8 8 9 5}$ & $\mathbf{8 , 0 6 8 9}$ & $\mathbf{1 0}$ & $\mathbf{0 , 5 9 1 9}$ & $\mathbf{1 6 , 7 9 9 7}$ & $\mathbf{0 , 8 0 0 0}$ \\
\hline 1- Normal Negativo & $\mathbf{9 , 9 9 7 4}$ & $\mathbf{1 , 2 1 5 3}$ & $\mathbf{1 0}$ & $\mathbf{0 , 5}$ & $\mathbf{1 6 , 6 6 6 7}$ & $\mathbf{0 , 7 5}$ \\
\hline 2- Normal Negativo & $\mathbf{2 , 9 5 1 5}$ & $\mathbf{9 , 9 9 7 2}$ & $\mathbf{1 0}$ & $\mathbf{0 , 8}$ & $\mathbf{1 6 , 6 6 6 7}$ & $\mathbf{0 , 8 7 5}$ \\
\hline 3- Normal Negativo & $\mathbf{5 , 0 6 7 8}$ & $\mathbf{3 , 7 3 2 6}$ & $\mathbf{1 0}$ & $\mathbf{0 , 8}$ & $\mathbf{2 4 , 9 9 8 1}$ & $\mathbf{1 , 0 7 5}$ \\
\hline Normal Negativo & $\mathbf{6 , 0 0 5 6}$ & $\mathbf{4 , 9 8 1 7}$ & $\mathbf{1 0}$ & $\mathbf{0 , 7}$ & $\mathbf{1 9 , 4 4 3 8}$ & $\mathbf{0 , 9}$ \\
\hline Média & & & & & & \\
\hline Normal Média Final & $\mathbf{4 , 9 4 7 5}$ & $\mathbf{6 , 5 2 5 3}$ & $\mathbf{1 0}$ & $\mathbf{0 , 6 4 6 0}$ & $\mathbf{1 8 , 1 2 1 7}$ & $\mathbf{0 , 8 5}$ \\
\hline 1- PIO Positivo & $\mathbf{6 , 0 6 2}$ & $\mathbf{1 , 1 5 4 3}$ & $\mathbf{0 , 6 5 9 5 4}$ & $\mathbf{0 , 8}$ & $\mathbf{2 4 , 4 1 0 5}$ & $\mathbf{0 , 5}$ \\
\hline 2- PIO Positivo & $\mathbf{6 , 2 2 5 3}$ & $\mathbf{0 , 9}$ & $\mathbf{0 , 9 9 8 4 8}$ & $\mathbf{0 , 8}$ & $\mathbf{2 4 , 9 8 1 3}$ & $\mathbf{0 , 7 5}$ \\
\hline 3- PIO Positivo & $\mathbf{5 , 6 2 4 5}$ & $\mathbf{1 , 0 4 7 8}$ & $\mathbf{1}$ & $\mathbf{0 , 8}$ & $\mathbf{2 3 , 6 1 2 2}$ & $\mathbf{0 , 8 2 5}$ \\
\hline PIO Positivo Média & $\mathbf{5 , 9 7 0 6}$ & $\mathbf{1 , 0 3 4 0}$ & $\mathbf{0 , 8 8 6 0}$ & $\mathbf{0 , 8}$ & $\mathbf{2 4 , 3 3 4 7}$ & $\mathbf{0 , 6 9 1 7}$ \\
\hline 1- PIO Negativo & $\mathbf{6 , 2 4 9 3}$ & $\mathbf{1 , 1 5 5}$ & $\mathbf{0 , 7 0 7 1 4}$ & $\mathbf{0 , 8}$ & $\mathbf{2 4 , 9 9 1 3}$ & $\mathbf{0 , 4 2 5}$ \\
\hline 2- PIO Negativo & $\mathbf{6 , 0 9 2 5}$ & $\mathbf{0 , 9}$ & $\mathbf{0 , 9 5 9 9 8}$ & $\mathbf{0 , 8}$ & $\mathbf{1 9 , 0 8 7 2 5}$ & $\mathbf{0 , 6}$ \\
\hline 3- PIO Negativo & $\mathbf{5 , 5 3 0 5}$ & $\mathbf{0 , 9}$ & $\mathbf{1}$ & $\mathbf{0 , 8}$ & $\mathbf{1 6 , 6 6 6 7}$ & $\mathbf{0 , 6}$ \\
\hline PIO Negativo Média & $\mathbf{5 , 9 5 7 4}$ & $\mathbf{0 , 9 8 5 0}$ & $\mathbf{0 , 8 8 9 0}$ & $\mathbf{0 , 8}$ & $\mathbf{2 0 , 2 4 8 4}$ & $\mathbf{0 , 5 4 1 7}$ \\
\hline PIO Média Final & $\mathbf{5 , 9 6 4 0}$ & $\mathbf{1 , 0 0 9 5}$ & $\mathbf{0 , 8 8 7 5}$ & $\mathbf{0 , 8}$ & $\mathbf{2 2 , 2 9 1 6}$ & $\mathbf{0 , 6 1 6 7}$ \\
\hline
\end{tabular}

